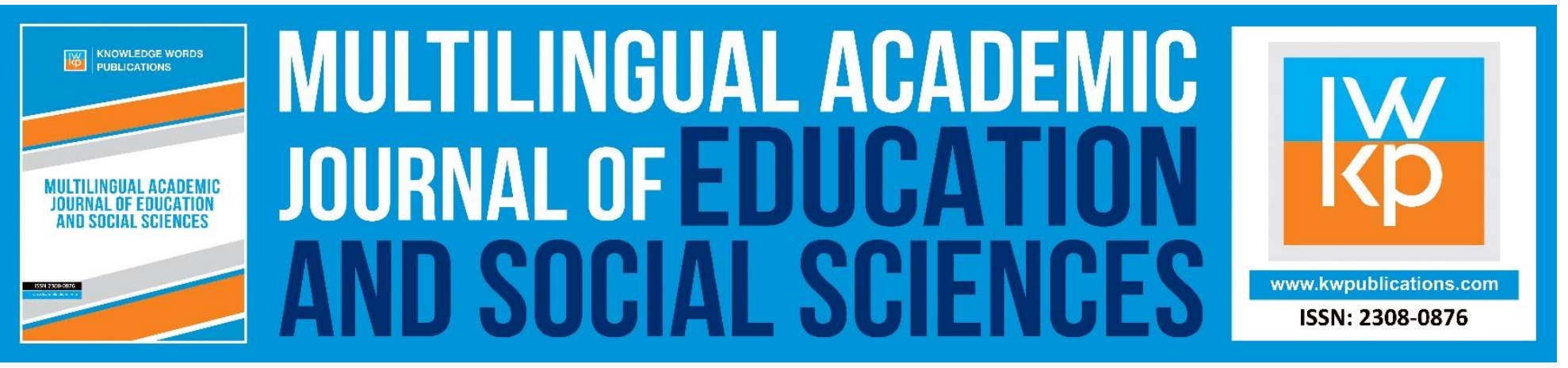

\title{
The Reproduction of the Dominant Ideology in School Practice: A Critical Debate with the Contents of the Course of History in Greek Primary School
}

Christos Tourtouras, Ifigeneia Vamvakidou, Argyris Kyridis \& Giannis Kaskaris

To Link this Article: http://dx.doi.org/10.46886/MAJESS/v5-i1/2432

DOI: 10.46886/MAJESS/v5-i1/2432

Received: 05 June 2017, Revised: 10 July 2017, Accepted: 16 September 2017

Published Online: 20 October 2017

In-Text Citation: (Tourtouras et al., 2017)

To Cite this Article: Tourtouras, C., Vamvakidou, I., Kyridis, A., Giannis, \& Kaskaris. (2017). The Reproduction of the Dominant Ideology in School Practice: A Critical Debate with the Contents of the Course of History in Greek Primary School. Multilingual Academic Journal of Education and Social Sciences, 5(1), 85-109.

\section{Copyright: (c) The Authors 2017}

Published by Knowledge Words Publications (www.kwpublications.com)

This article is published under the Creative Commons Attribution (CC BY 4.0) license. Anyone may reproduce, distribute, translate and create derivative works of this article (for both commercial and non-commercial purposes), subject to full attribution to the original publication and authors. The full terms of this license may be seen at: http://creativecommons.org/licences/by/4.0/legalcode

Vol. 5, No. 1, 2017, Pg. 85 - 109 


\title{
The Reproduction of the Dominant Ideology in School Practice: A Critical Debate with the Contents of the Course of History in Greek Primary School
}

\author{
Christos Tourtouras, Ifigeneia Vamvakidou, Argyris Kyridis \& \\ Giannis Kaskaris
}

Department of Early Childhood Education, University of Western Macedonia, Florina, Greece.

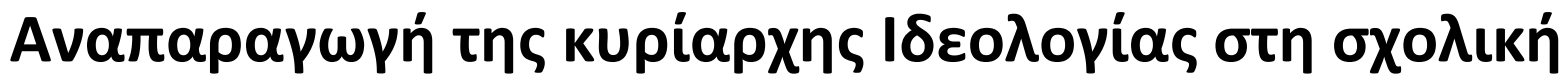

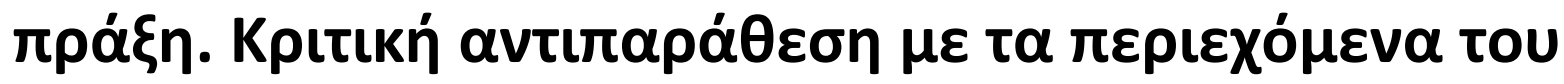

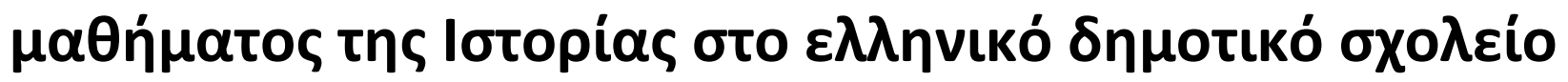

\begin{abstract}
In this study we present a critical discourse analysis to the contents of a section of the textbook of History of the 5th grade in Primary Education. The selected chapters (13-16 of the third (C) section) are included in the student's school book and they are chosen because of their deep political hue and individual political messages emerging in symbolic or declaratory field. The researching historic interest is focused on the main frame transition from the Roman to the Byzantine world, with references to the social, juridical-legal, economic, cultural and political structures. The constructed narrative shows off the presentation of the Byzantine Emperor. The main objective is to understand and study the epistemological potential of a marxistic proposal posed as an open issue: a) What is the subject in the process of teaching history? b) What we teach in history class (content), to whom we address (configuration personal characteristics), why, who pose the questions and why? Thus we suggest three possible methods: a) qualitative content analysis -and particularly critical discourse analysis - of textbooks, b) a review of education policy, c) a pedagogic composition through critical dialectical analysis in order to comprehend the marxistic historicity which seems to be hiding.

Keywords: Historical School Books, Ideology, Byzantium, Marxistic Issues.
\end{abstract}


MULTILINGUAL ACADEMIC JOURNAL OF EDUCATION AND SOCIAL SCIENCES

Vol. 5 No. 1, 2017, E-ISSN: 2308-0876 @ 2017 KWP

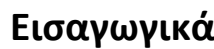

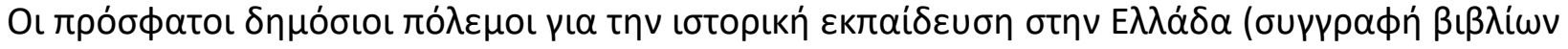

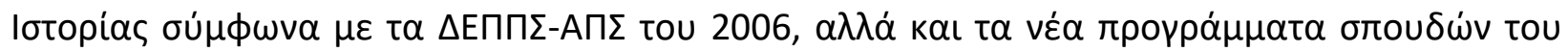

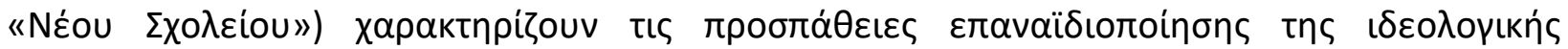

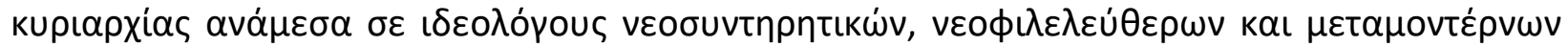

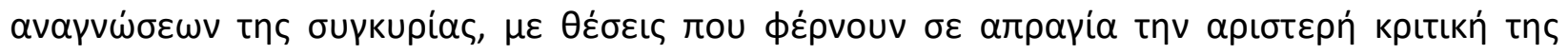

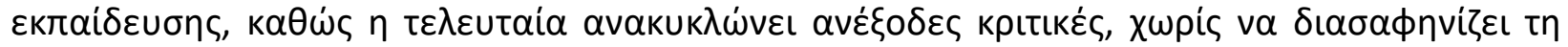

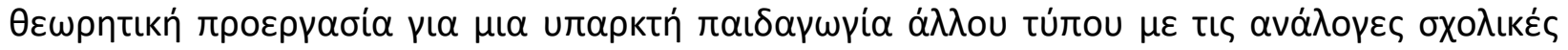

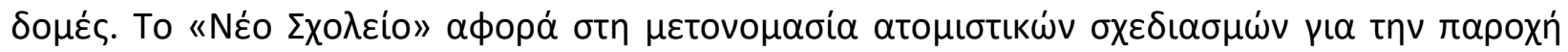

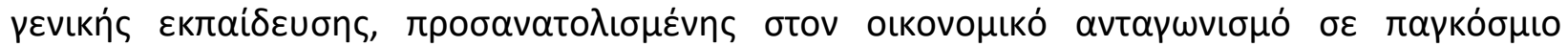

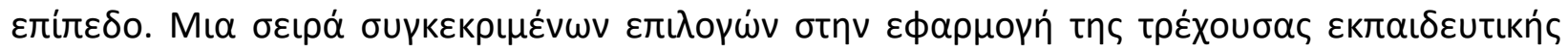

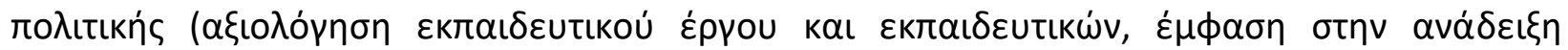

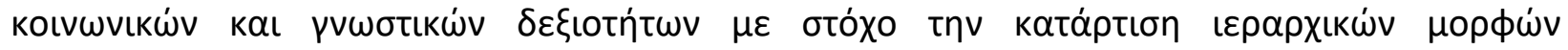

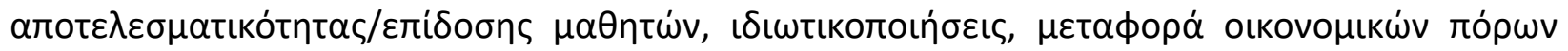

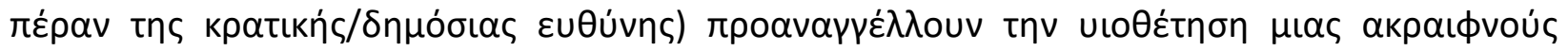

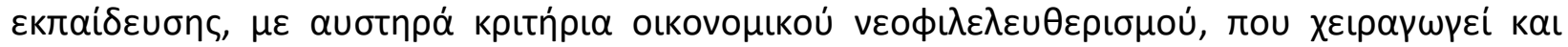

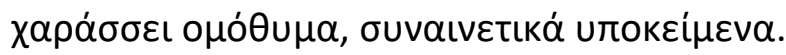

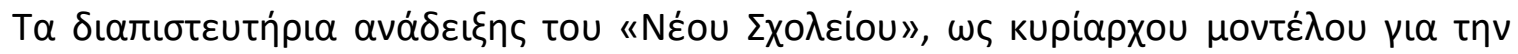

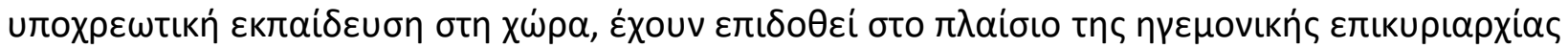

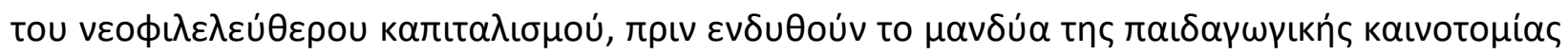

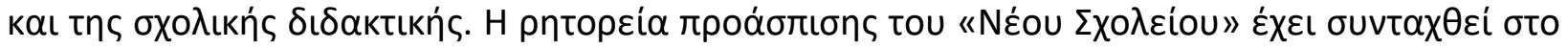

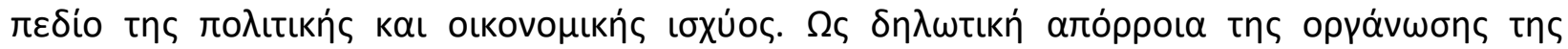

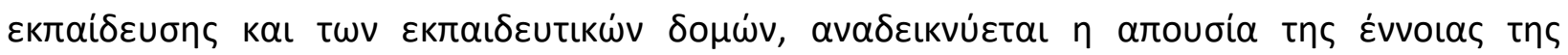

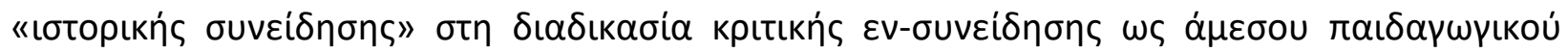

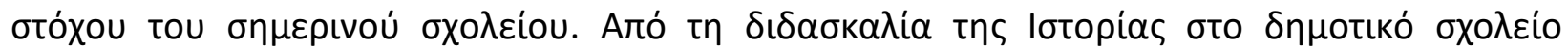

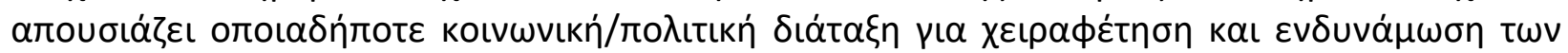

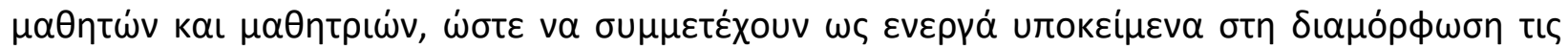

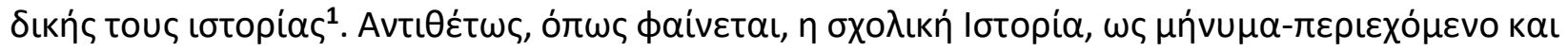

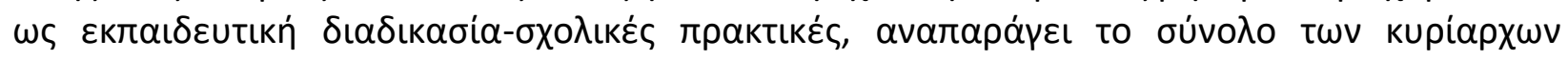

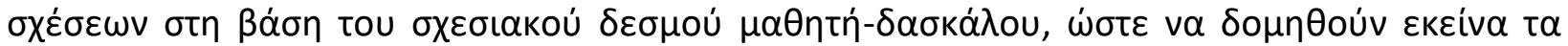

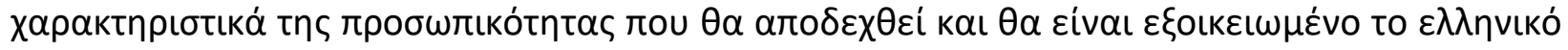

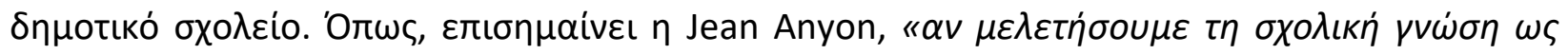

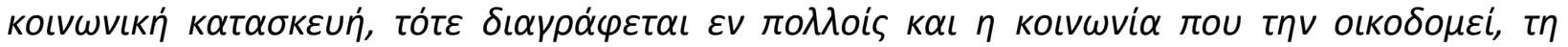

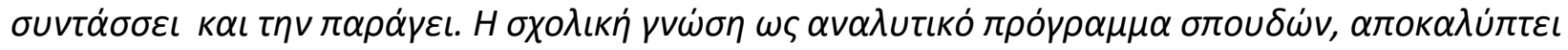

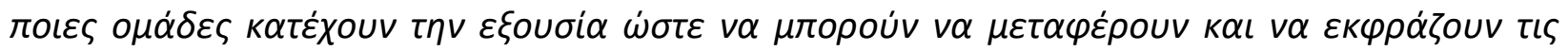

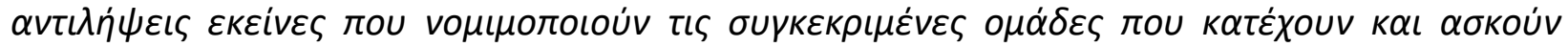

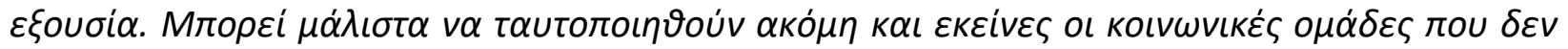
$\varepsilon v \delta u v \alpha \mu \omega \dot{v o v \tau \alpha \iota ~ \mu \varepsilon ́ \sigma \omega ~ \tau \omega v ~ \delta \varepsilon \delta о \mu \varepsilon ́ v \omega v ~ o \iota k o v o \mu \iota к \omega ́ v ~ к \alpha \iota ~ к о \iota v \omega v \iota k \omega ́ v ~ \delta \iota \varepsilon \rho ү \alpha \sigma \iota \omega ́ v ~ к \alpha \iota ~ \varepsilon \pi о \mu \varepsilon ́ v \omega \varsigma ~}$

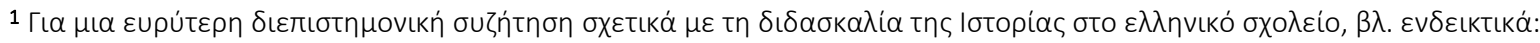

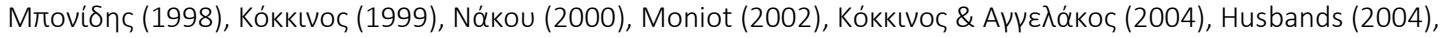

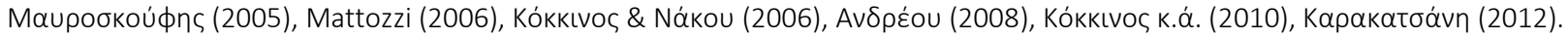


MULTILINGUAL ACADEMIC JOURNAL OF EDUCATION AND SOCIAL SCIENCES

Vol. 5 No. 1, 2017, E-ISSN: 2308-0876 @ 2017 KWP

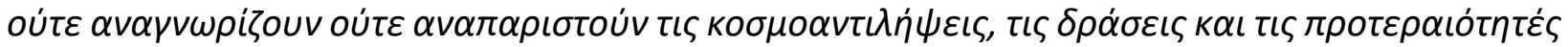

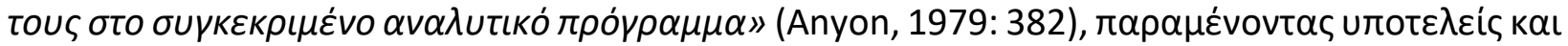

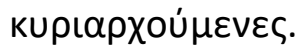

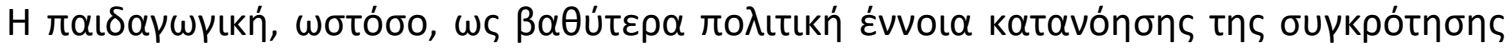

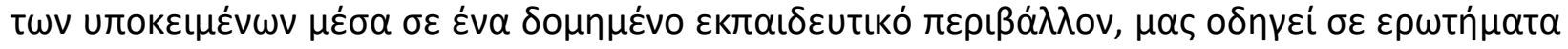

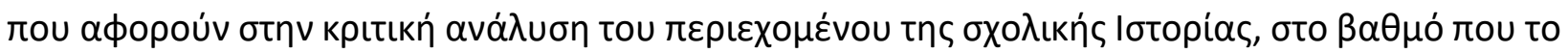

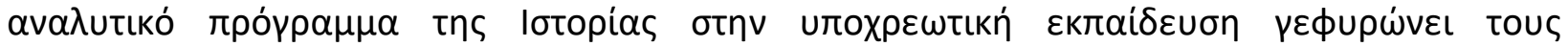

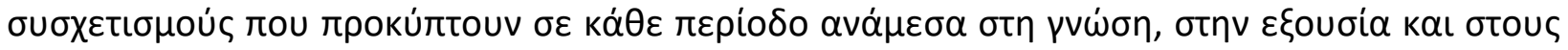

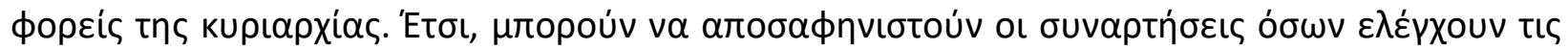

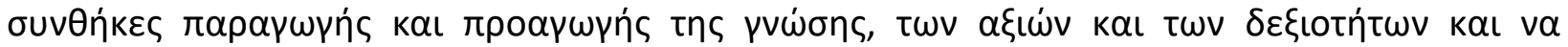

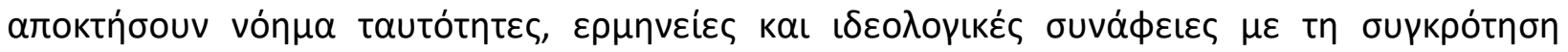

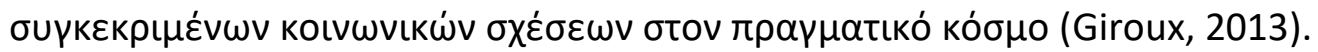

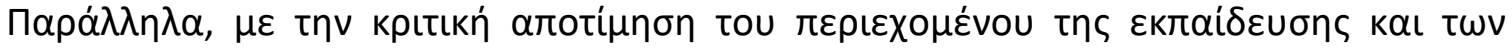

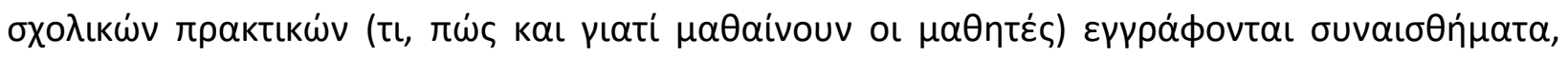

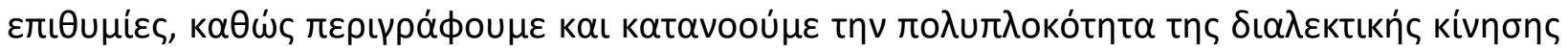

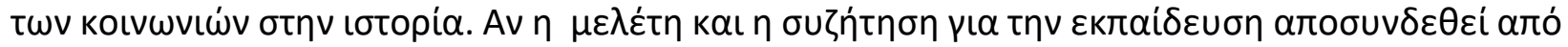

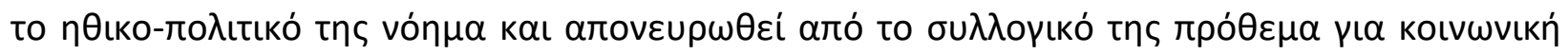

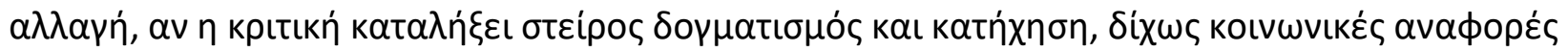

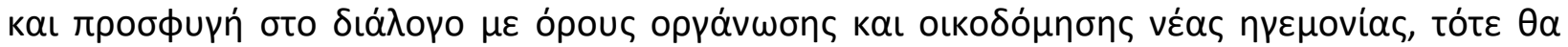

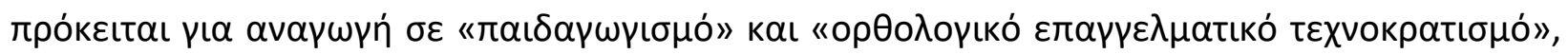

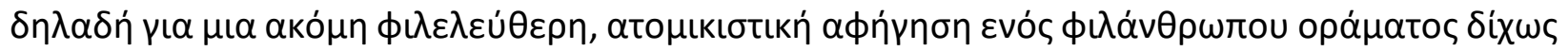
$\alpha v \theta \rho \omega \pi เ \sigma \mu o ́$.

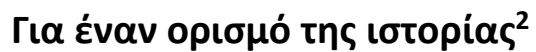

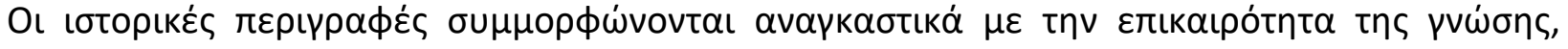

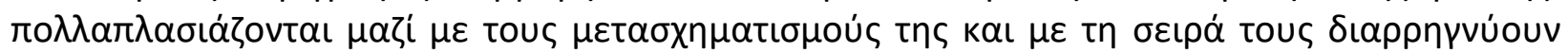

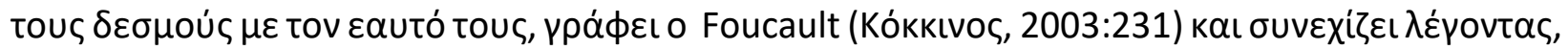

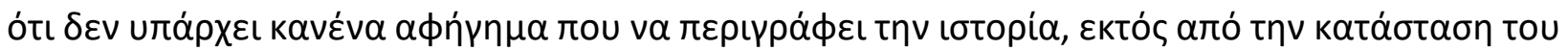

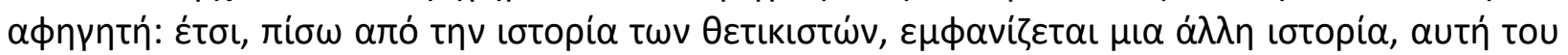

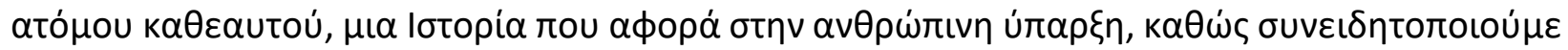

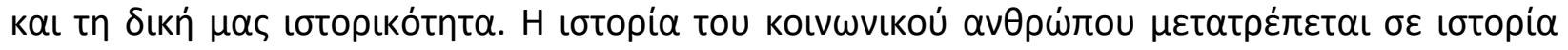

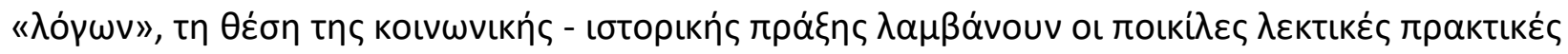

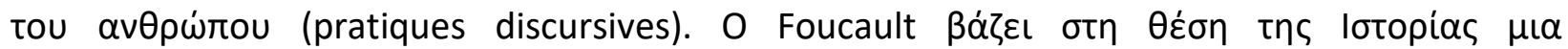

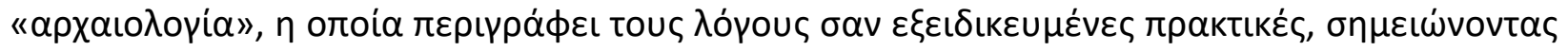

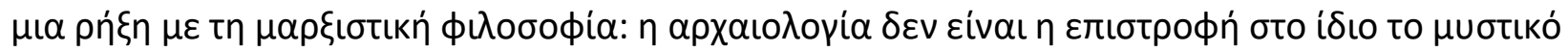

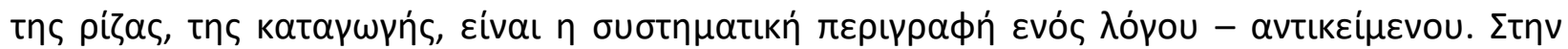

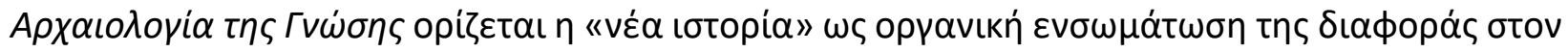

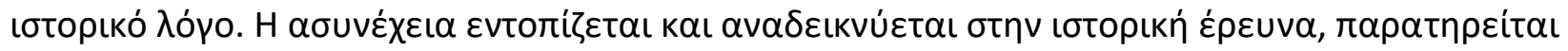

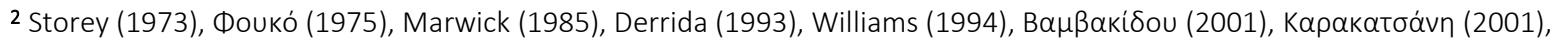
Hobsbawm (2002), Kókкıvos (2003), Maupookoúфns (2005), Mattozzi (2006), Smith (2006). 
MULTILINGUAL ACADEMIC JOURNAL OF EDUCATION AND SOCIAL SCIENCES

Vol. 5 No. 1, 2017, E-ISSN: 2308-0876 @ 2017 KWP

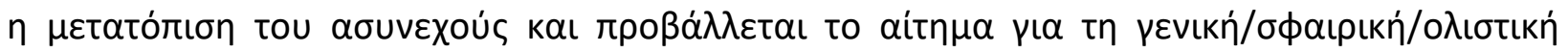

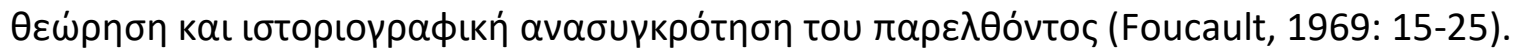

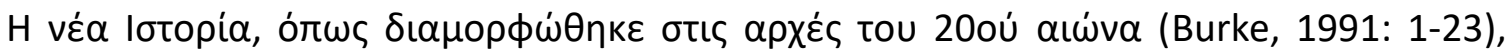

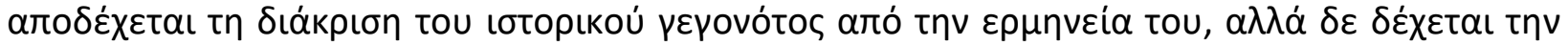

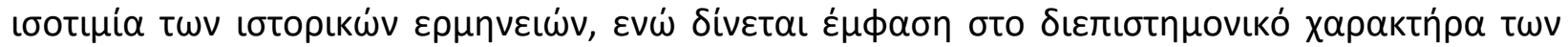

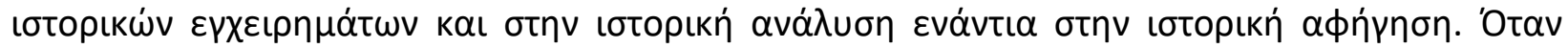

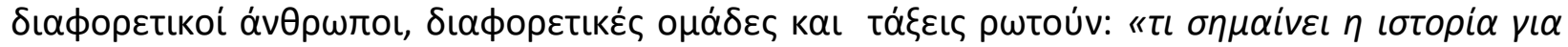

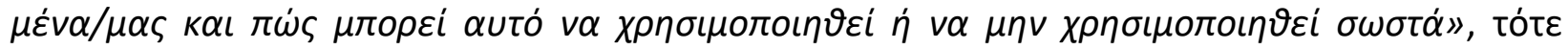

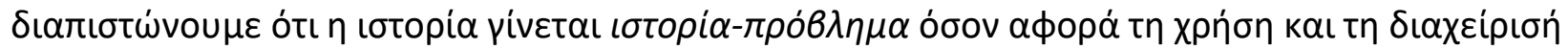

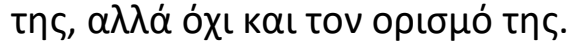

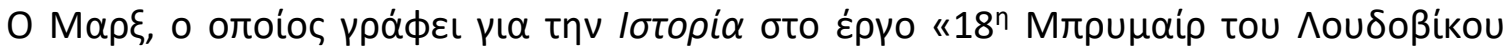

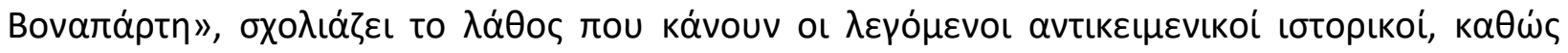

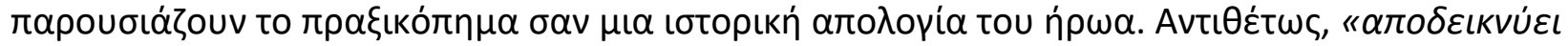

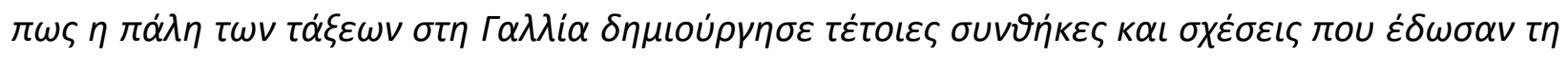

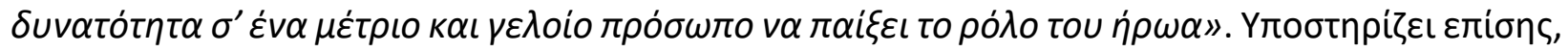

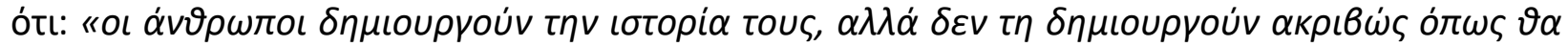

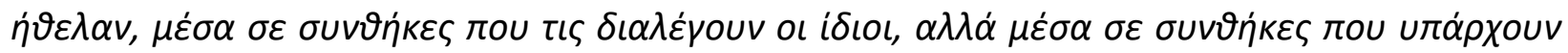

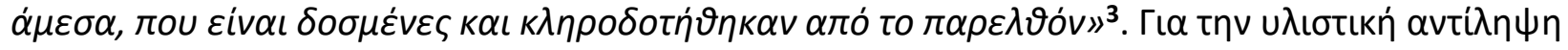

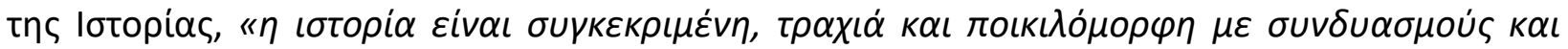

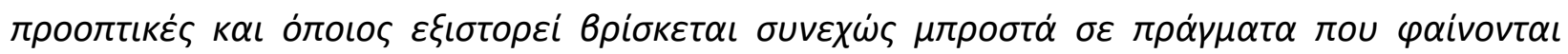

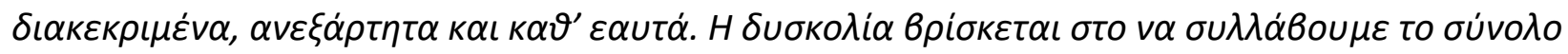

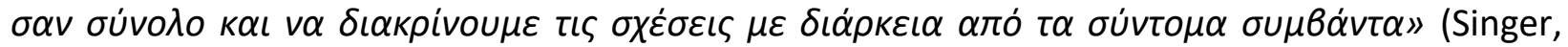
2006).

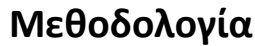

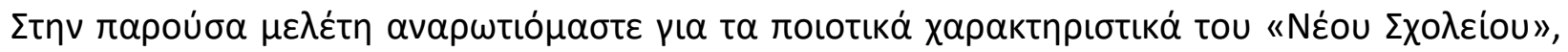

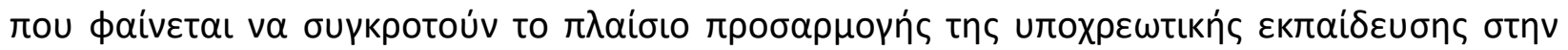

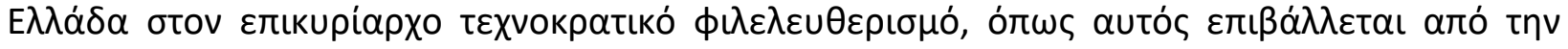

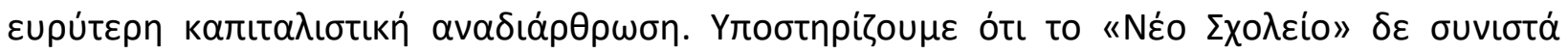

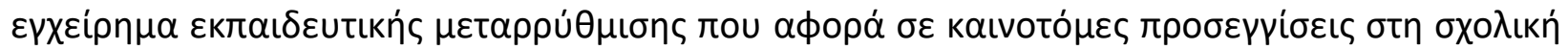

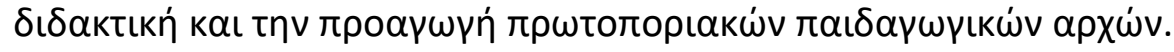

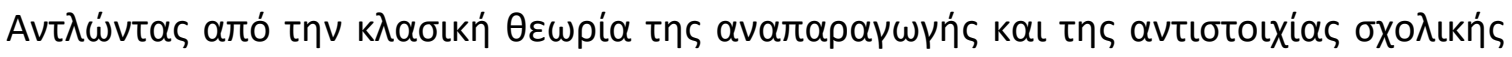

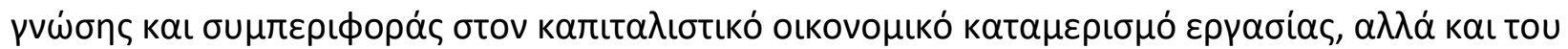

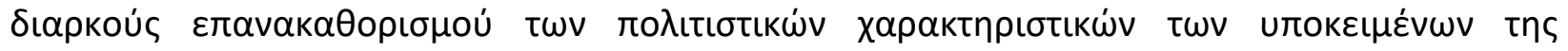

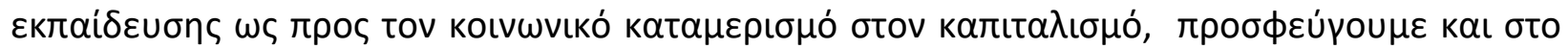

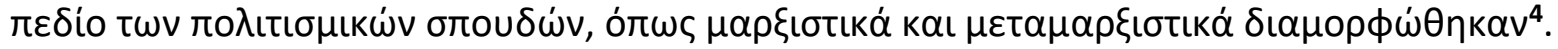

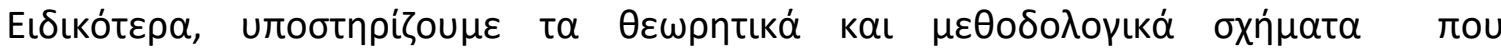

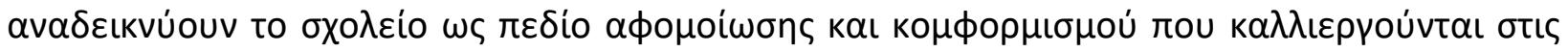

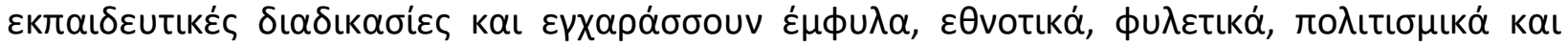

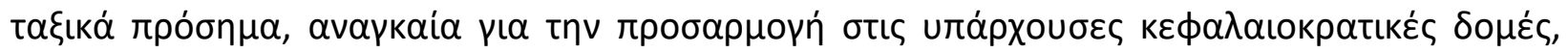

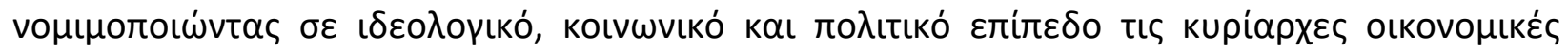

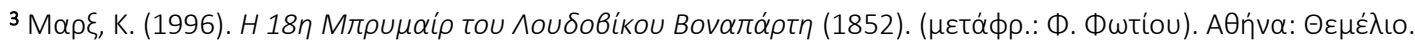

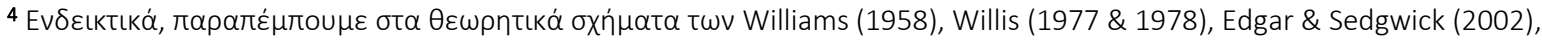

Andrew \& Sedgwick (2005). 
MULTILINGUAL ACADEMIC JOURNAL OF EDUCATION AND SOCIAL SCIENCES

Vol. 5 No. 1, 2017, E-ISSN: 2308-0876 @ 2017 KWP

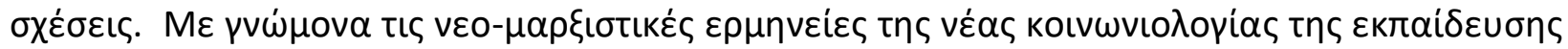

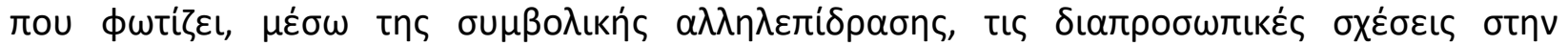

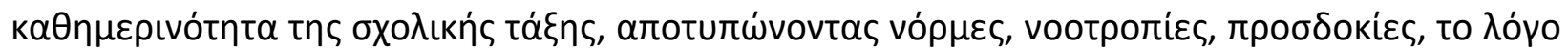

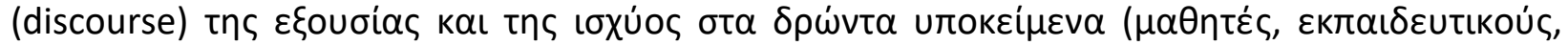

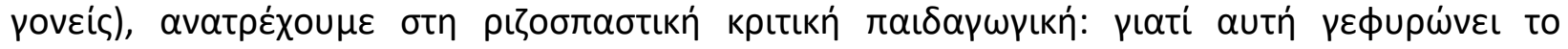

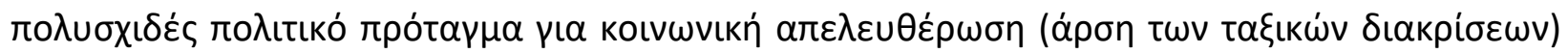

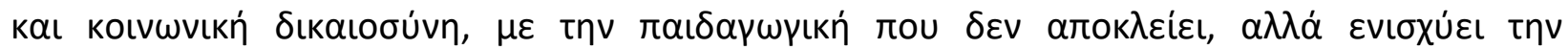

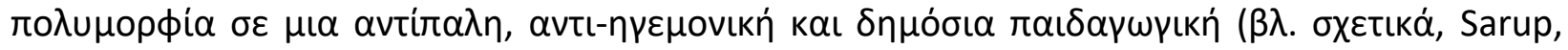
2006).

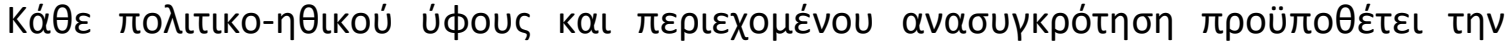

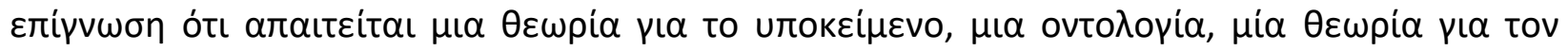

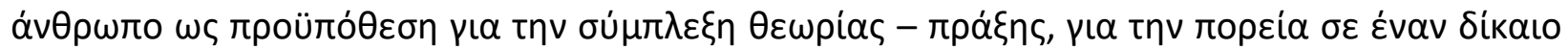

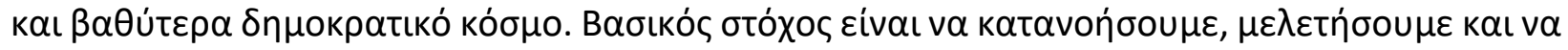

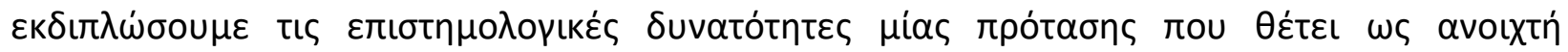

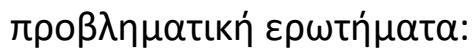

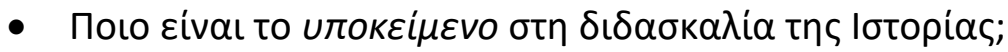

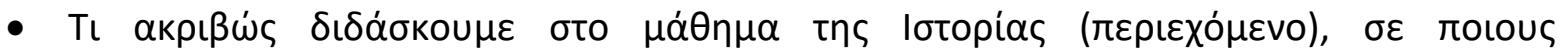

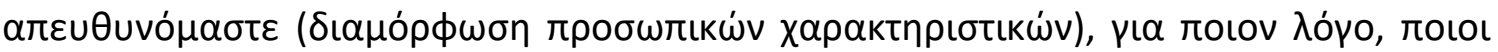

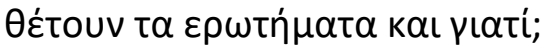

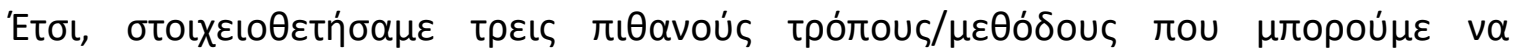

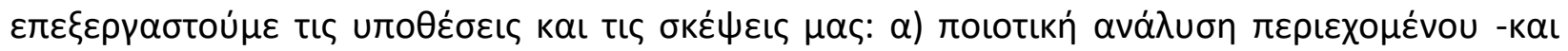

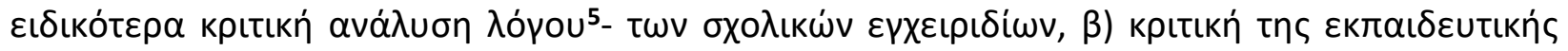

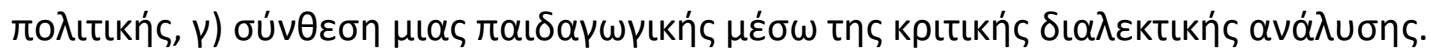

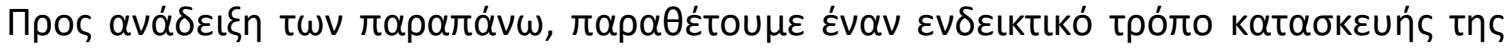

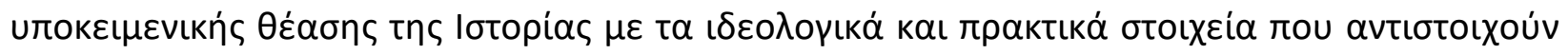

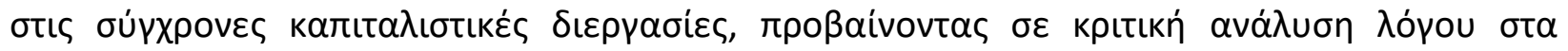

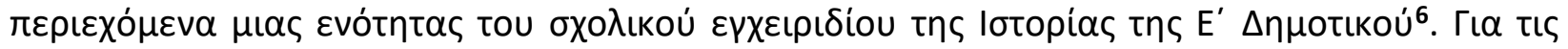

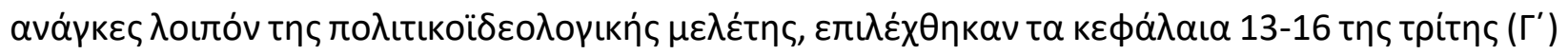

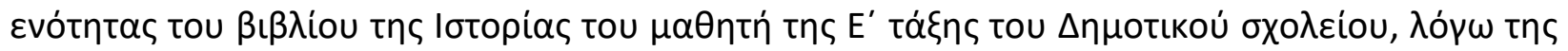

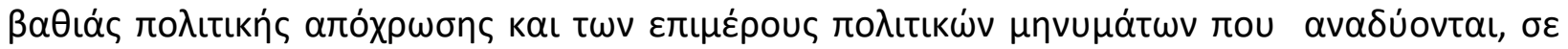

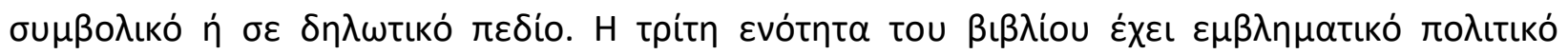

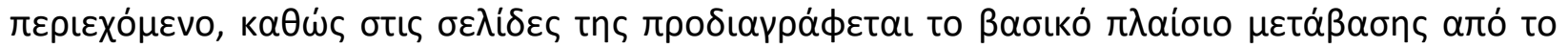

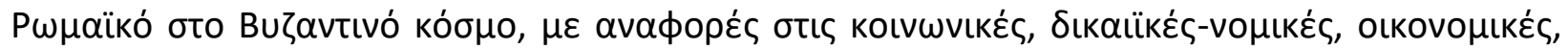

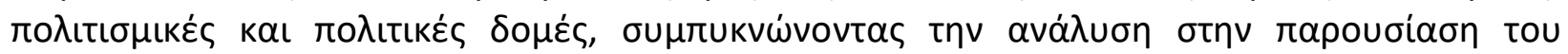
Buگavtıvoú Autoкра́тора.

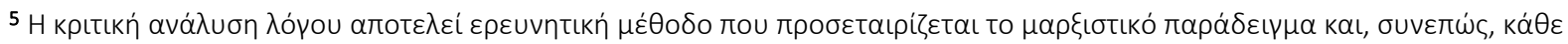

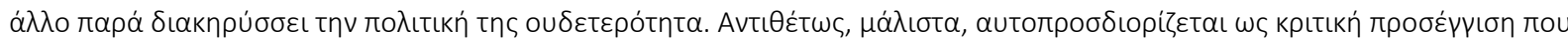

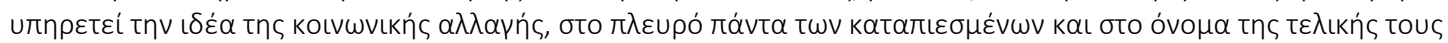

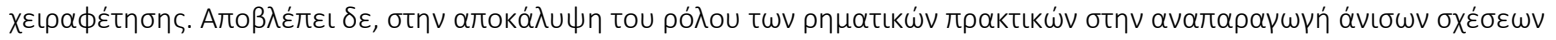

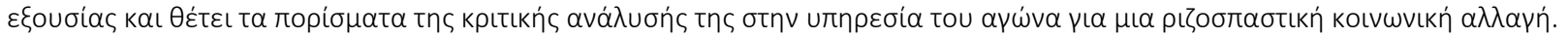

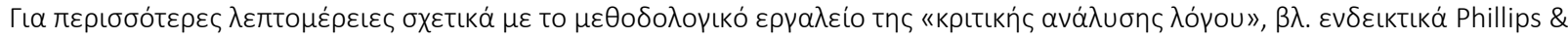
Jørgensen (2009).

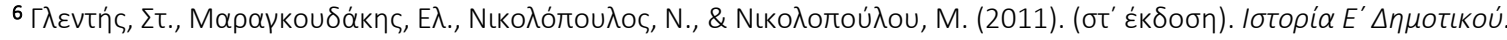

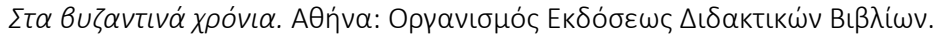


MULTILINGUAL ACADEMIC JOURNAL OF EDUCATION AND SOCIAL SCIENCES

Vol. 5 No. 1, 2017, E-ISSN: 2308-0876 @ 2017 KWP

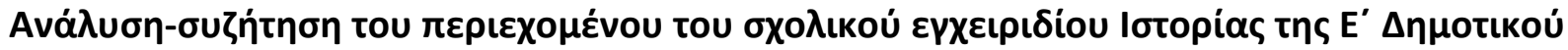 Yтовvótnta 13}

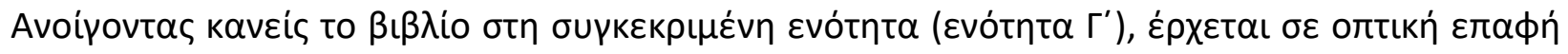

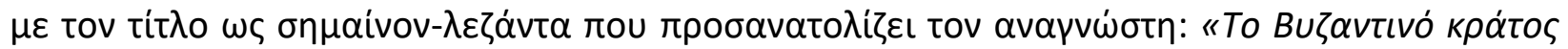

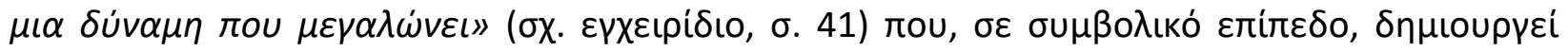

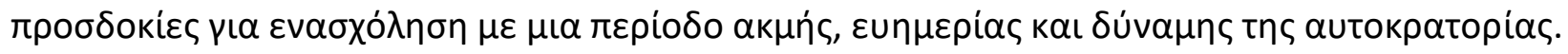

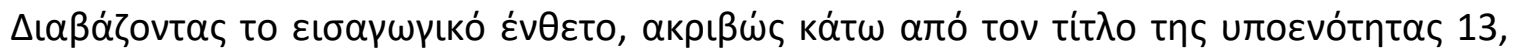

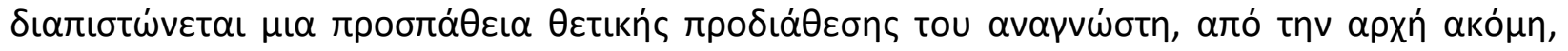

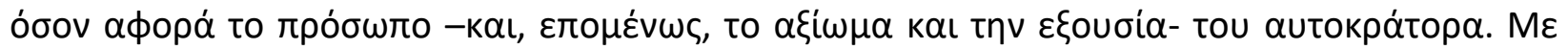

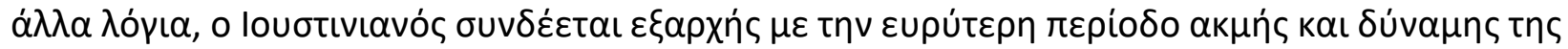

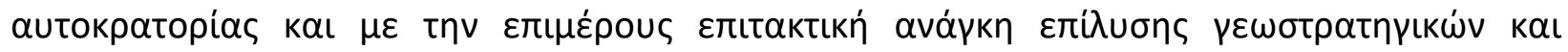

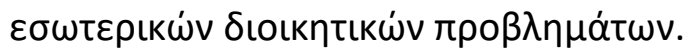

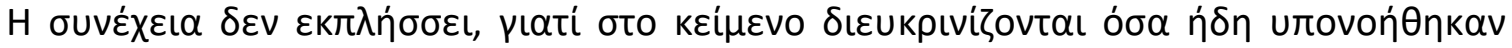

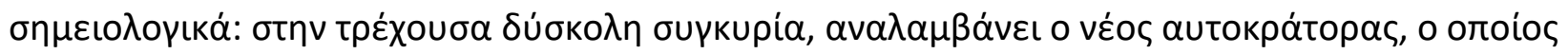

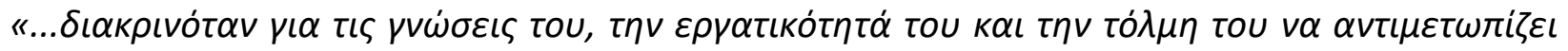

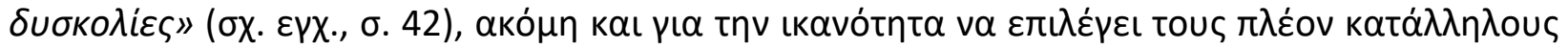

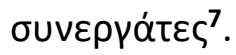

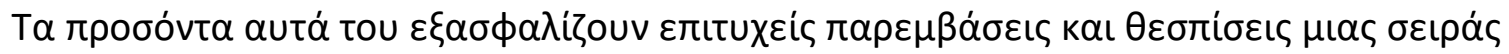

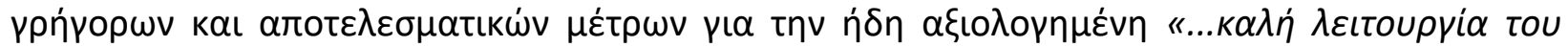

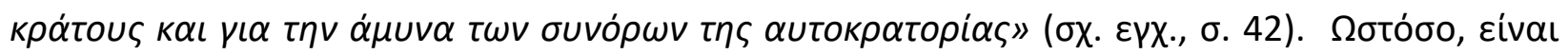

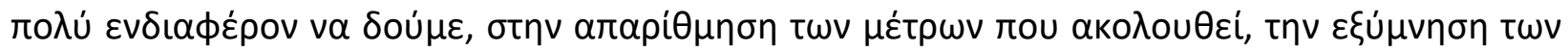

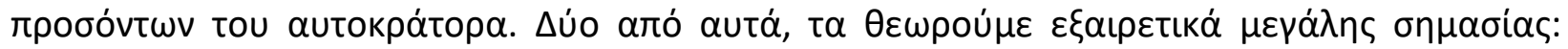

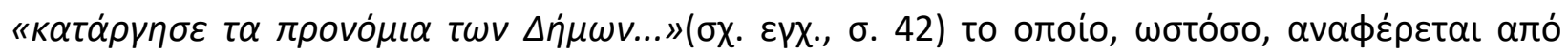

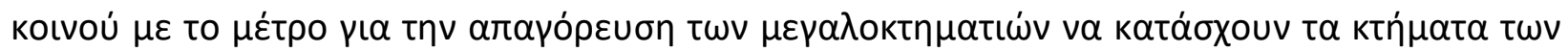

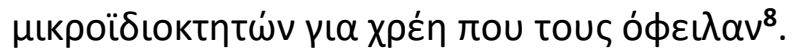

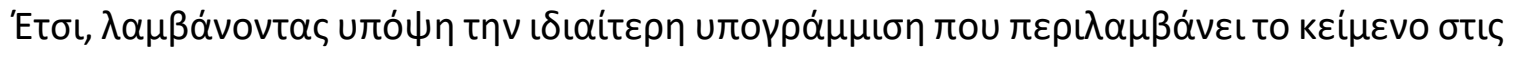

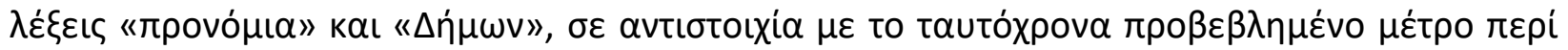

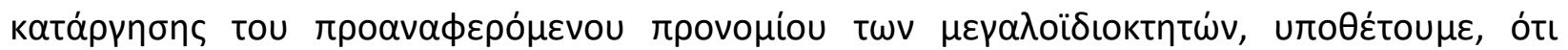

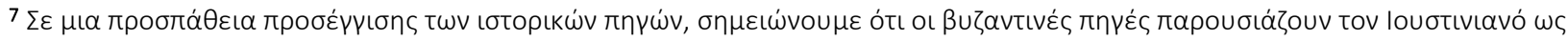

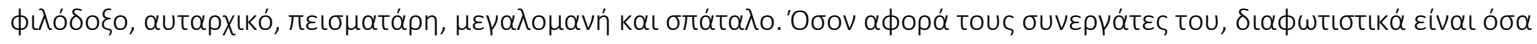

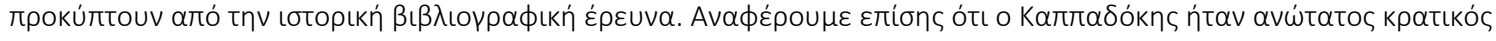

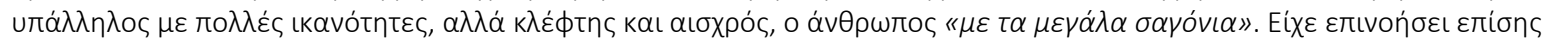

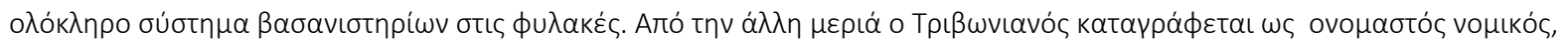

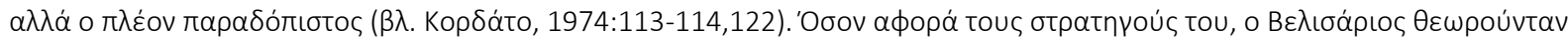

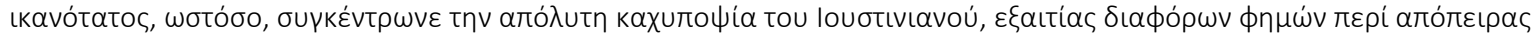

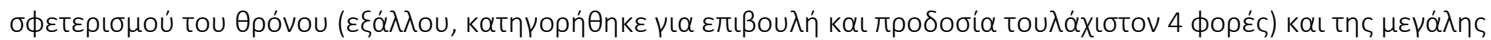

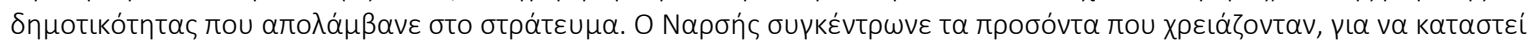

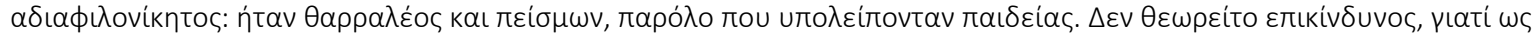

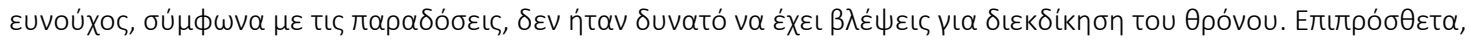

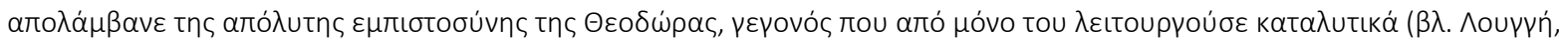

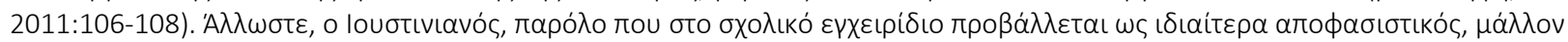

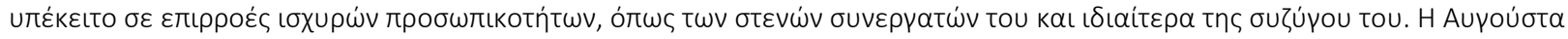

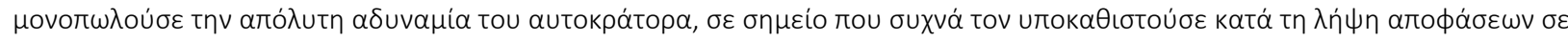

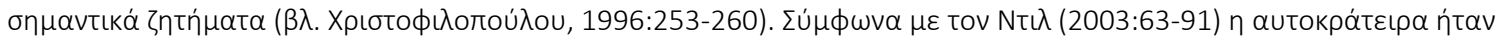

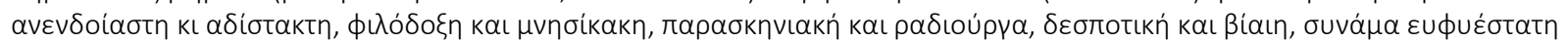

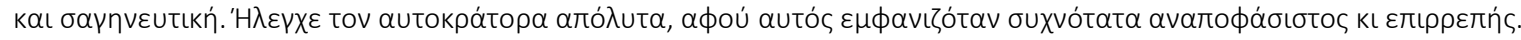

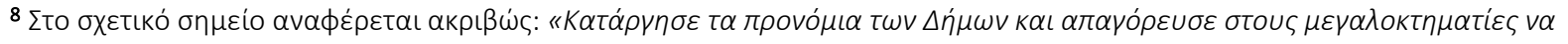

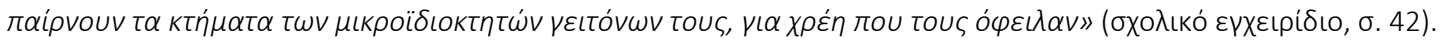


MULTILINGUAL ACADEMIC JOURNAL OF EDUCATION AND SOCIAL SCIENCES

Vol. 5 No. 1, 2017, E-ISSN: 2308-0876 @ 2017 KWP

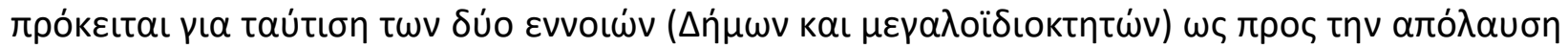

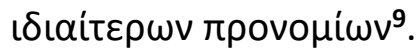

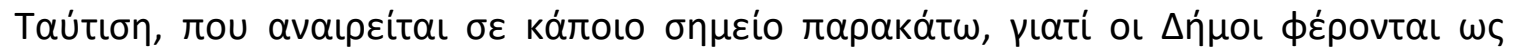

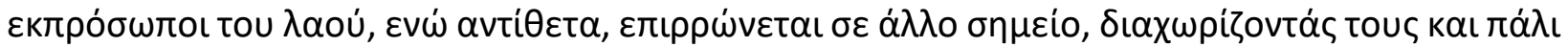

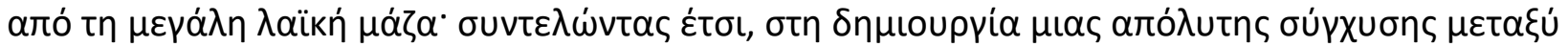

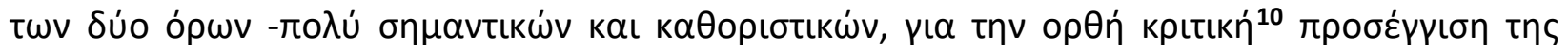

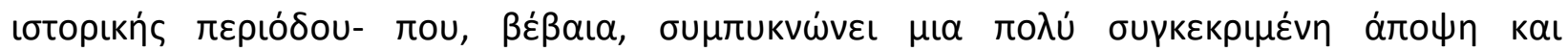

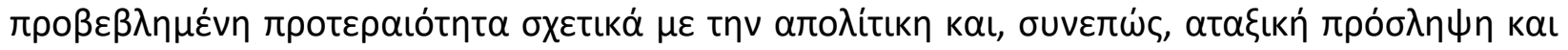

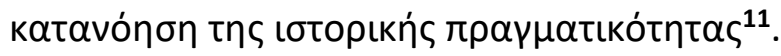

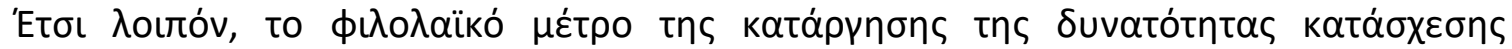

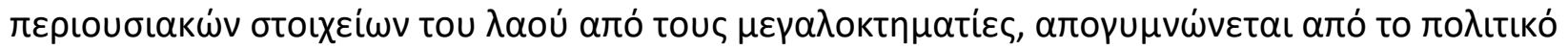

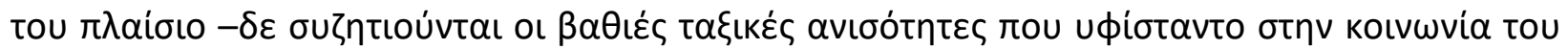

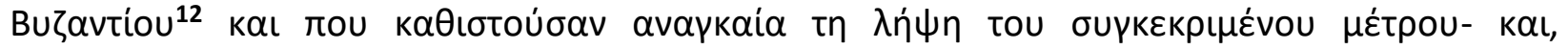

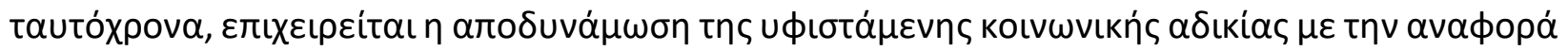

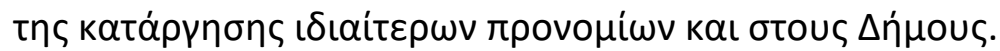

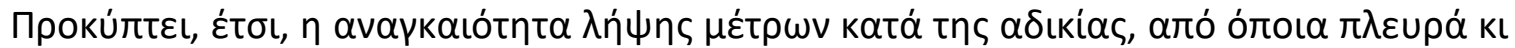

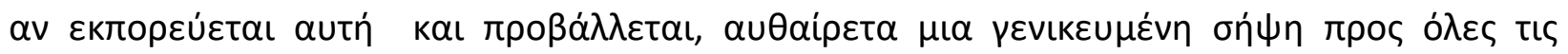

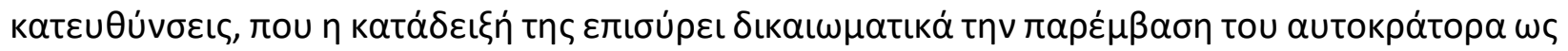

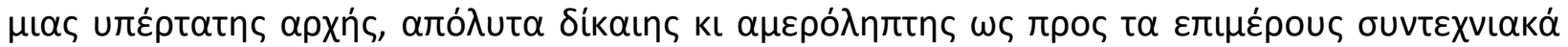

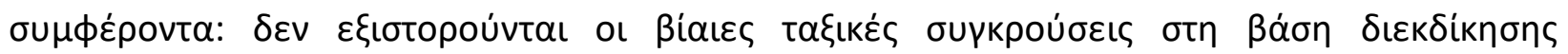

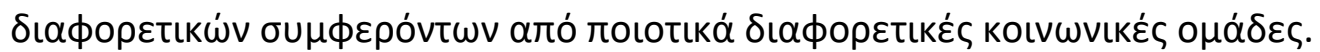

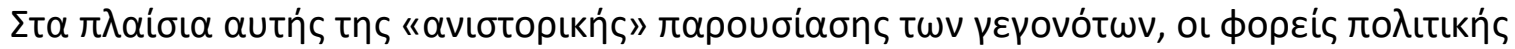

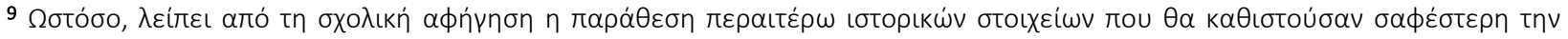

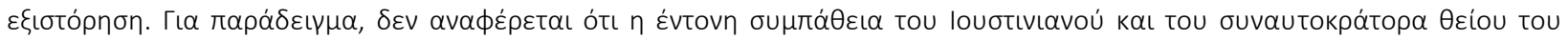

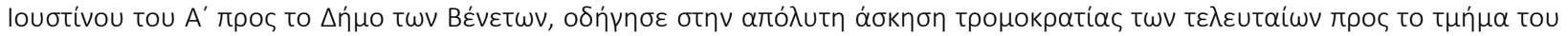

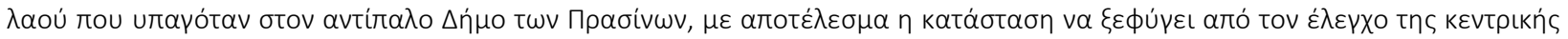

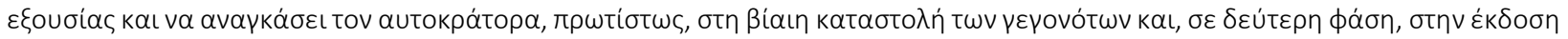

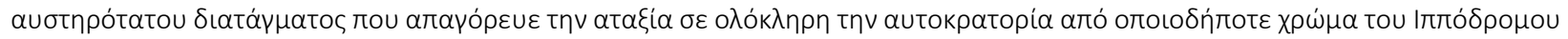

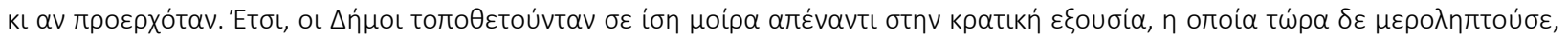

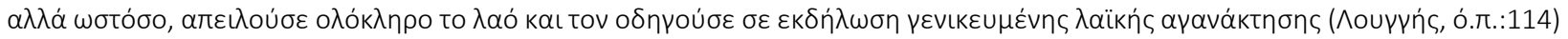

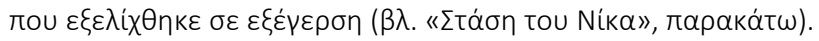

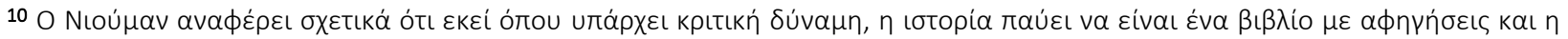

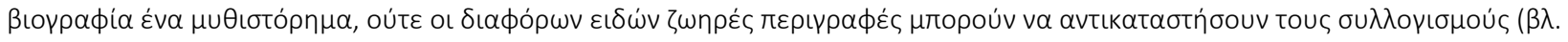
Гкра́ $\mu \sigma \iota, 2005 \beta: 42)$.

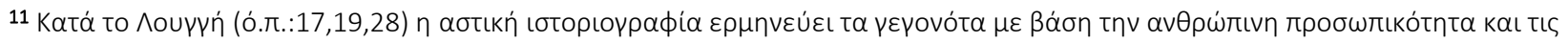

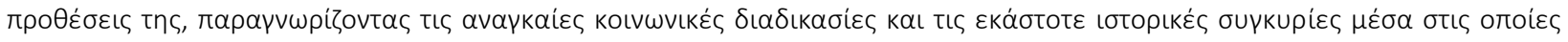

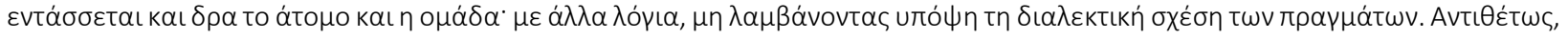

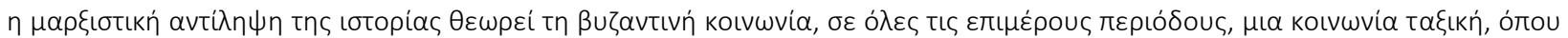

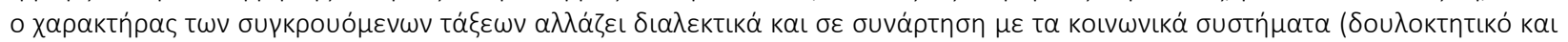

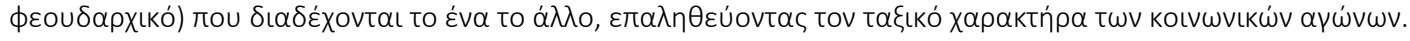

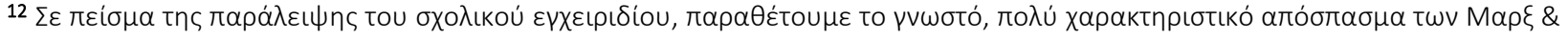

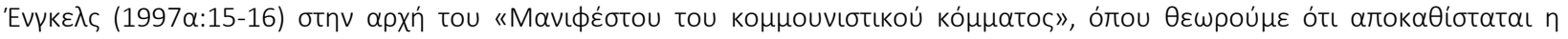

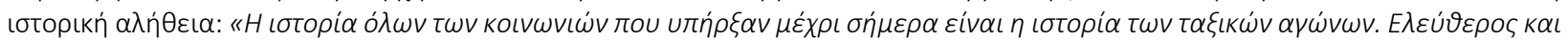

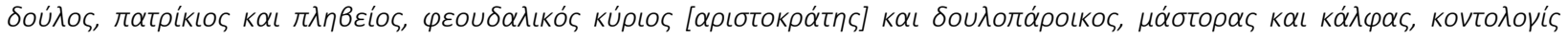

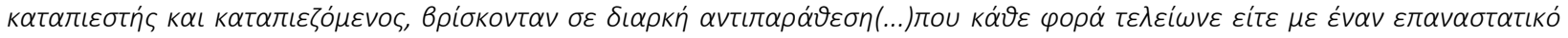

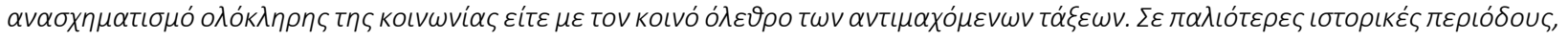

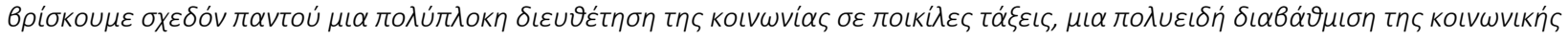

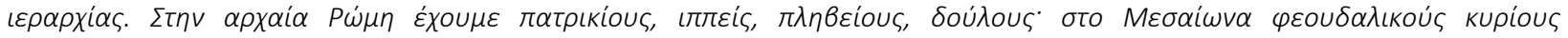

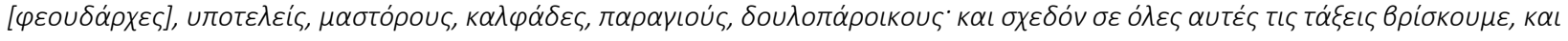

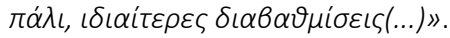


MULTILINGUAL ACADEMIC JOURNAL OF EDUCATION AND SOCIAL SCIENCES

Vol. 5 No. 1, 2017, E-ISSN: 2308-0876 @ 2017 KWP

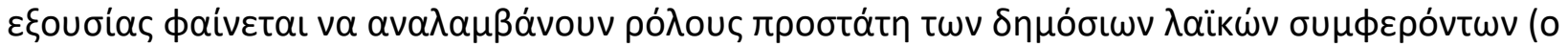

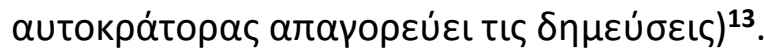

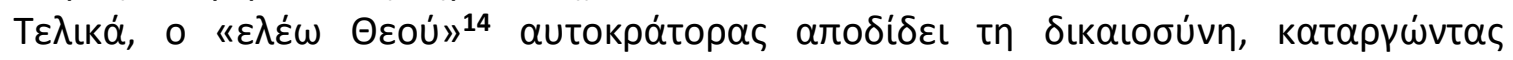

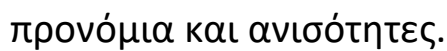

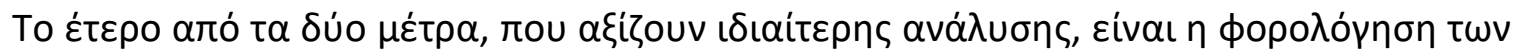

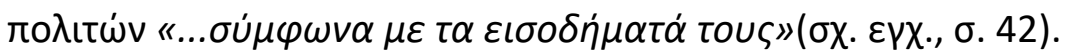

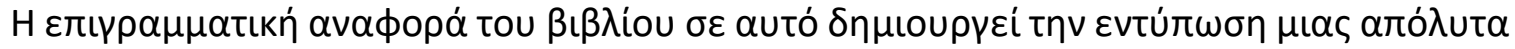

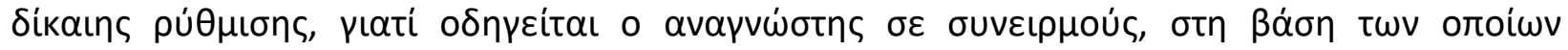

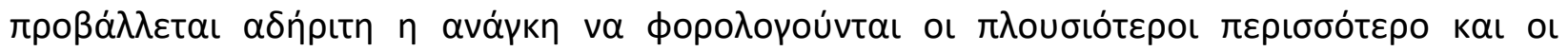

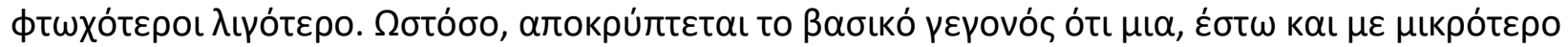

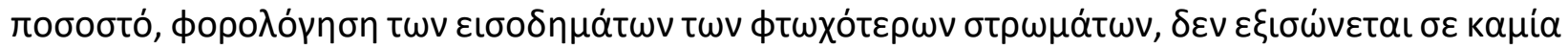

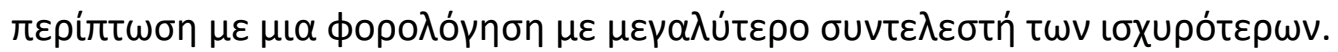

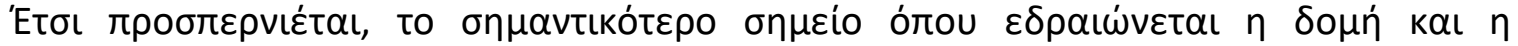

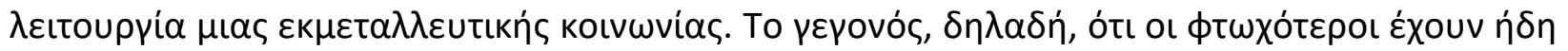

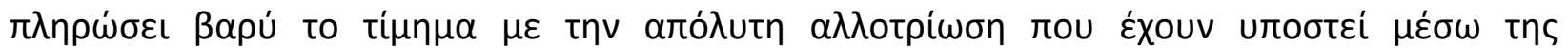

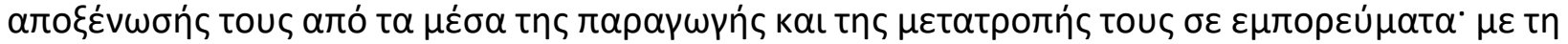

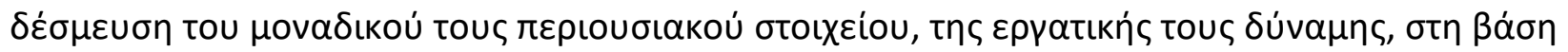

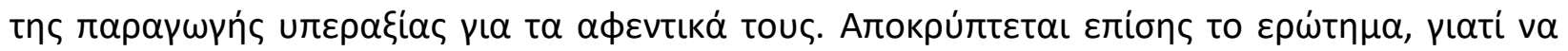

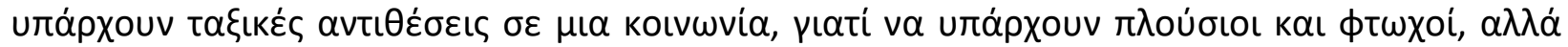

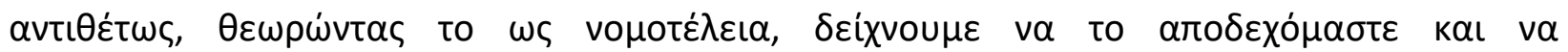

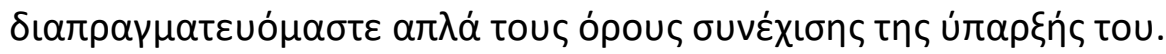

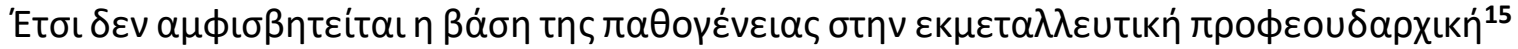

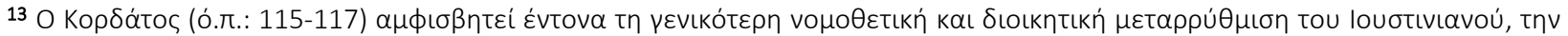

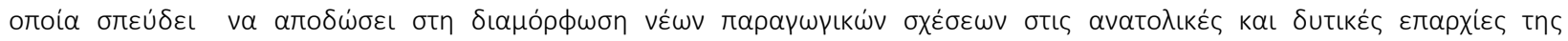

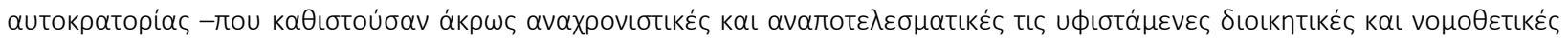

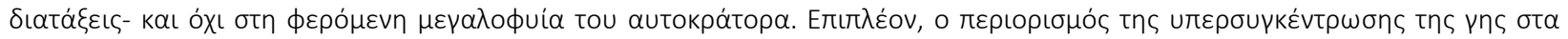

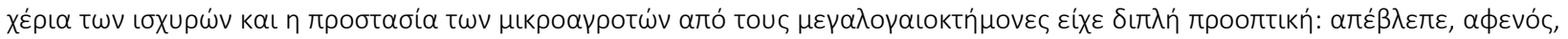

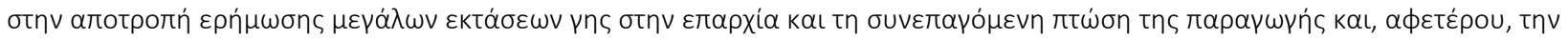

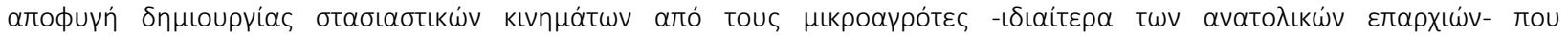

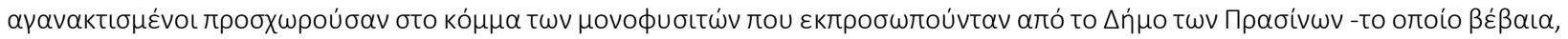

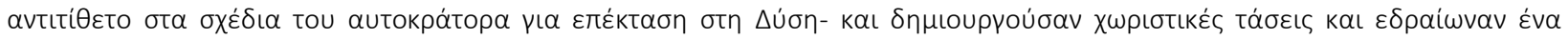

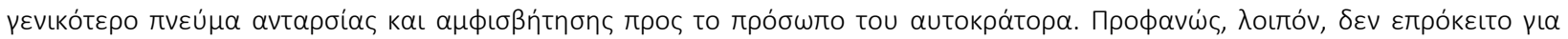

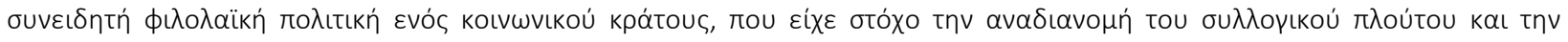

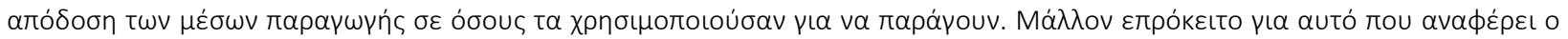

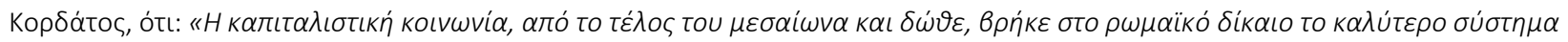

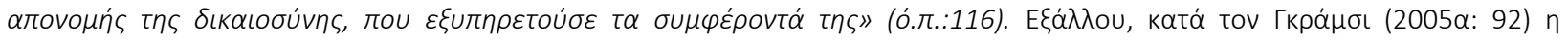

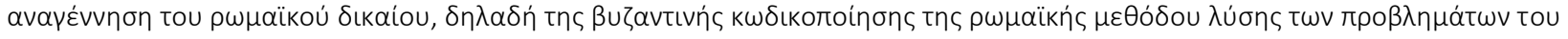

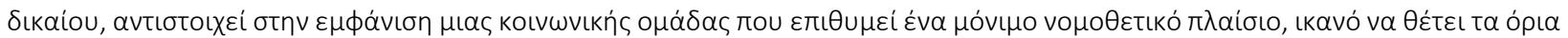

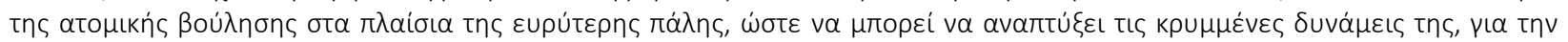

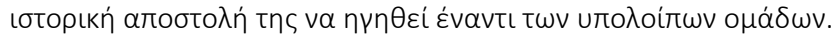

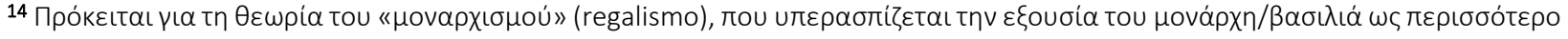

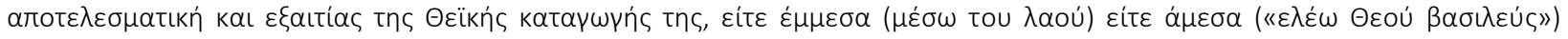

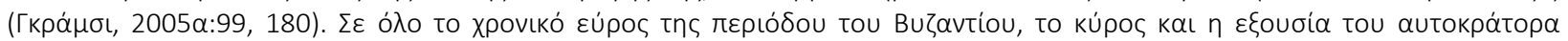

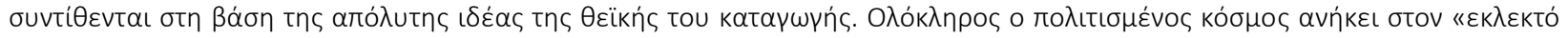

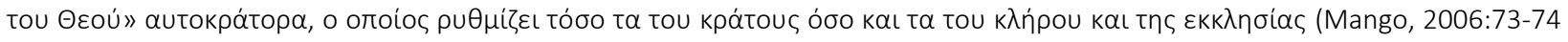

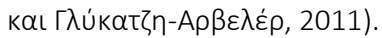

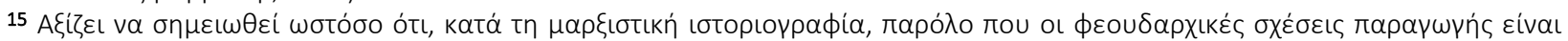

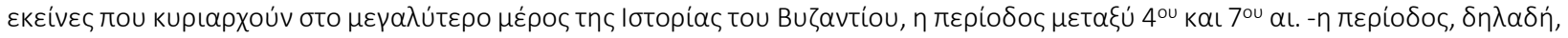

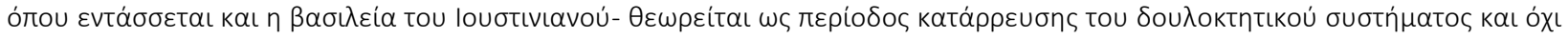

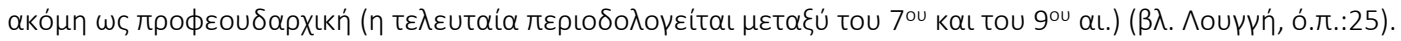


MULTILINGUAL ACADEMIC JOURNAL OF EDUCATION AND SOCIAL SCIENCES

Vol. 5 No. 1, 2017, E-ISSN: 2308-0876 @ 2017 KWP

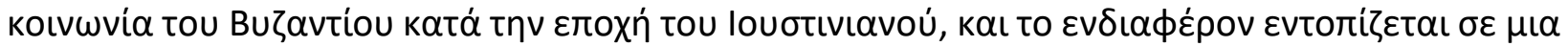

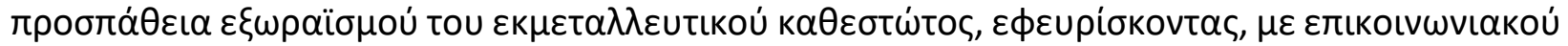

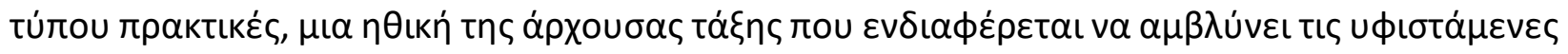

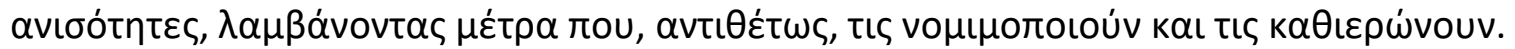

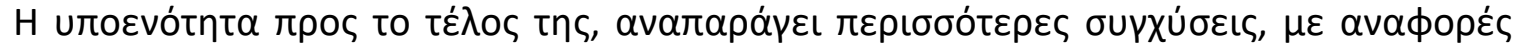

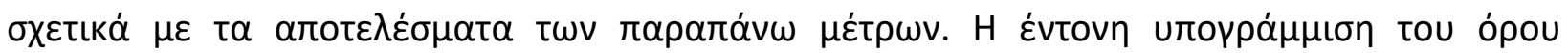

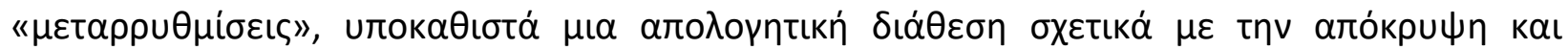

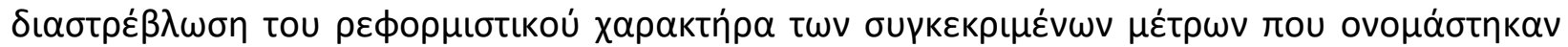

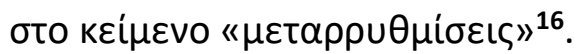

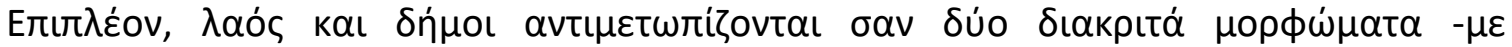

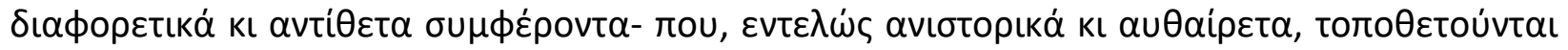

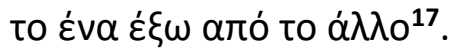

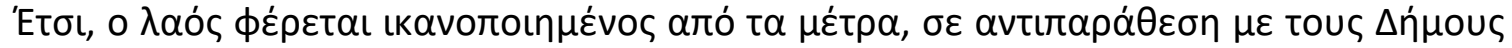

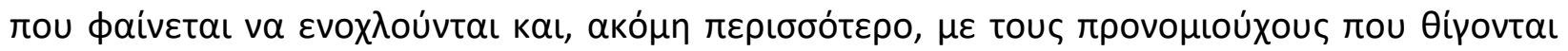

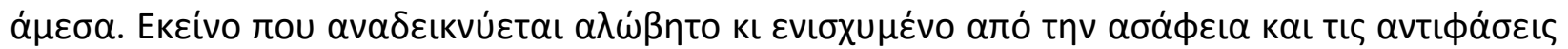

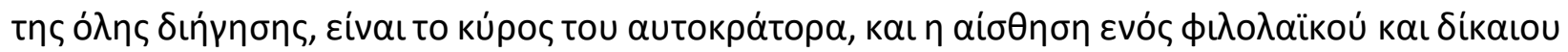
ápxovta.

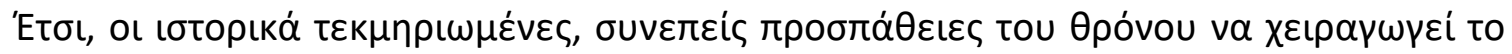

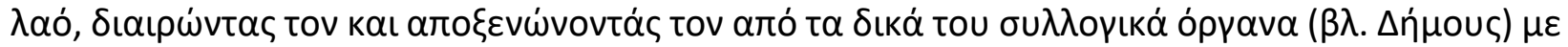

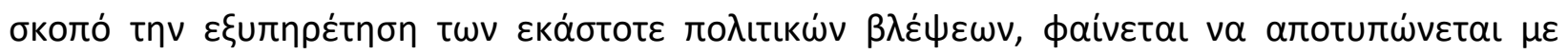

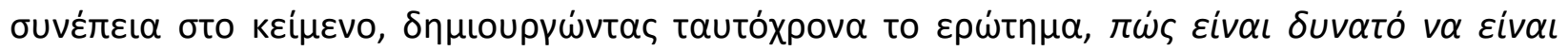

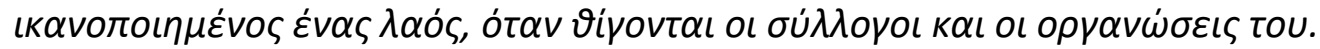

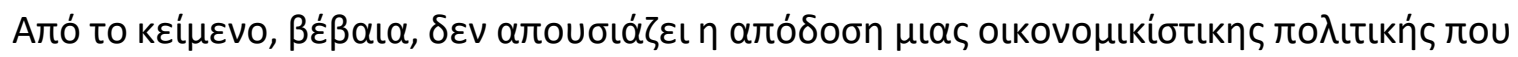

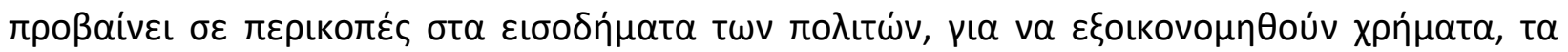

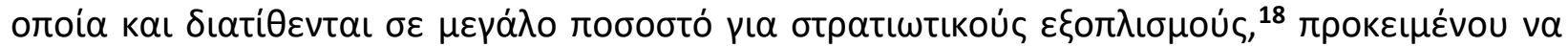

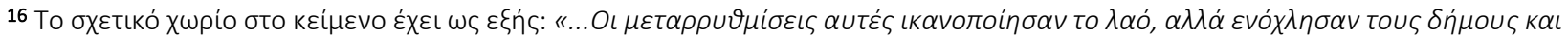

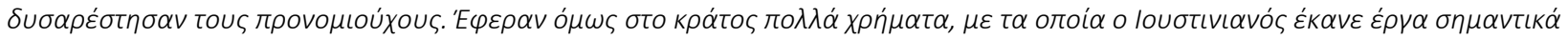

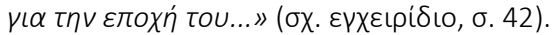

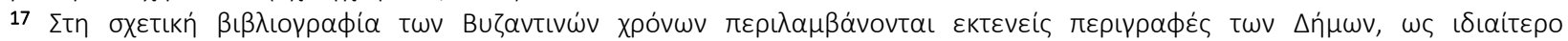

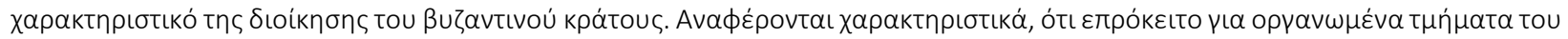

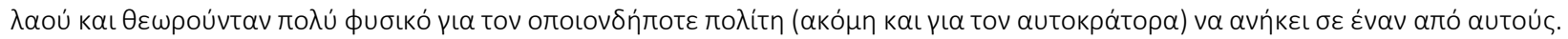

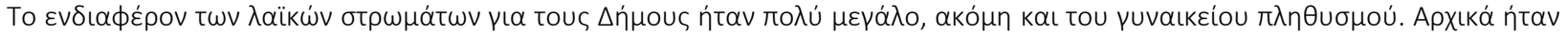

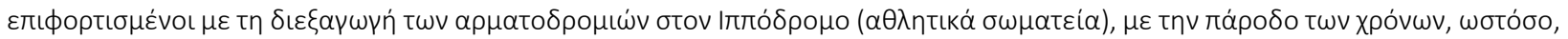

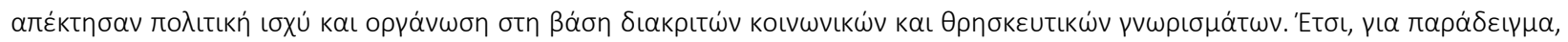

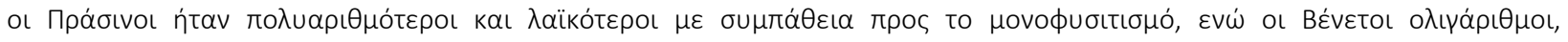

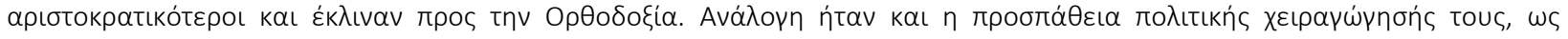

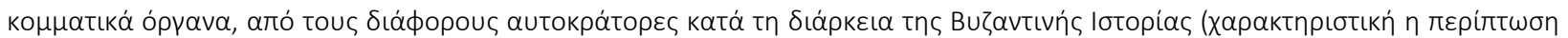

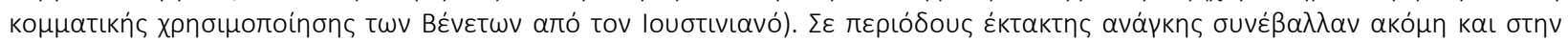

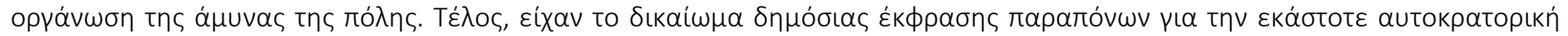

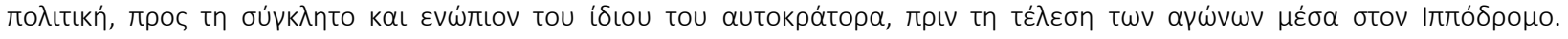

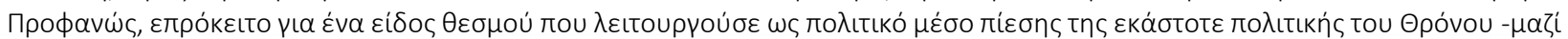

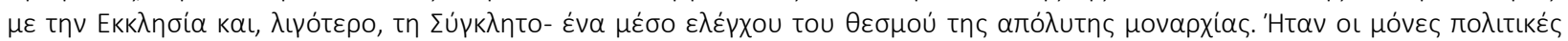

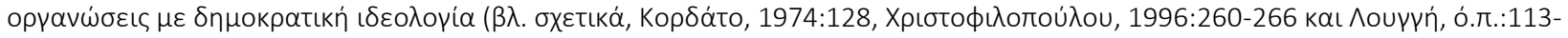
114).

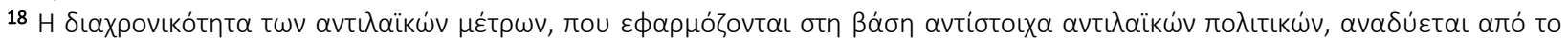

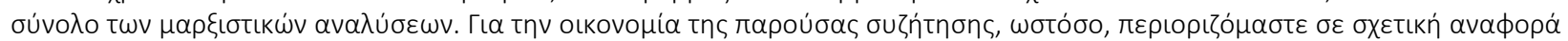

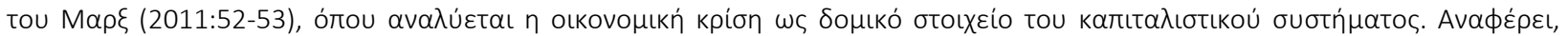

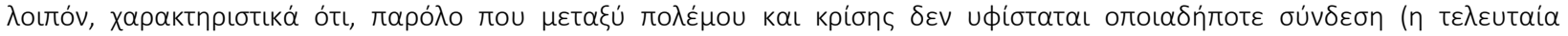

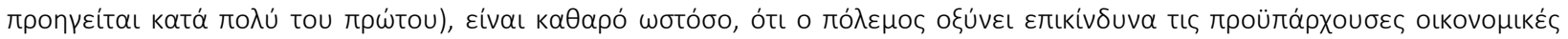


MULTILINGUAL ACADEMIC JOURNAL OF EDUCATION AND SOCIAL SCIENCES

Vol. 5 No. 1, 2017, E-ISSN: 2308-0876 @ 2017 KWP

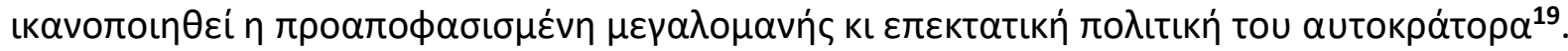

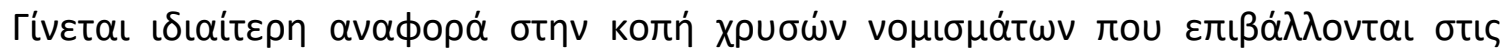

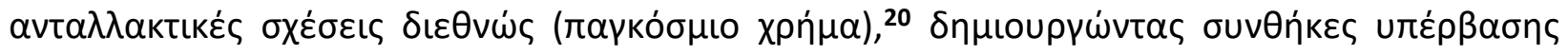

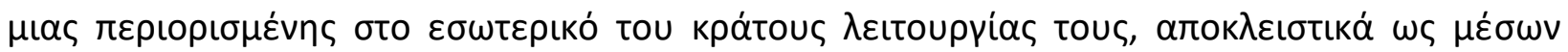

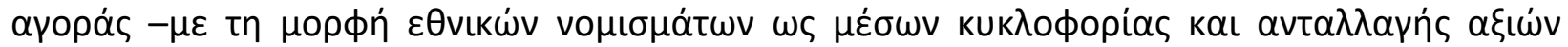

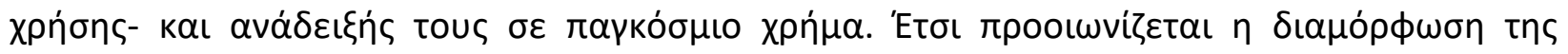

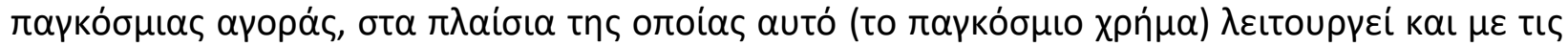

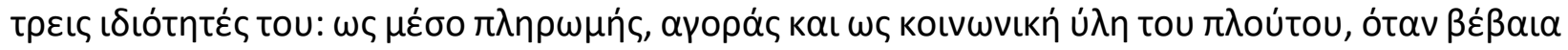

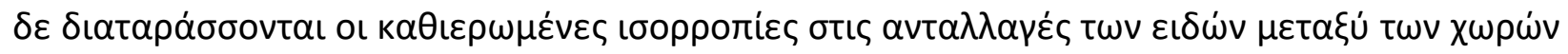

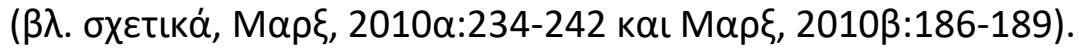

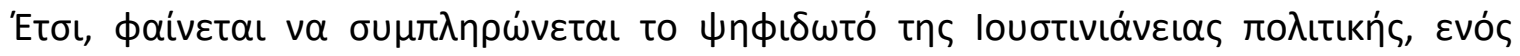

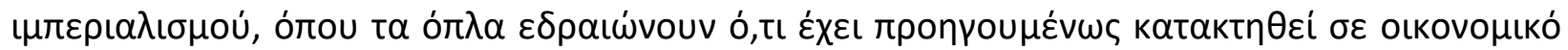

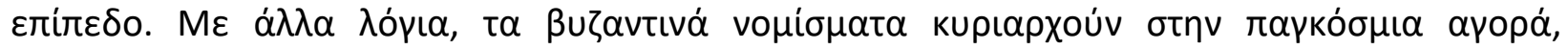

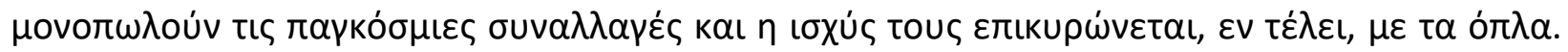

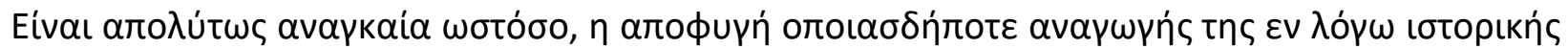

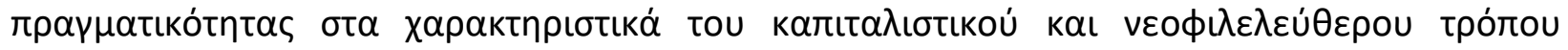

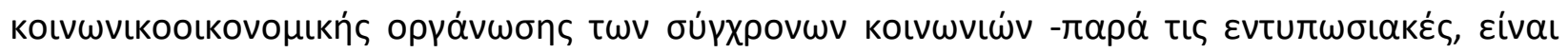

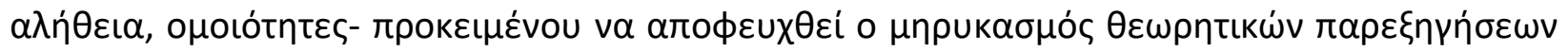

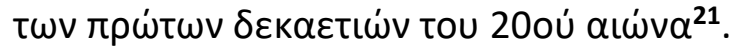

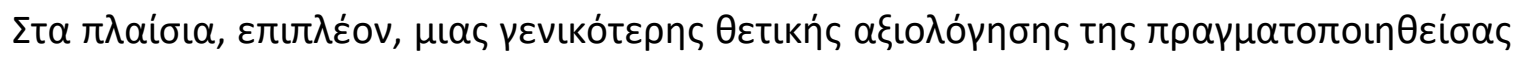

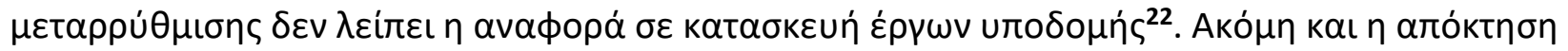

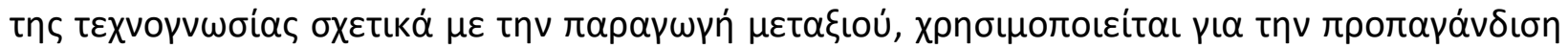

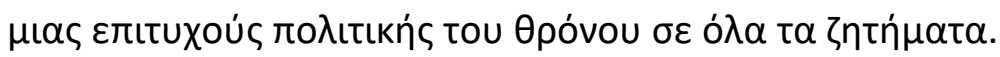

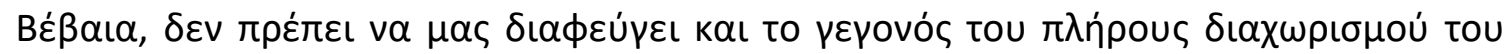

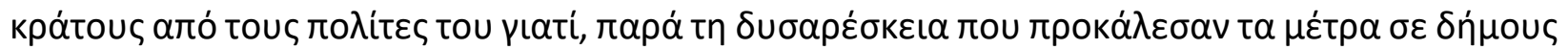

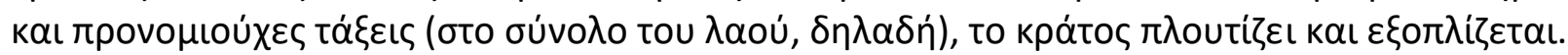

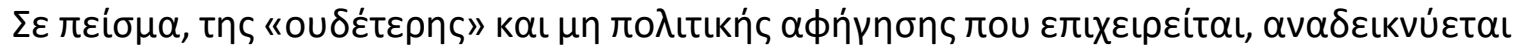

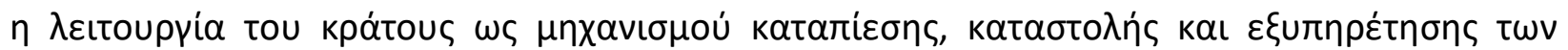

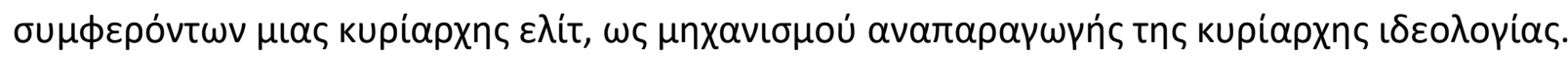

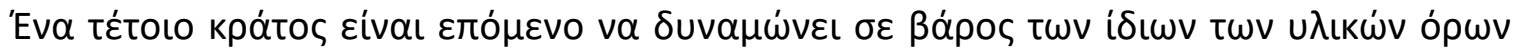

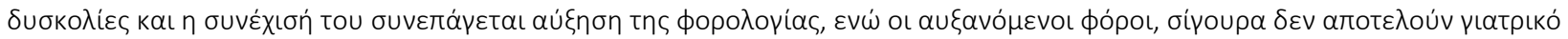

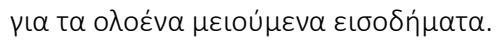

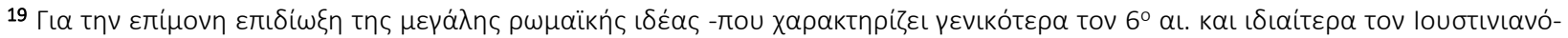

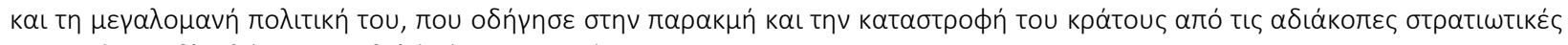

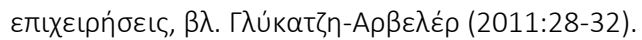

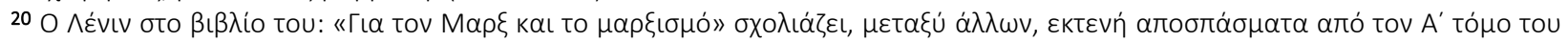

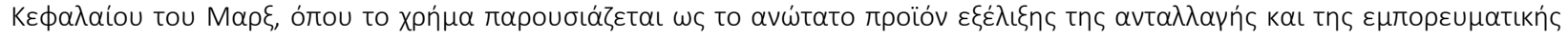

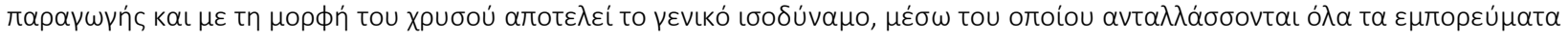

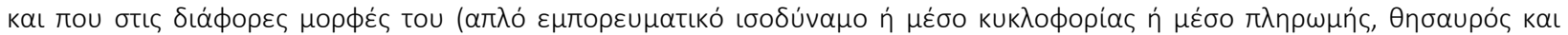

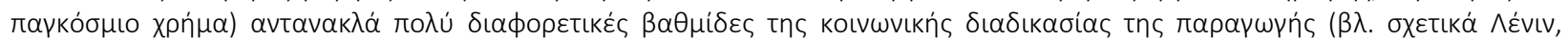
2011:46-47).

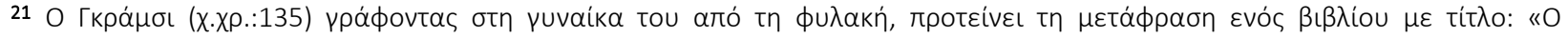

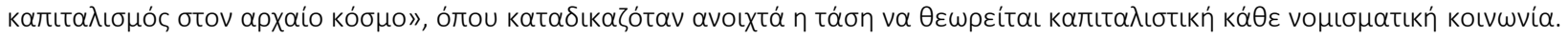

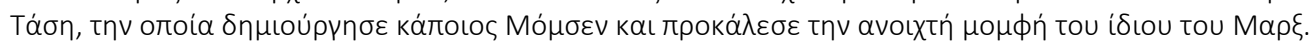

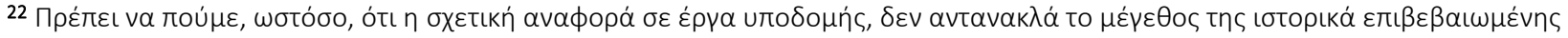

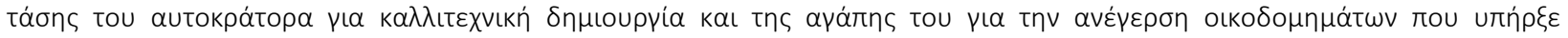

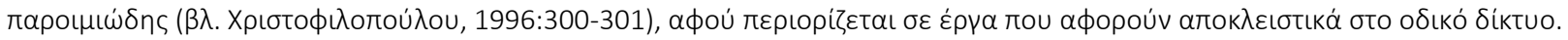


MULTILINGUAL ACADEMIC JOURNAL OF EDUCATION AND SOCIAL SCIENCES

Vol. 5 No. 1, 2017, E-ISSN: 2308-0876 @ 2017 KWP

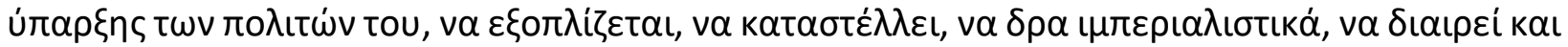

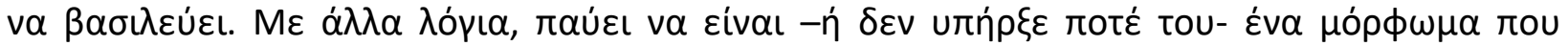

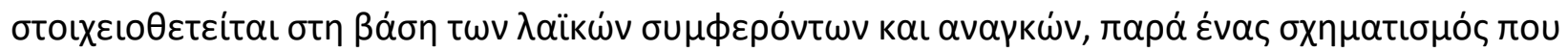

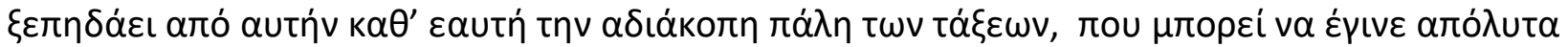

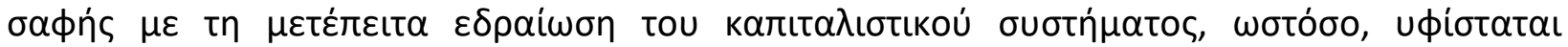

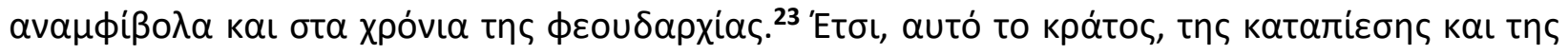

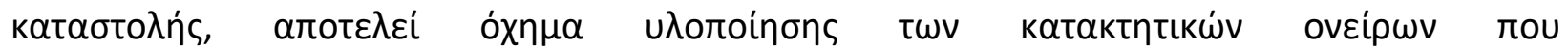

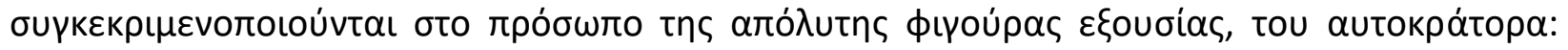

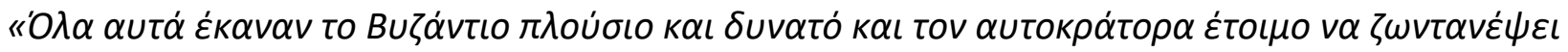

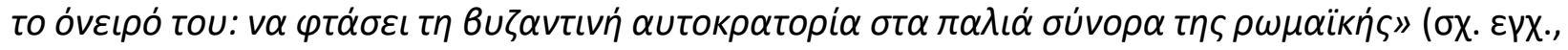
$\sigma .43)$.

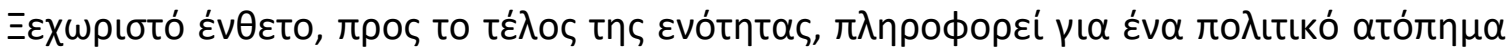

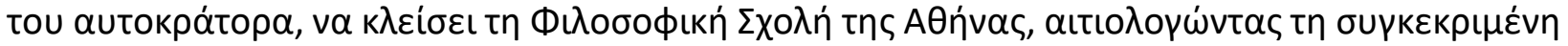

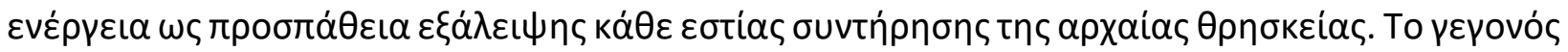

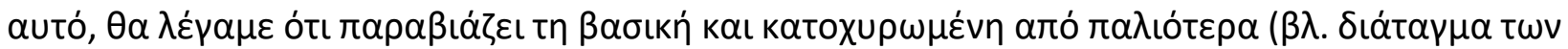

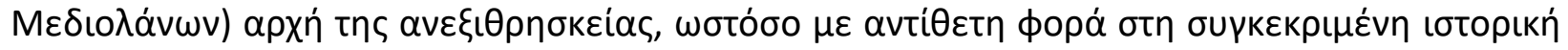

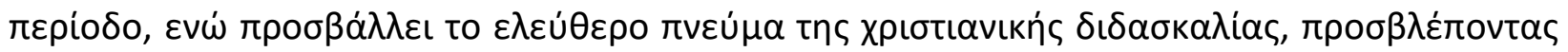

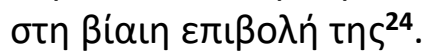

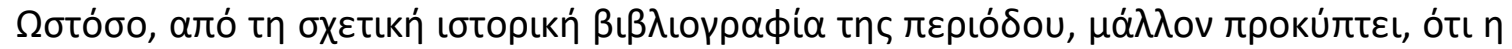

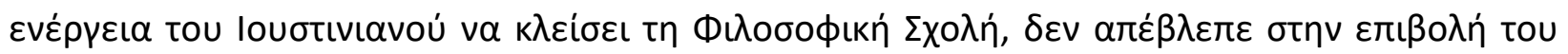

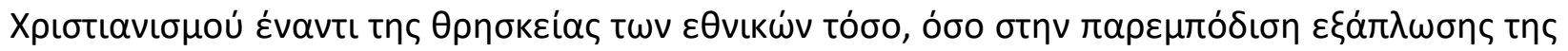

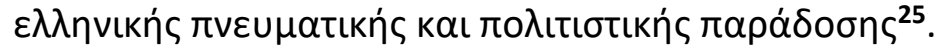

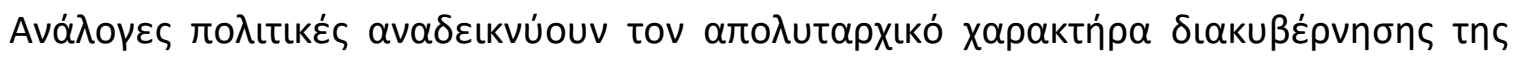

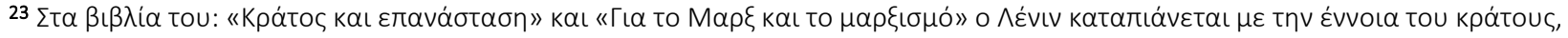

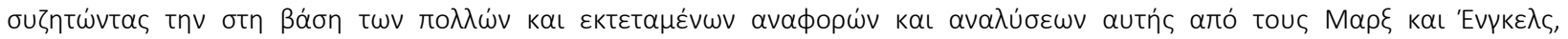

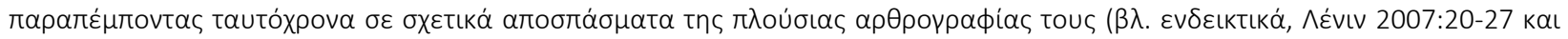

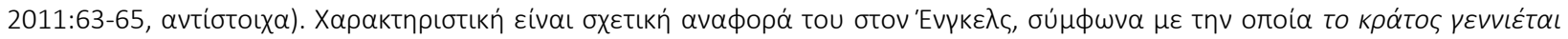

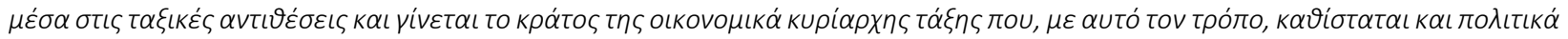

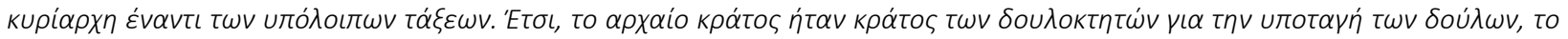

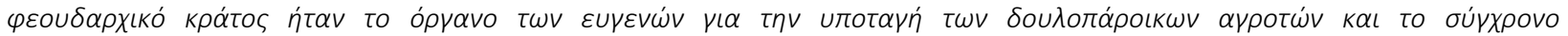

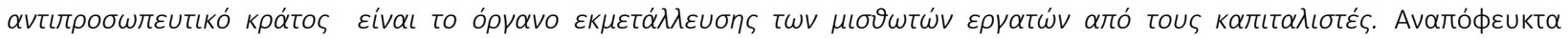

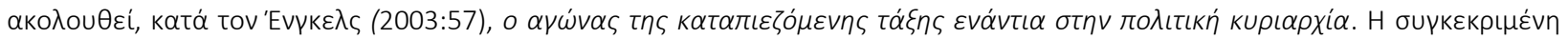

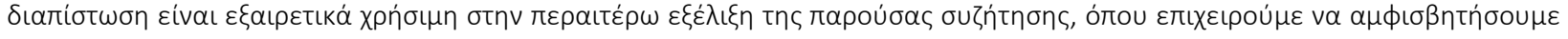

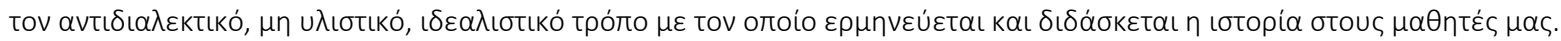

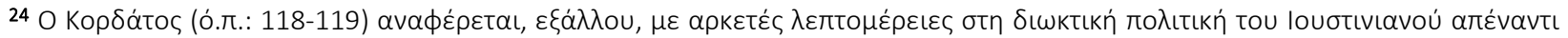

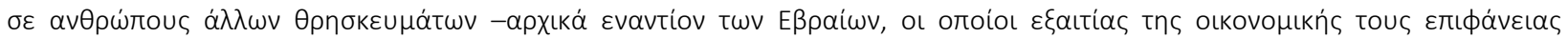

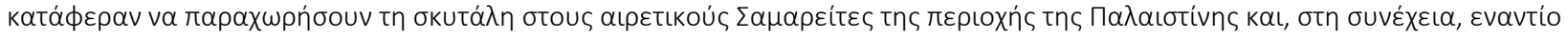

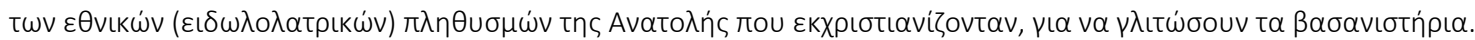

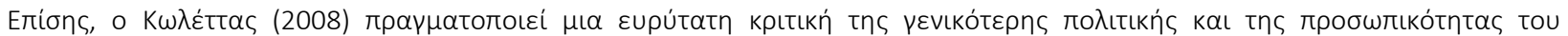

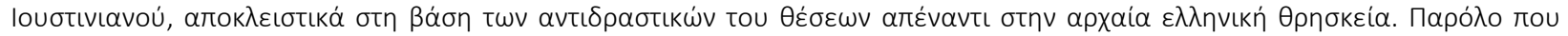
Ө

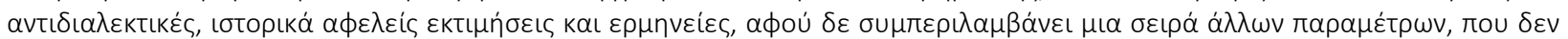

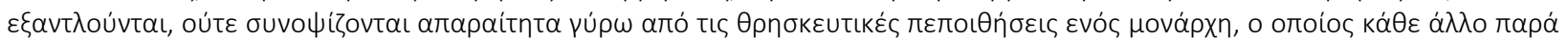

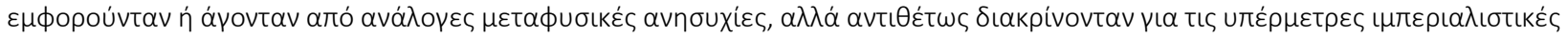

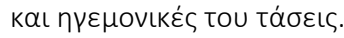

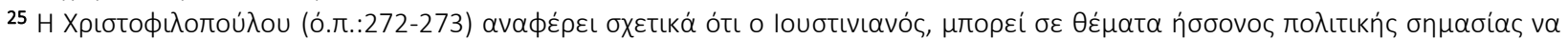

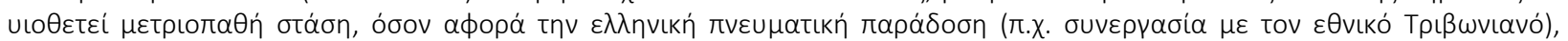

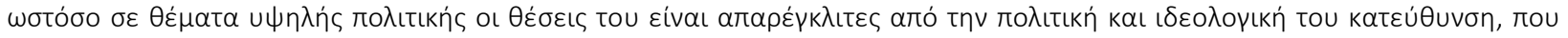

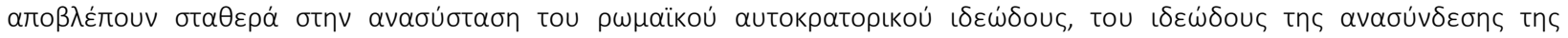

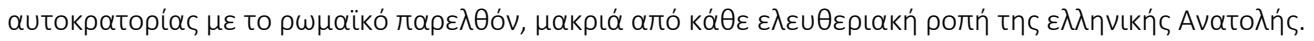


MULTILINGUAL ACADEMIC JOURNAL OF EDUCATION AND SOCIAL SCIENCES

Vol. 5 No. 1, 2017, E-ISSN: 2308-0876 @ 2017 KWP

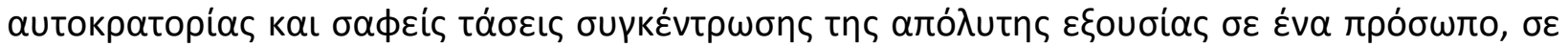

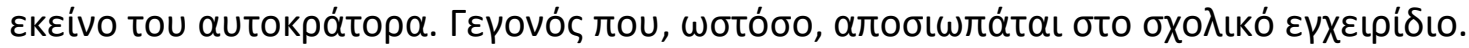

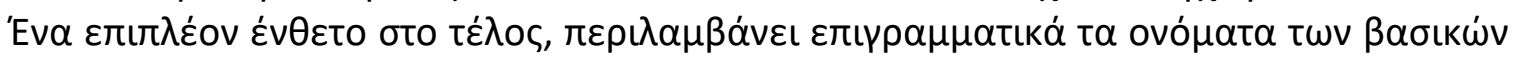

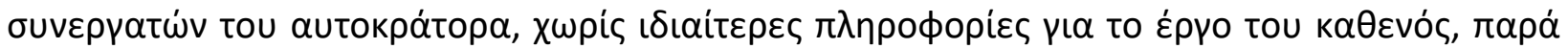

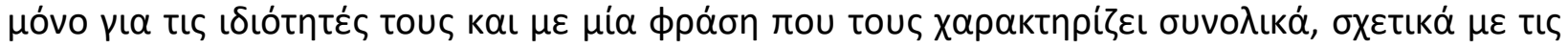

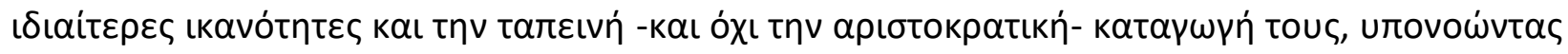

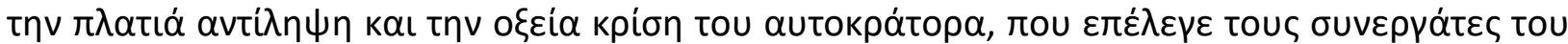

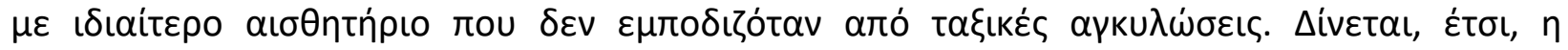

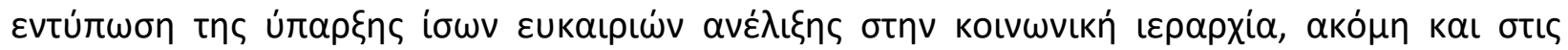

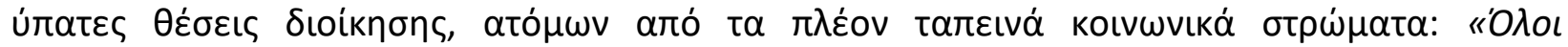

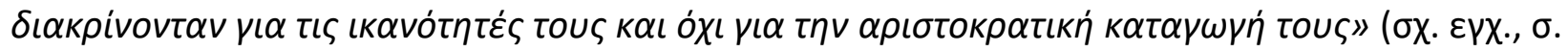
44).

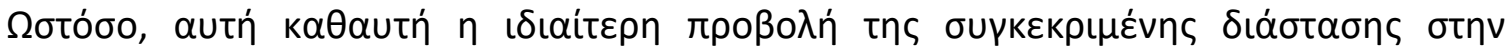

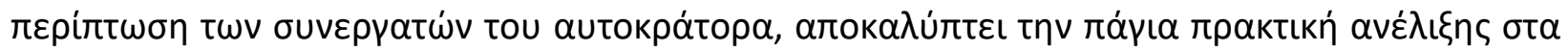

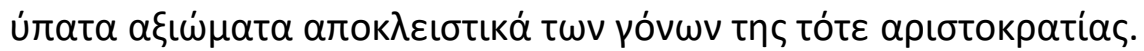

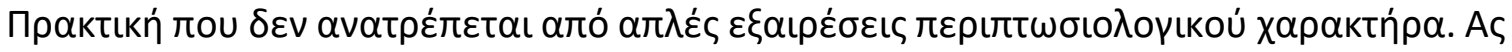

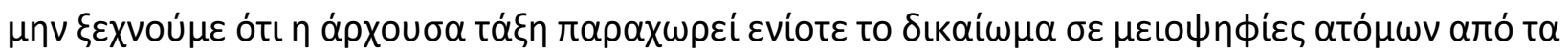

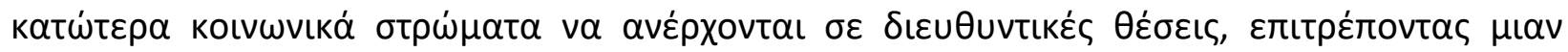

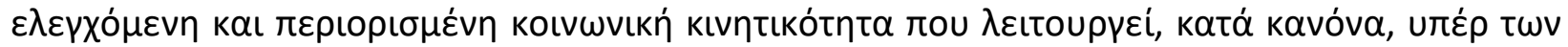

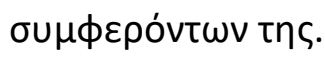

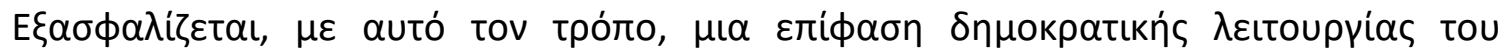

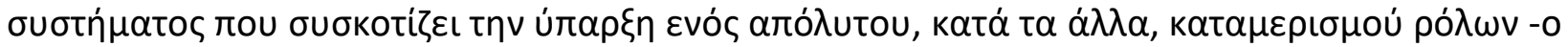

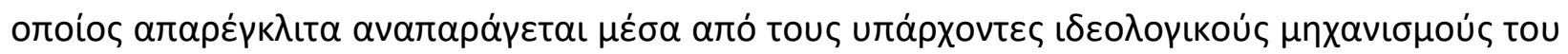

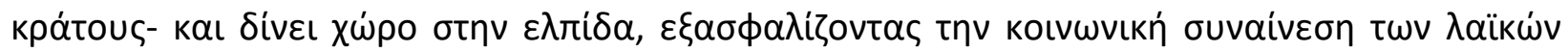

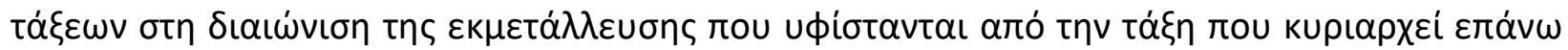
tous.

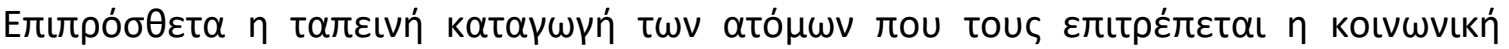

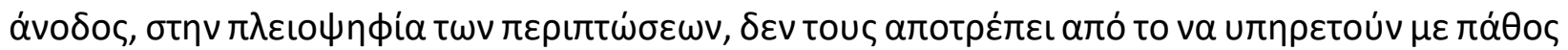

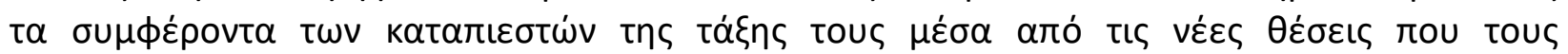
$\pi \alpha \rho \alpha \chi \omega \eta \dot{\theta \eta \kappa \alpha v . ~}$

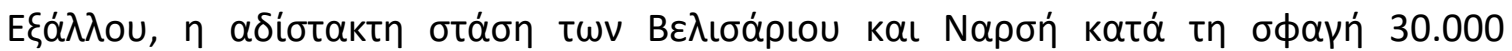

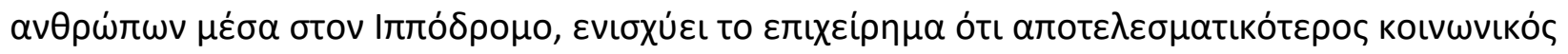

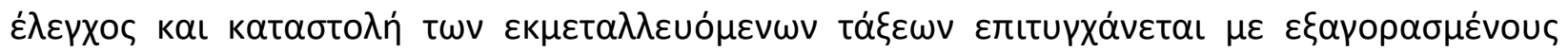

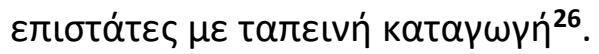

\section{Yловvótnта 14}

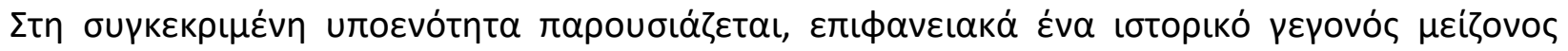

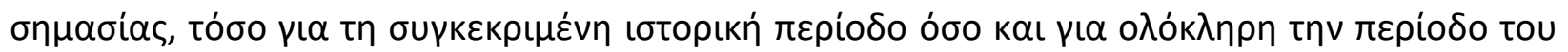

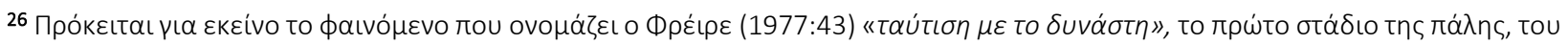

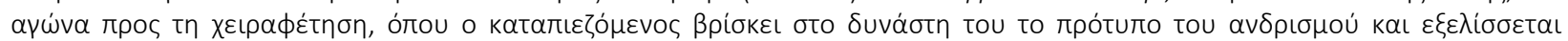

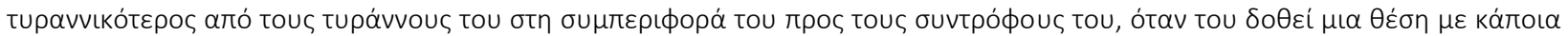

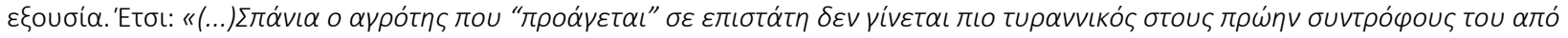

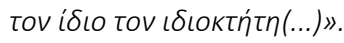


MULTILINGUAL ACADEMIC JOURNAL OF EDUCATION AND SOCIAL SCIENCES

Vol. 5 No. 1, 2017, E-ISSN: 2308-0876 @ 2017 KWP

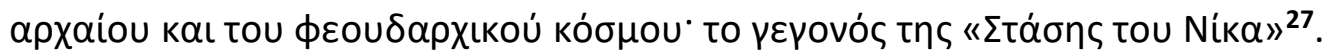

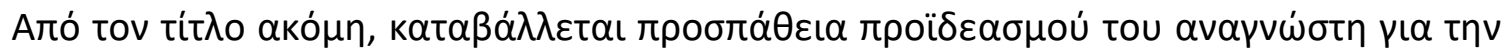

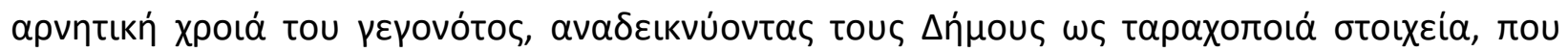

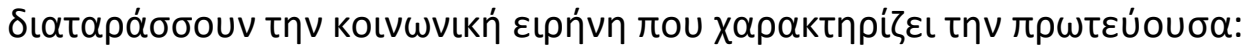

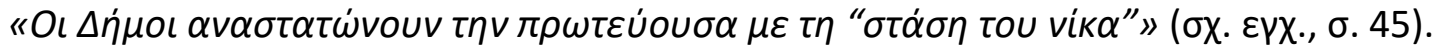

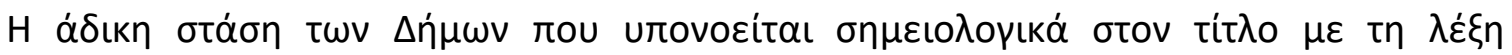

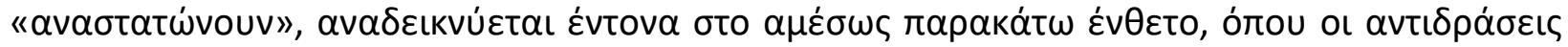

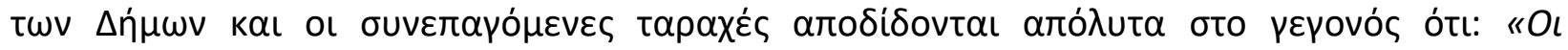

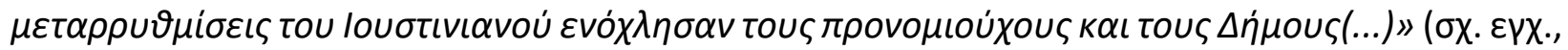
$\sigma .45)$.

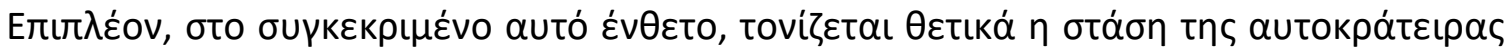

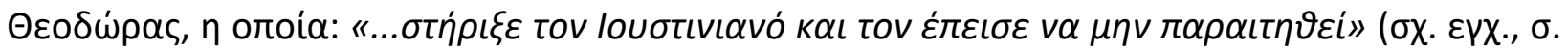

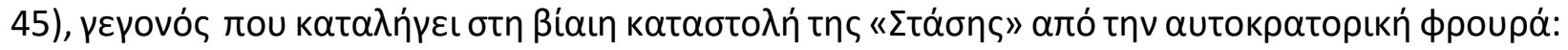

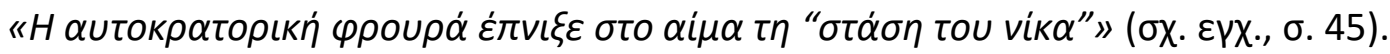

$\Delta$ Uo

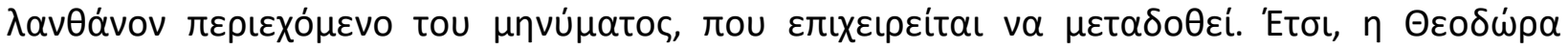

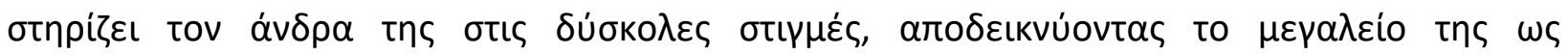

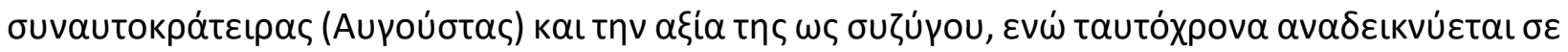

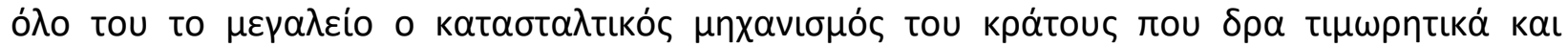

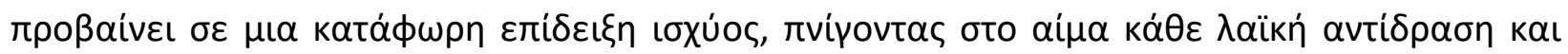

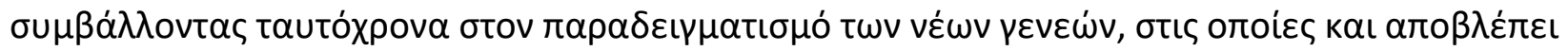
$\eta \alpha \phi \dot{v \eta \eta \eta}$.

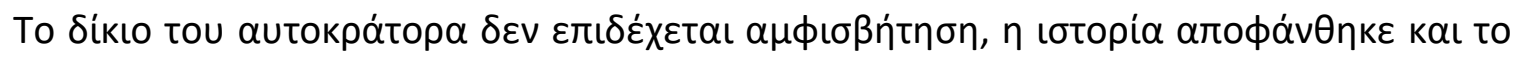

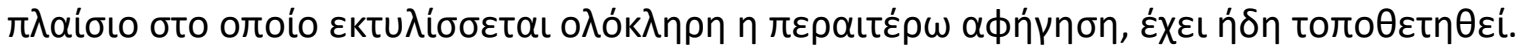

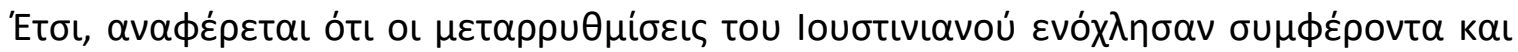

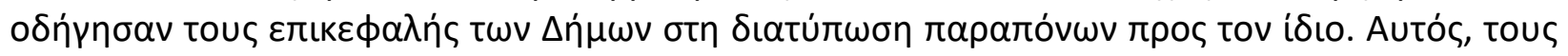

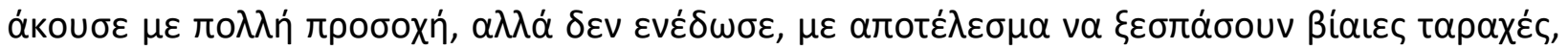

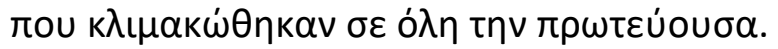

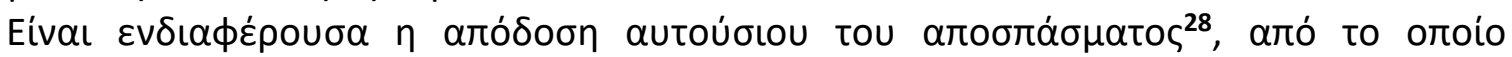

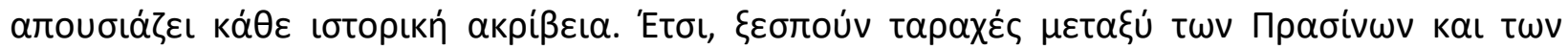

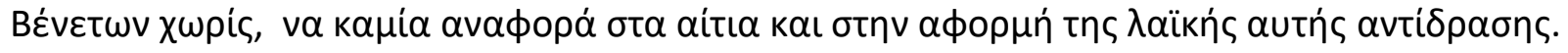

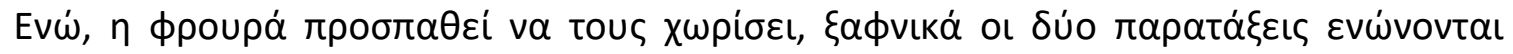

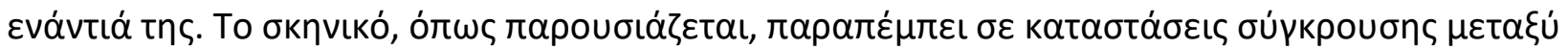

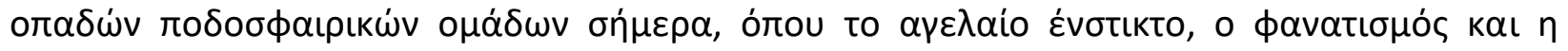

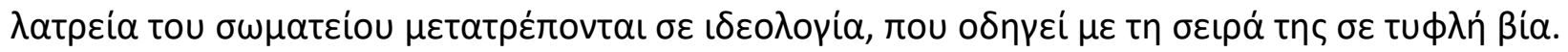

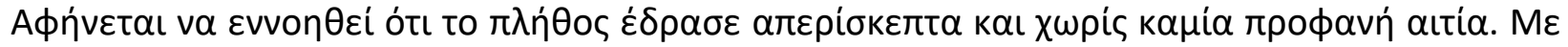

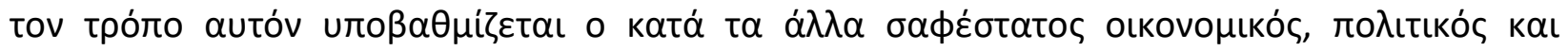

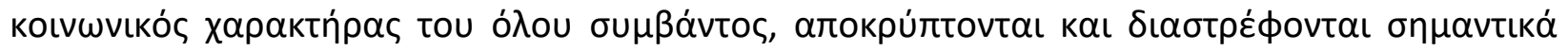

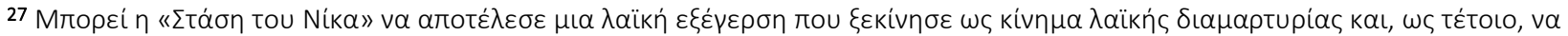

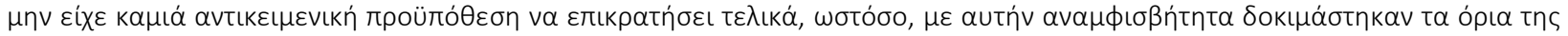

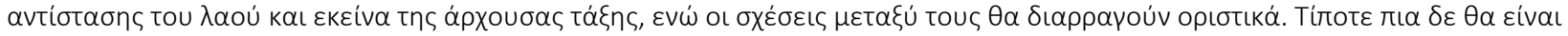

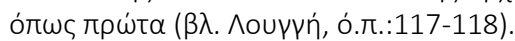

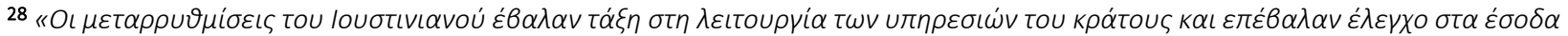

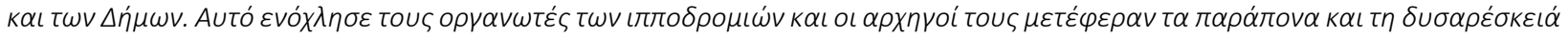

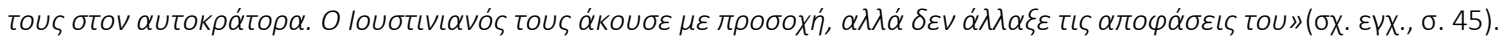


MULTILINGUAL ACADEMIC JOURNAL OF EDUCATION AND SOCIAL SCIENCES

Vol. 5 No. 1, 2017, E-ISSN: 2308-0876 @ 2017 KWP

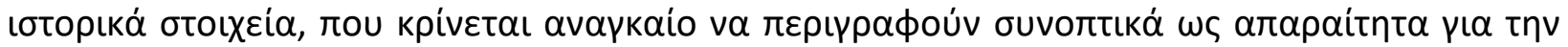

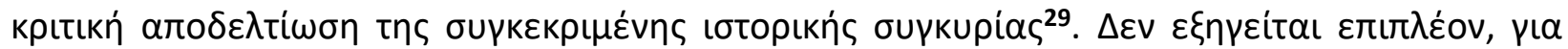

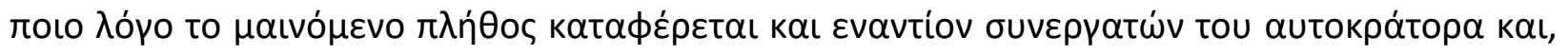

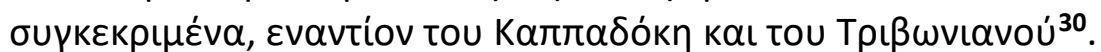

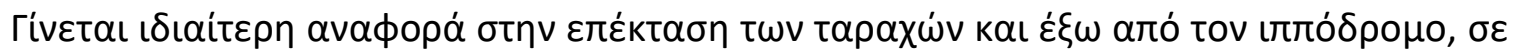

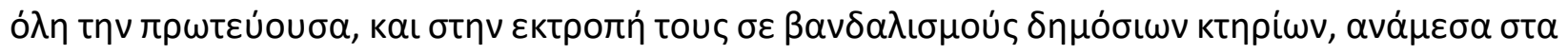

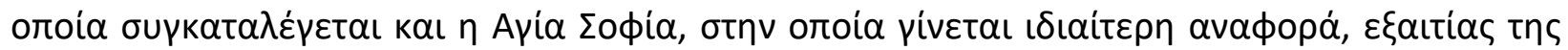

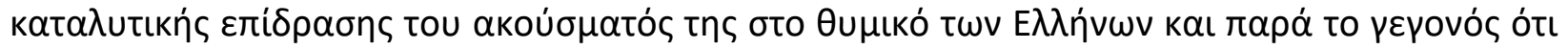

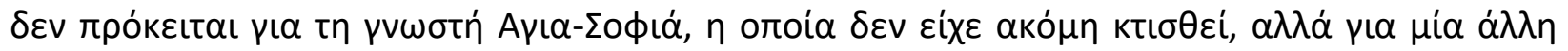

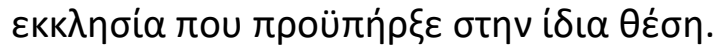

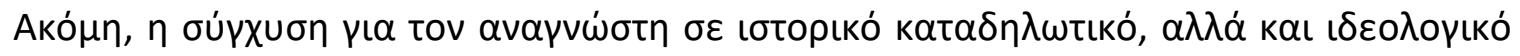

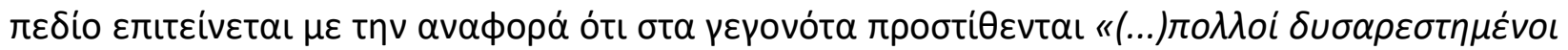

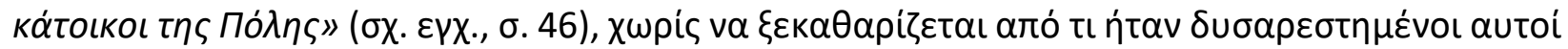

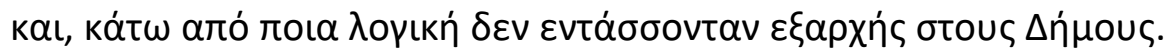

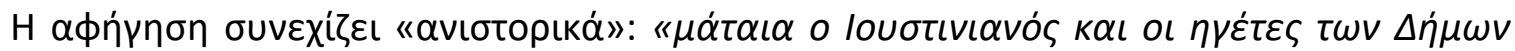

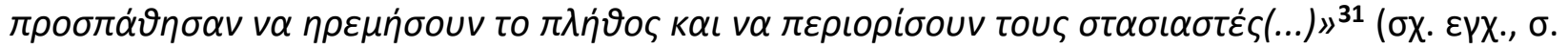
46).

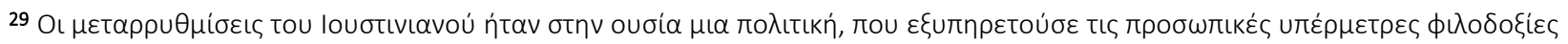

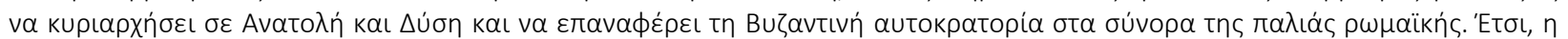

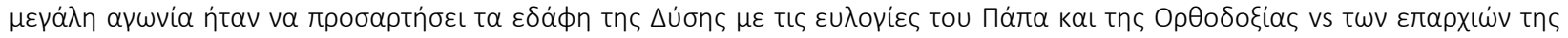

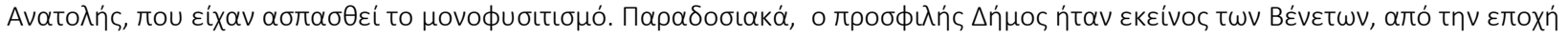

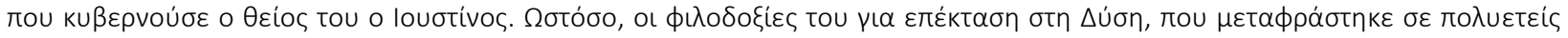

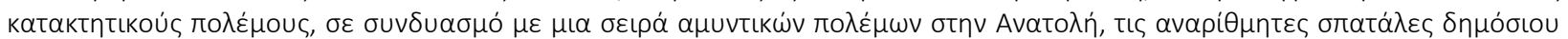

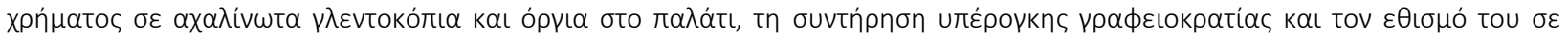

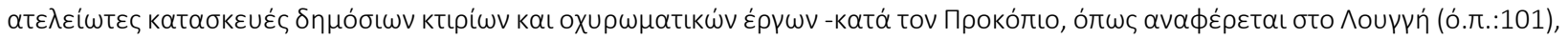

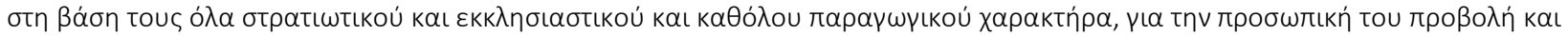

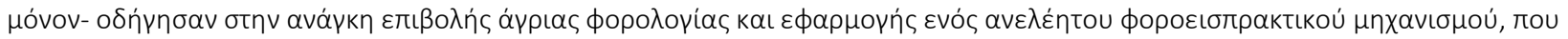

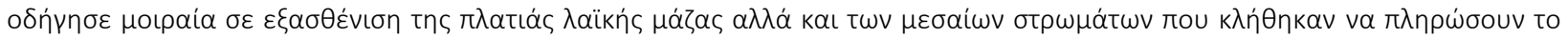

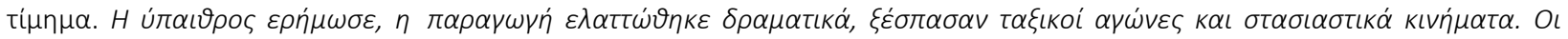

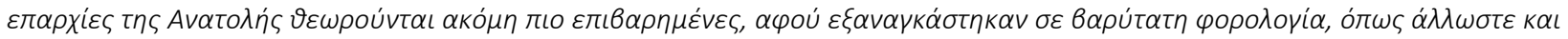

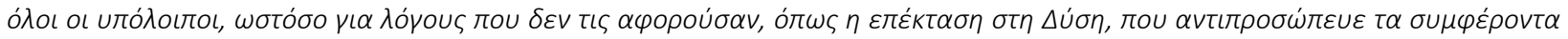

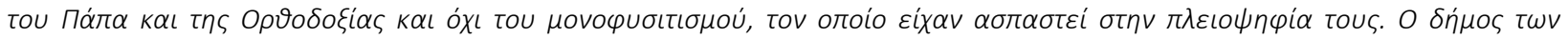

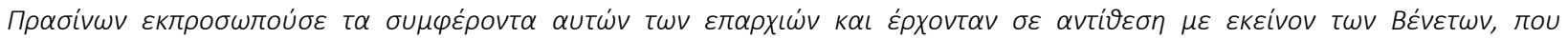

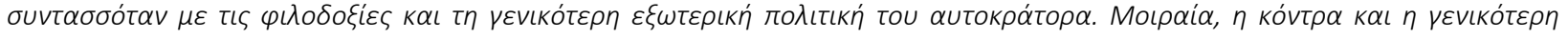

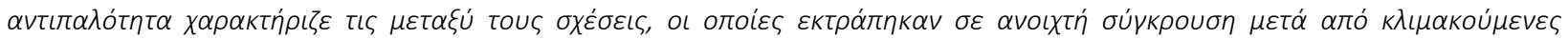

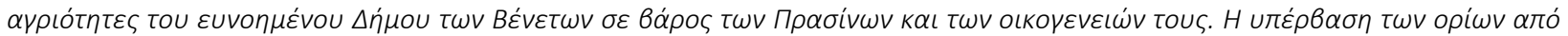

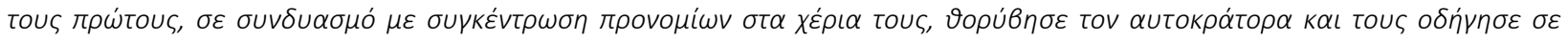

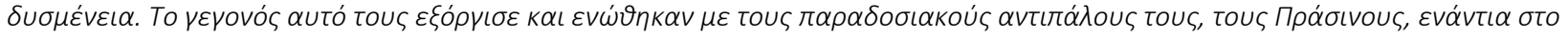

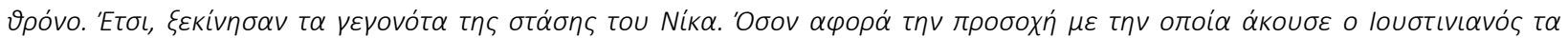

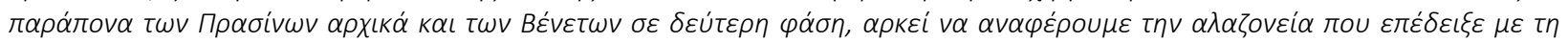

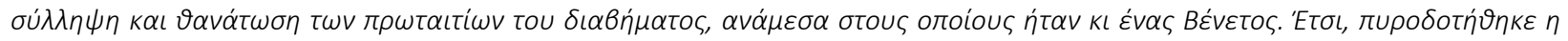

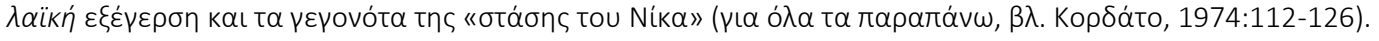

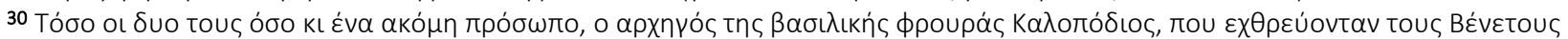

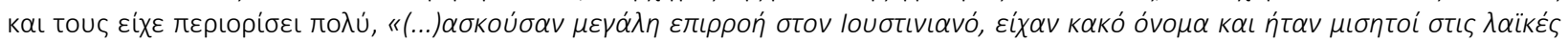

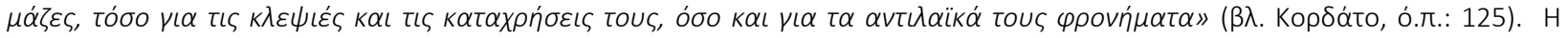

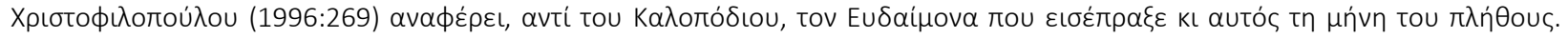

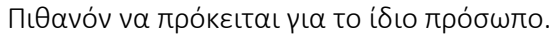

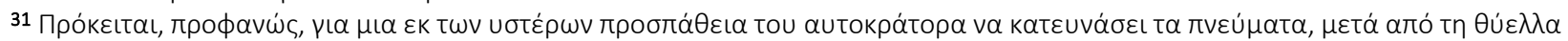

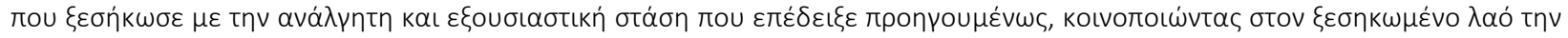

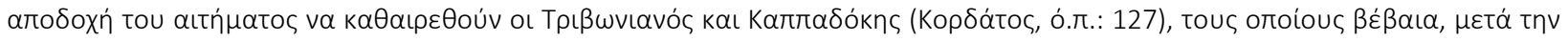

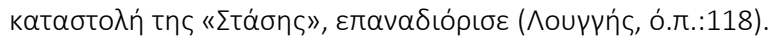


MULTILINGUAL ACADEMIC JOURNAL OF EDUCATION AND SOCIAL SCIENCES

Vol. 5 No. 1, 2017, E-ISSN: 2308-0876 @ 2017 KWP

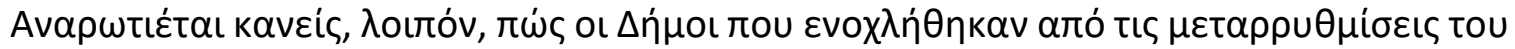

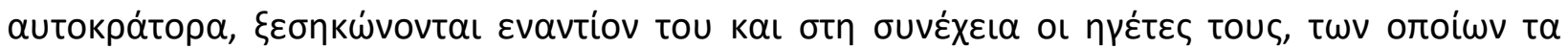

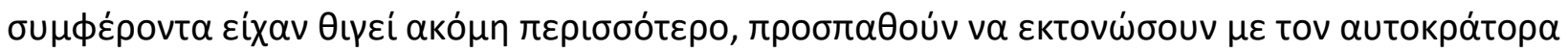

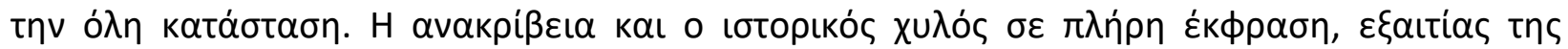

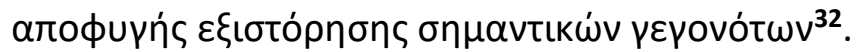

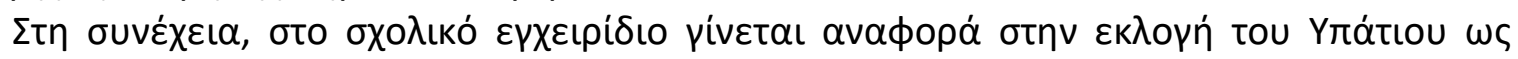

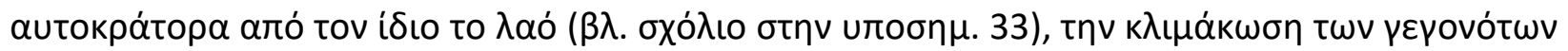

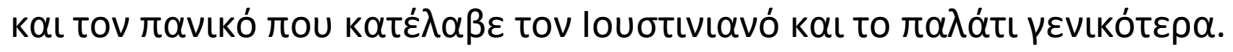

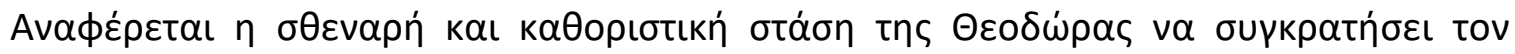

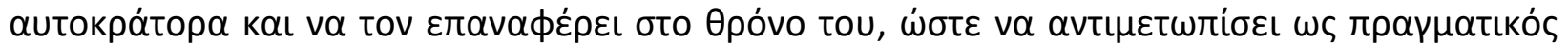

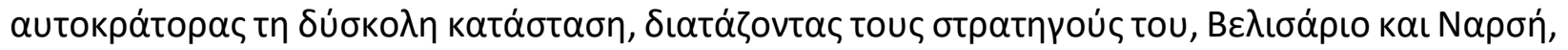

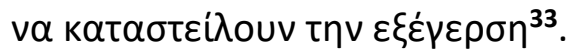

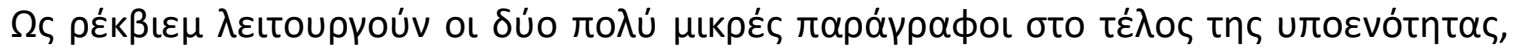

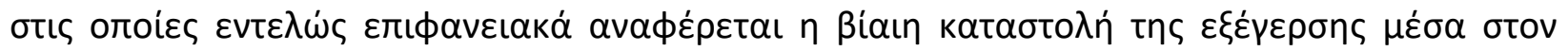

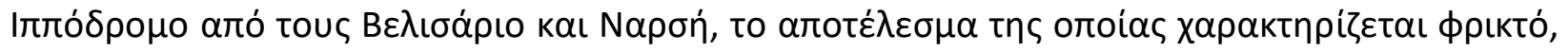

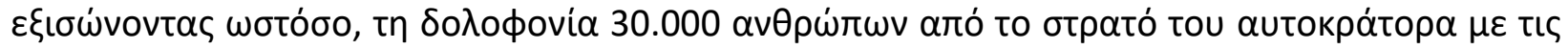

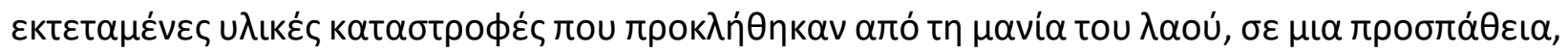

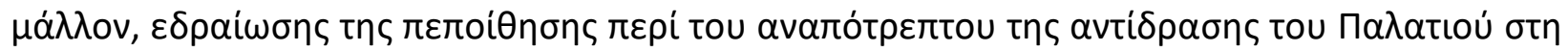

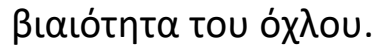

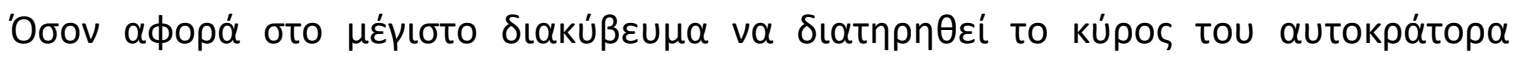

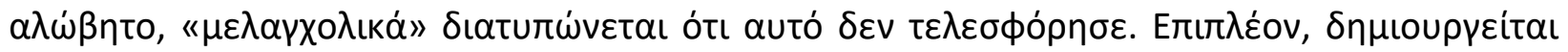

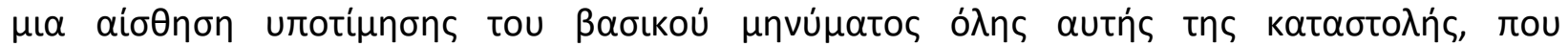

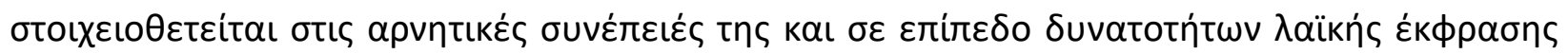

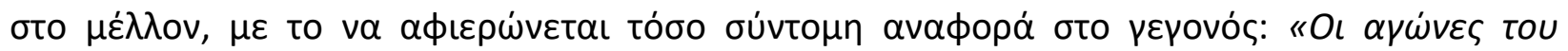

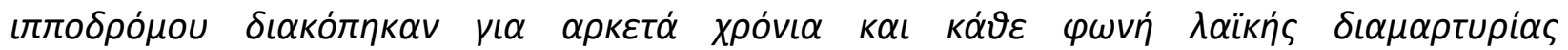
$\sigma \dot{\omega} \pi \alpha \sigma \varepsilon(\ldots) »(\sigma \chi . \varepsilon \gamma \chi ., \sigma .46)$.

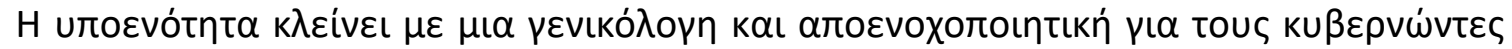

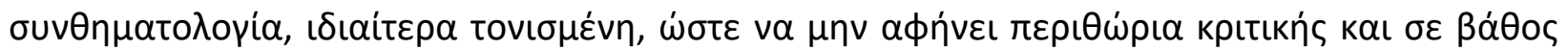

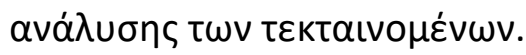

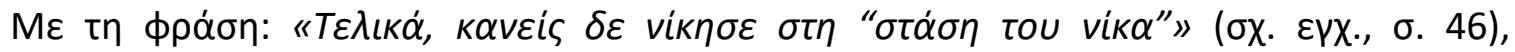

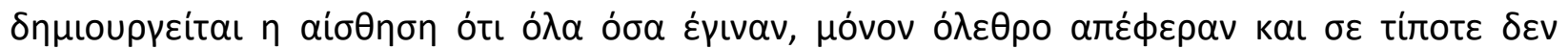

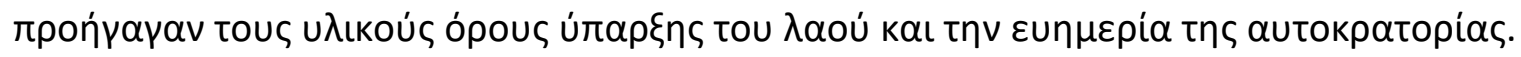

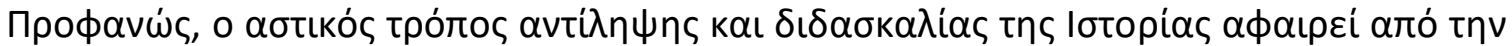

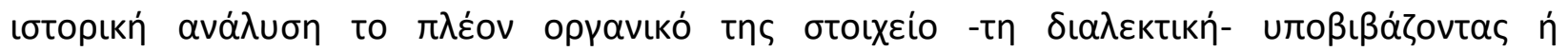

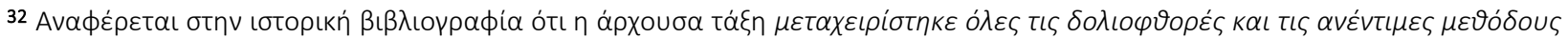

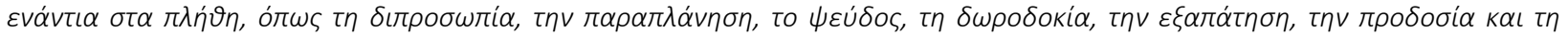

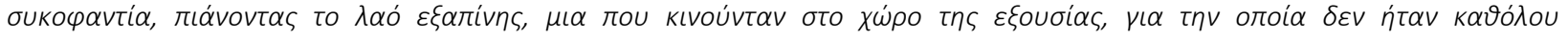

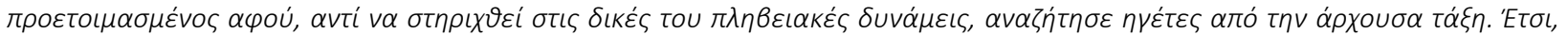

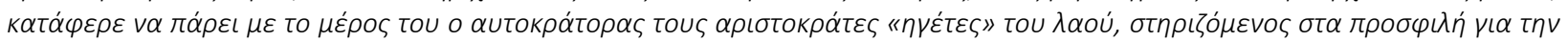

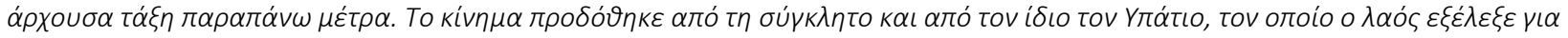

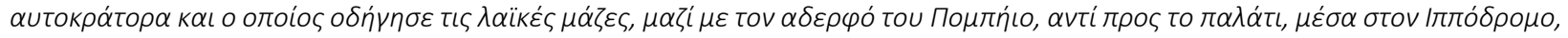

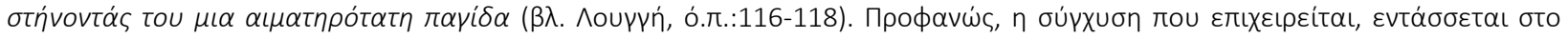

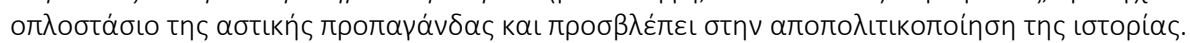

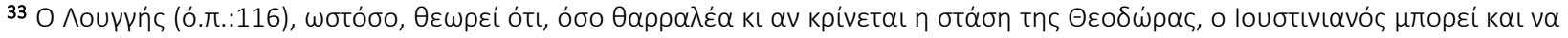

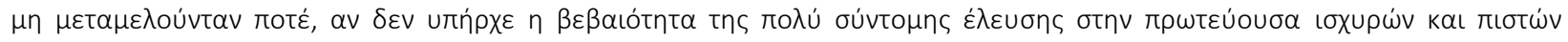

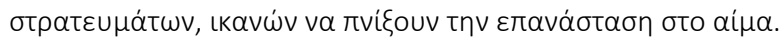


MULTILINGUAL ACADEMIC JOURNAL OF EDUCATION AND SOCIAL SCIENCES

Vol. 5 No. 1, 2017, E-ISSN: 2308-0876 @ 2017 KWP

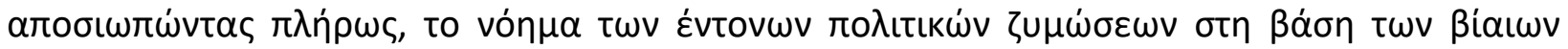

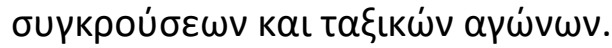

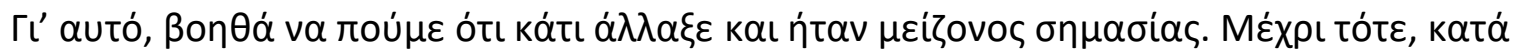

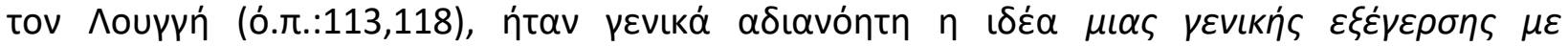

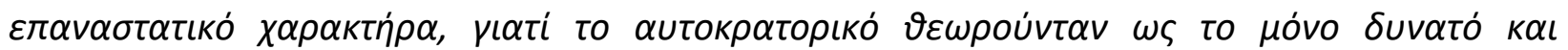

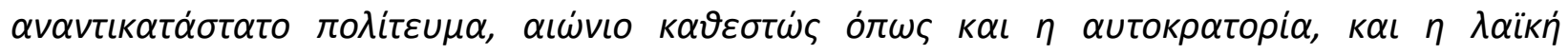

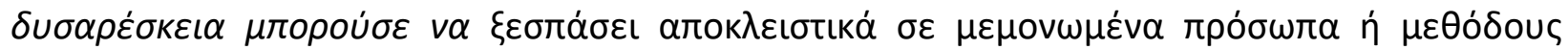

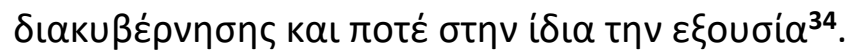

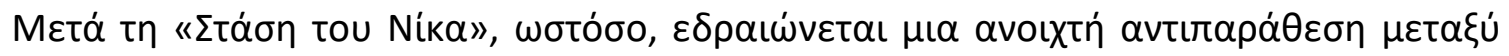

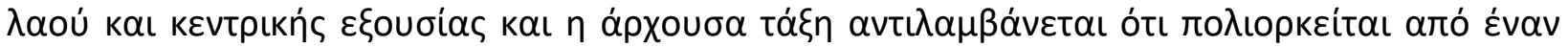

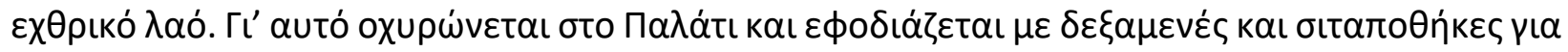

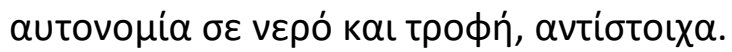

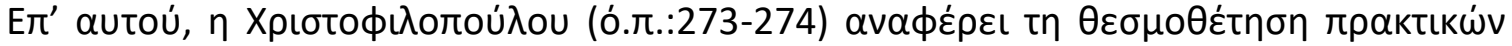

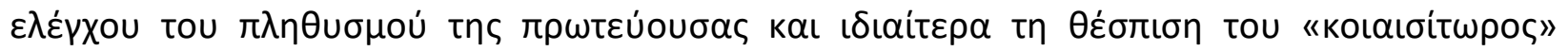

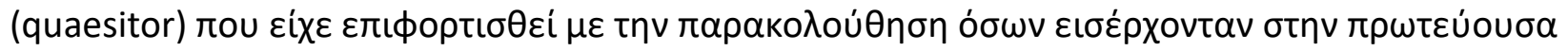

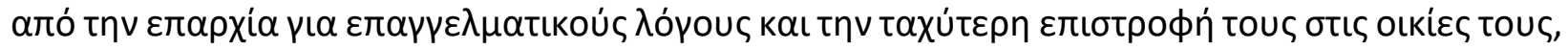

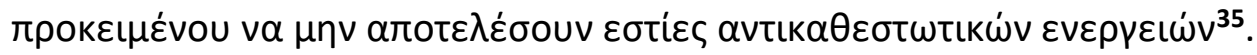

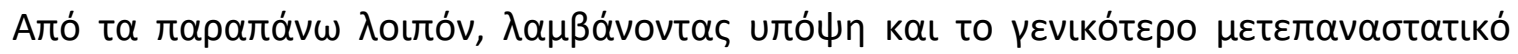

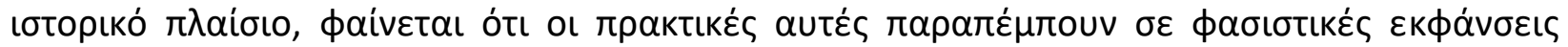

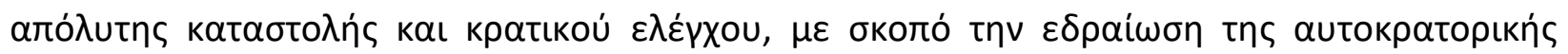

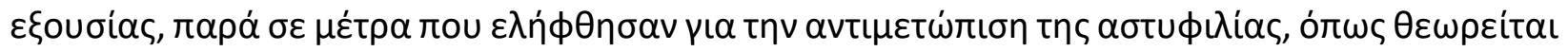

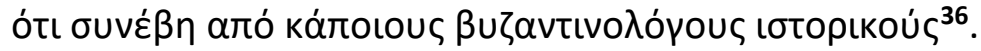

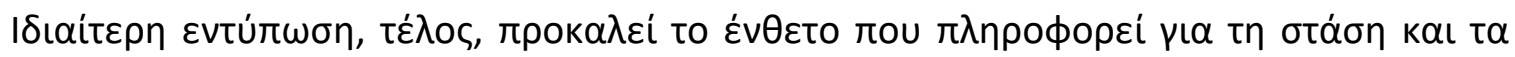

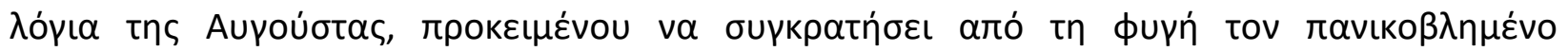

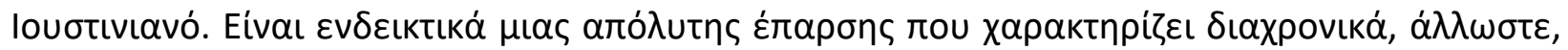

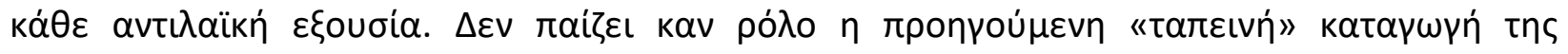

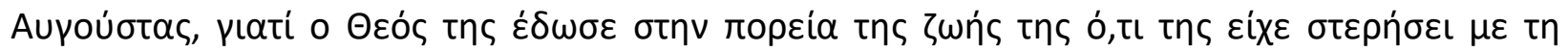

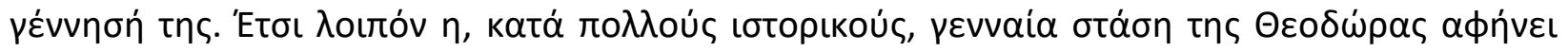

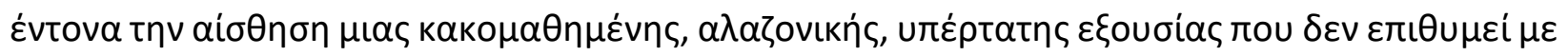

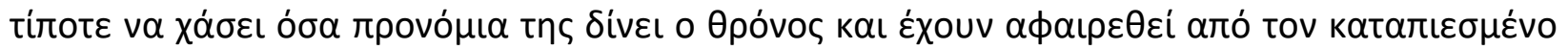
$\lambda \alpha o ́$.

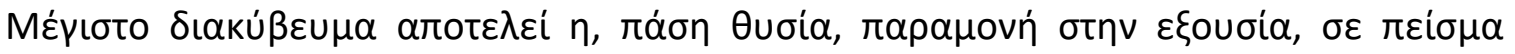

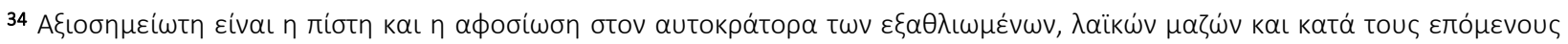

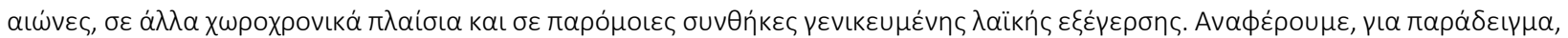

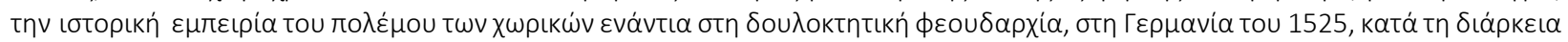

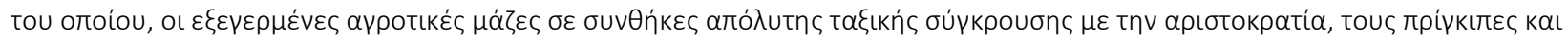

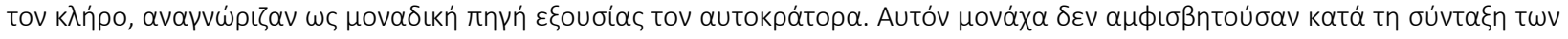

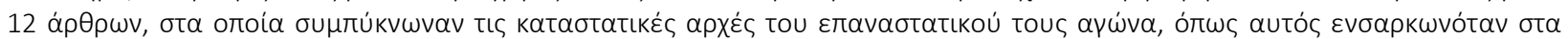

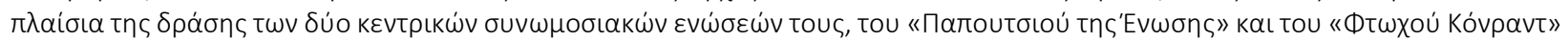
( $\beta \lambda . ' E v ү \kappa \varepsilon \lambda \varsigma, 1991)$.

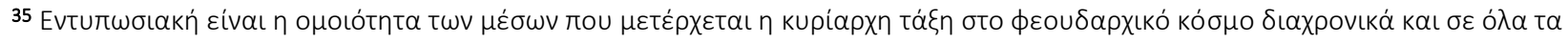

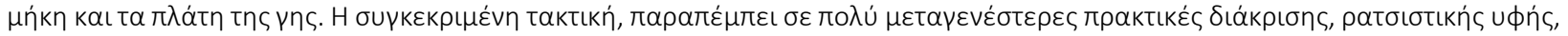

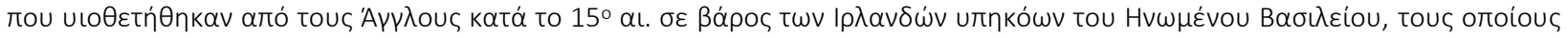

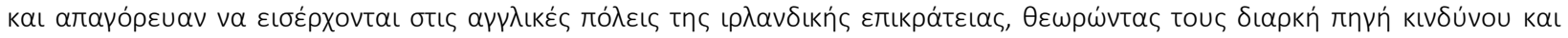

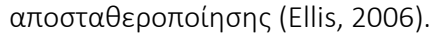

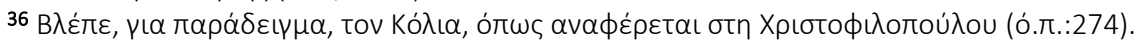


MULTILINGUAL ACADEMIC JOURNAL OF EDUCATION AND SOCIAL SCIENCES

Vol. 5 No. 1, 2017, E-ISSN: 2308-0876 @ 2017 KWP

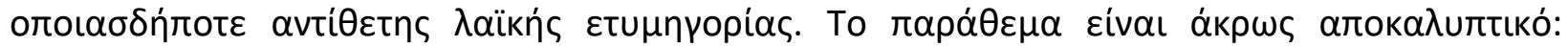

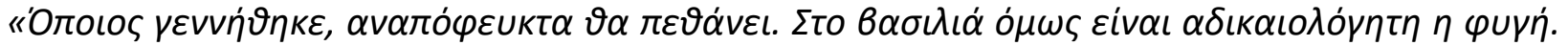

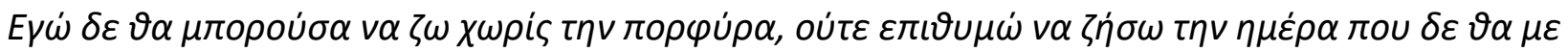

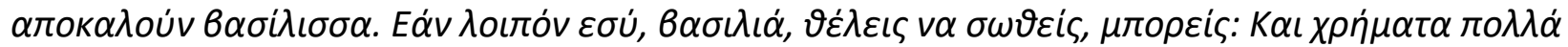

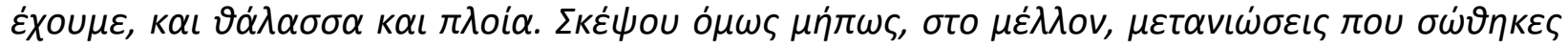

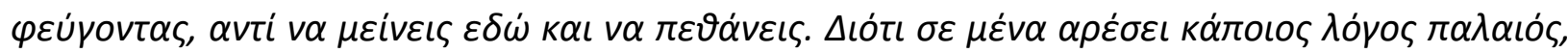

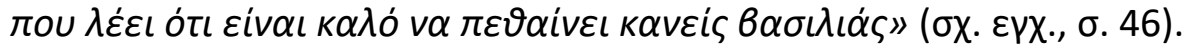

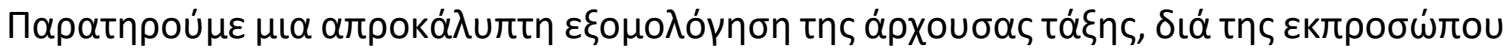

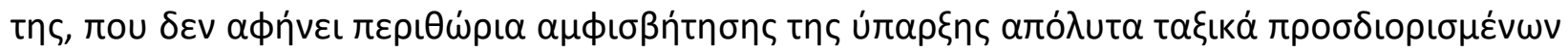

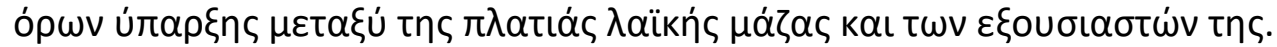

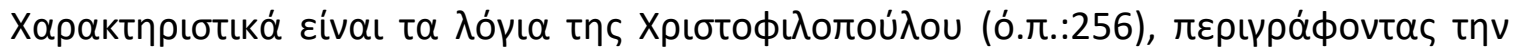

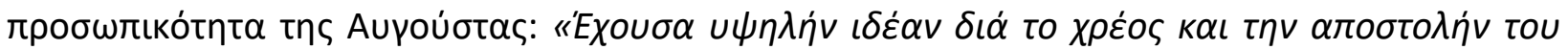

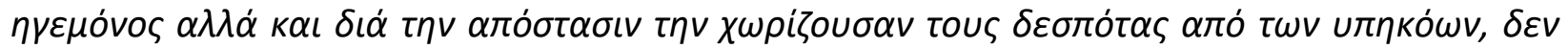

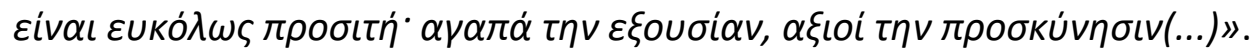

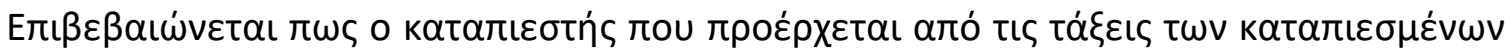

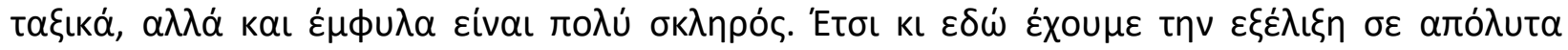

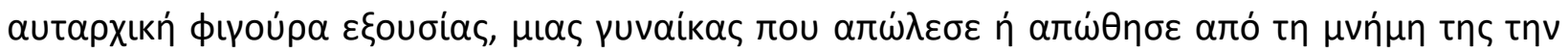

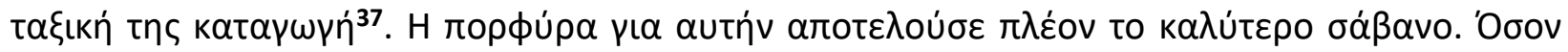

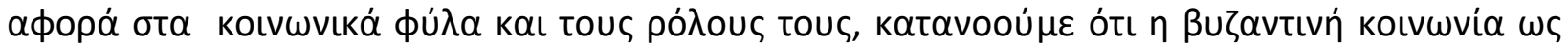

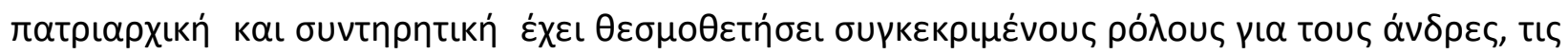

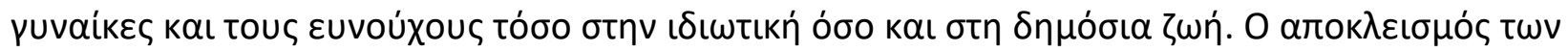

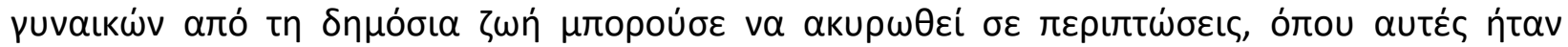

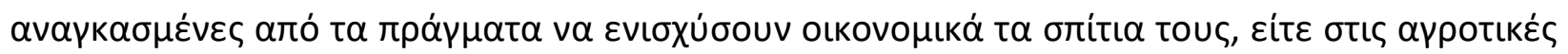

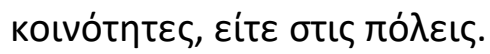

\section{Yтовvót̄тa 15}

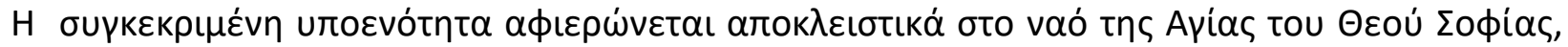

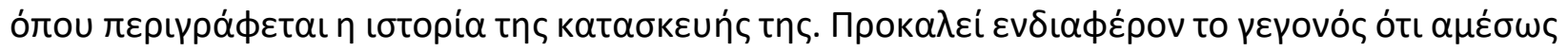

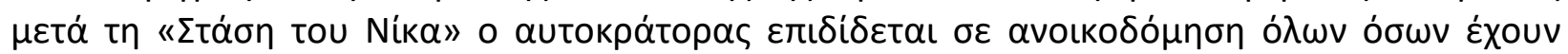

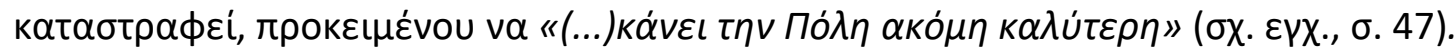

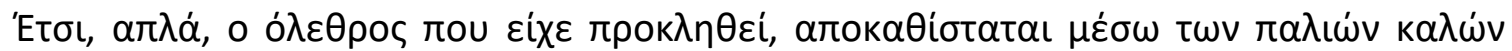

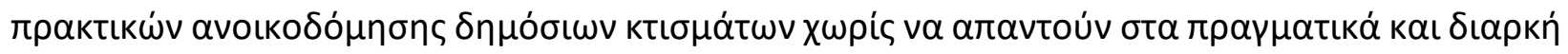

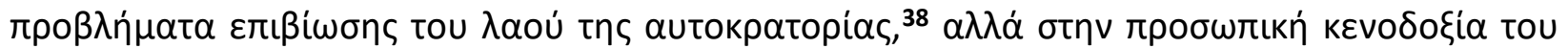
louotiviavoú39.

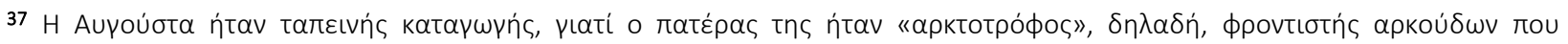

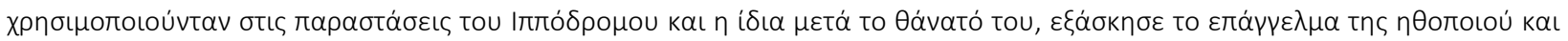

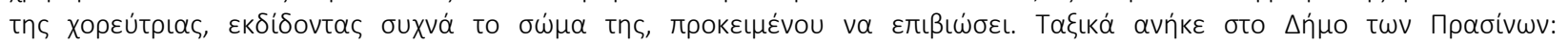

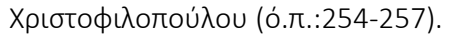

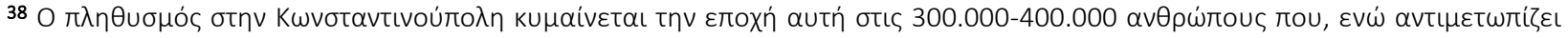

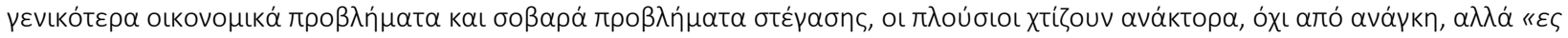

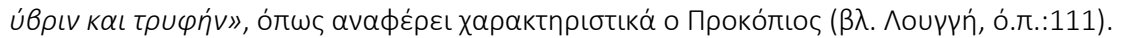

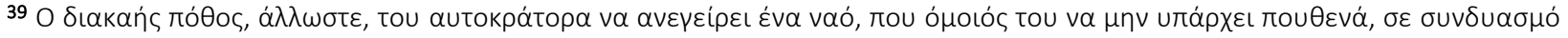

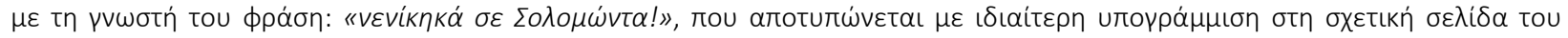

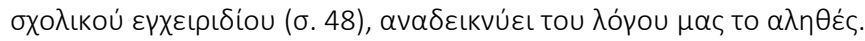


MULTILINGUAL ACADEMIC JOURNAL OF EDUCATION AND SOCIAL SCIENCES

Vol. 5 No. 1, 2017, E-ISSN: 2308-0876 @ 2017 KWP

\section{Yловvótña 16}

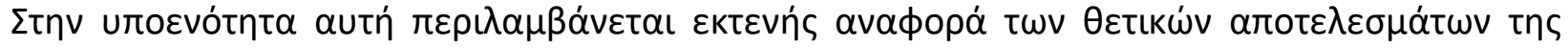

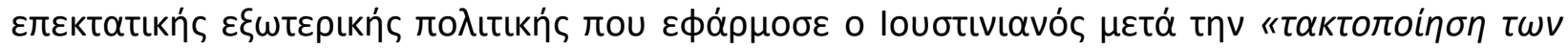

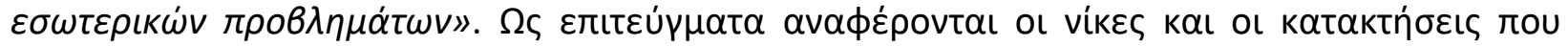

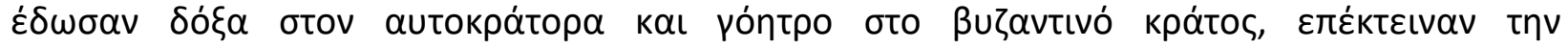

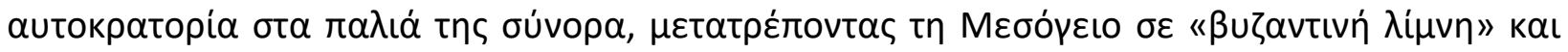

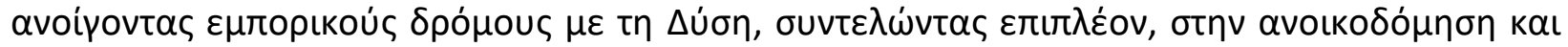

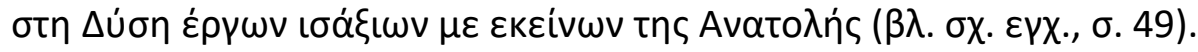

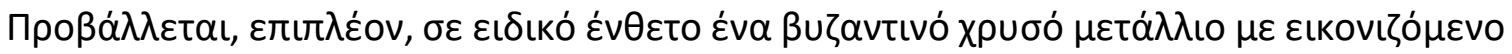

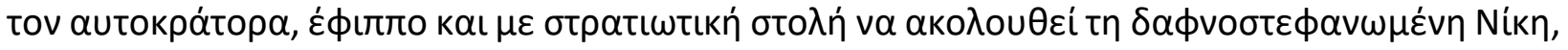

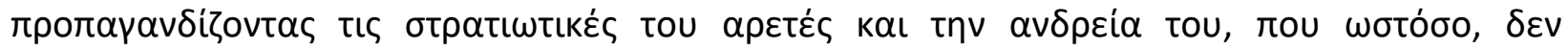

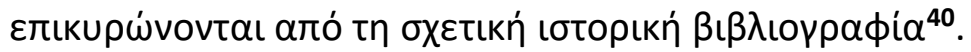

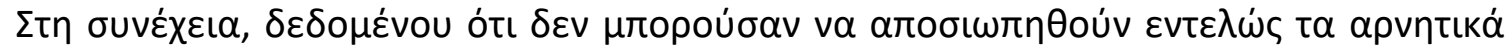

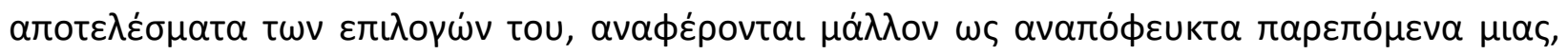

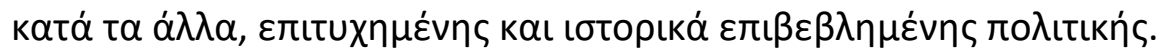

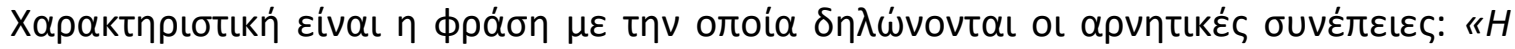

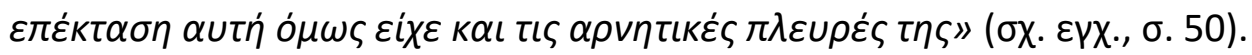

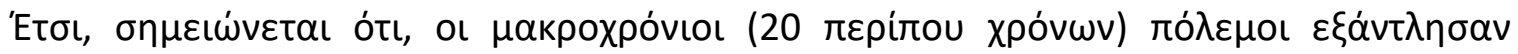

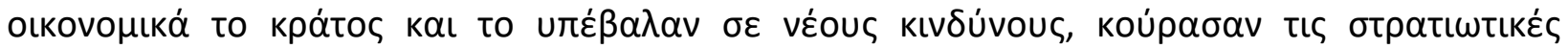

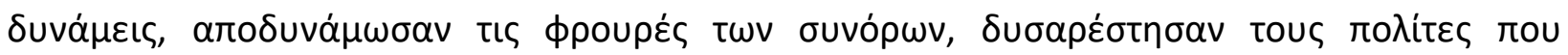

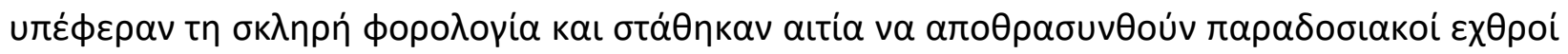

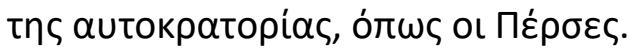

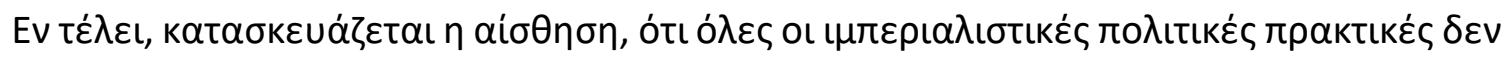

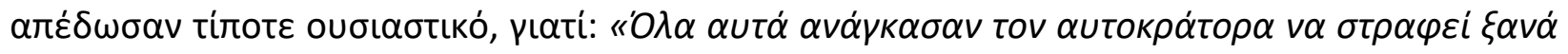

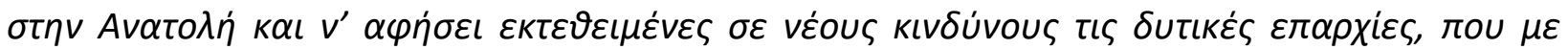

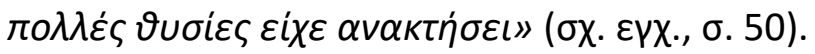

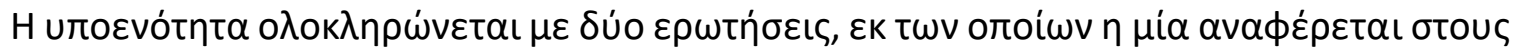

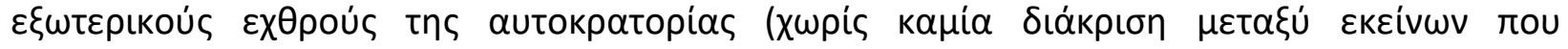

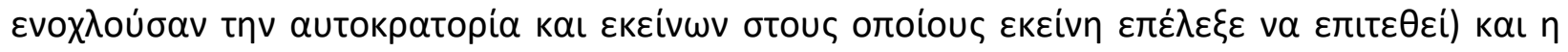

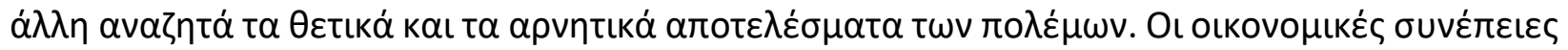

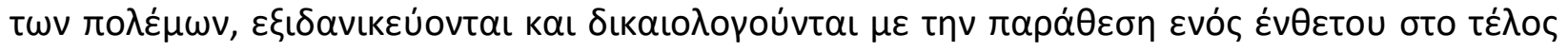

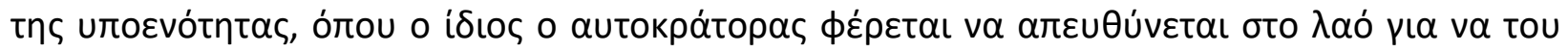

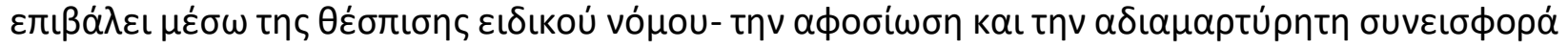

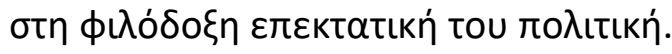

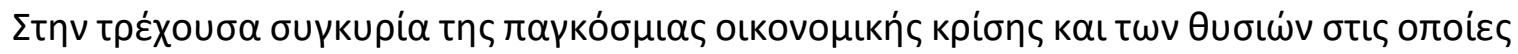

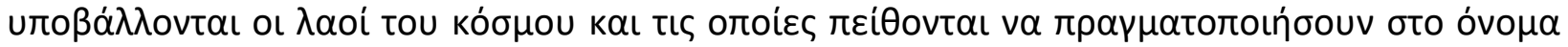

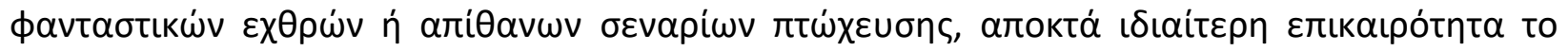

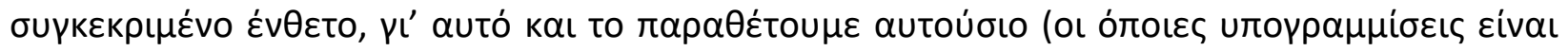

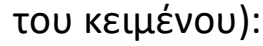

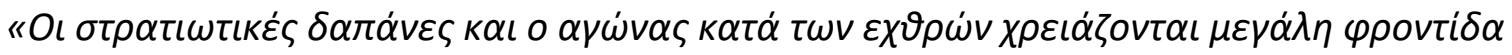

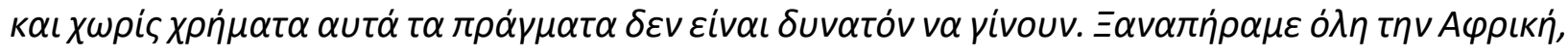

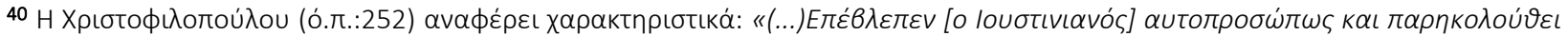

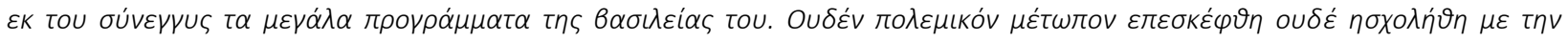

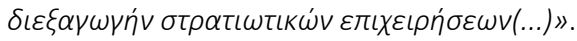


MULTILINGUAL ACADEMIC JOURNAL OF EDUCATION AND SOCIAL SCIENCES

Vol. 5 No. 1, 2017, E-ISSN: 2308-0876 @ 2017 KWP

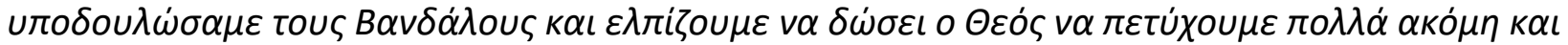

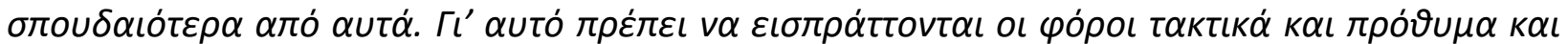

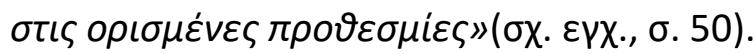

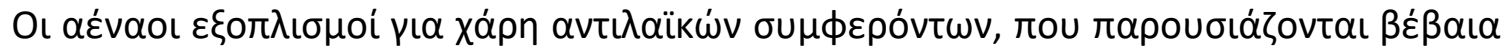

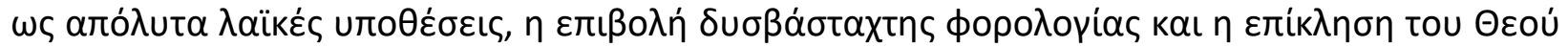

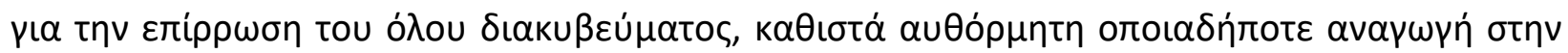

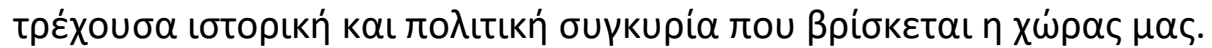

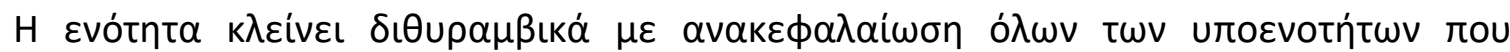

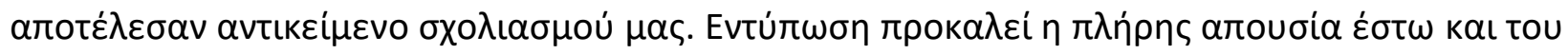

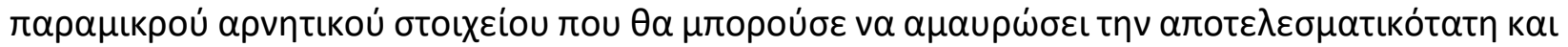

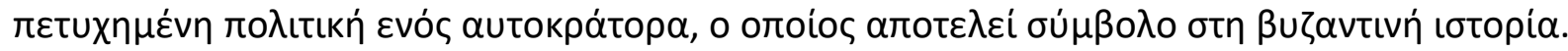

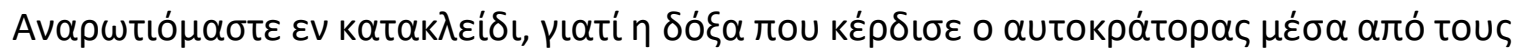

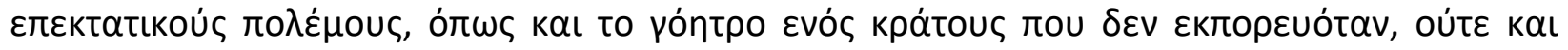

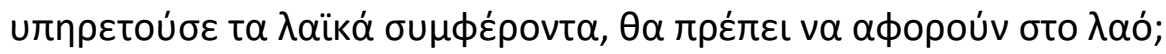

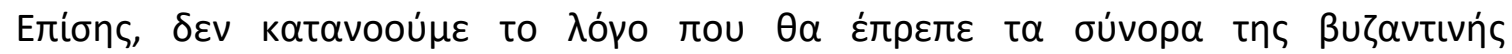

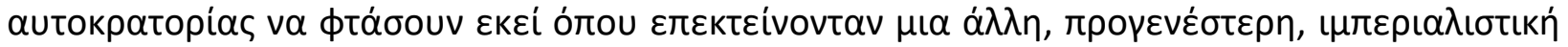

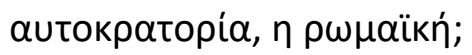

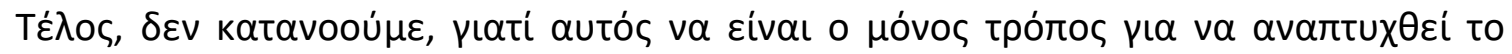

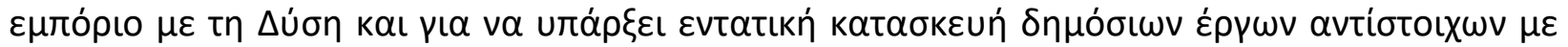

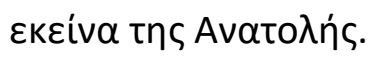

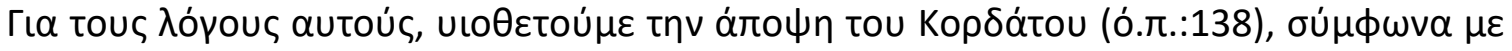

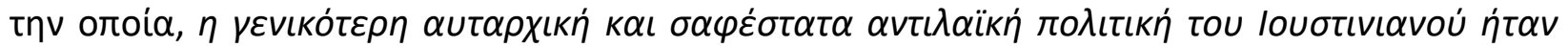

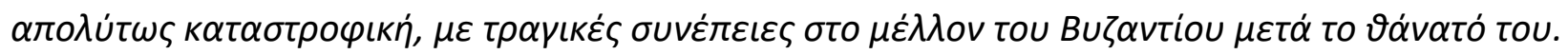

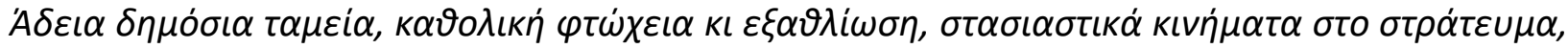

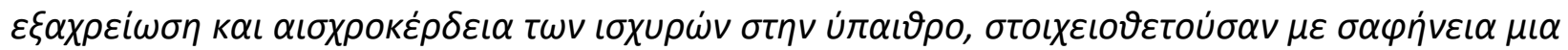

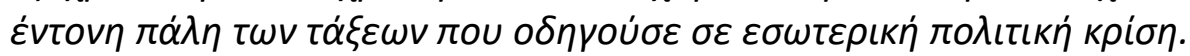

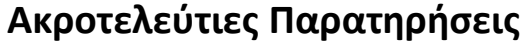

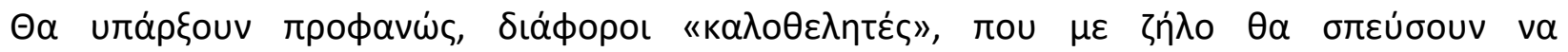

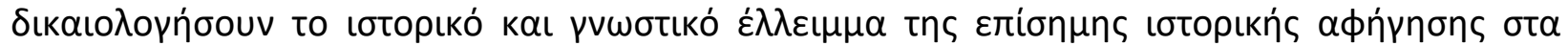

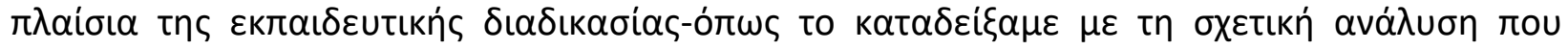

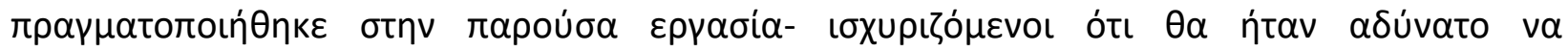

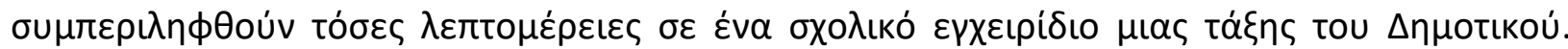

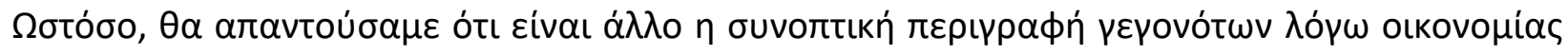

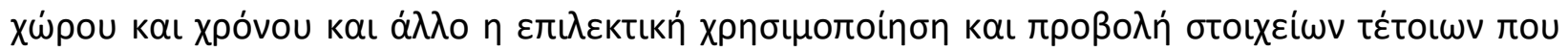

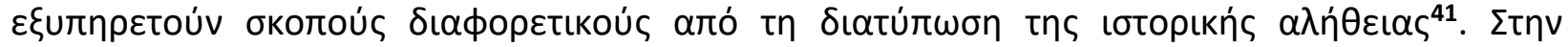

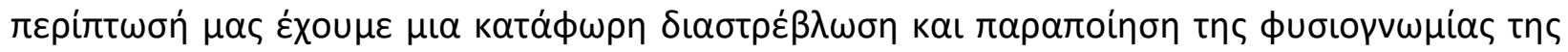

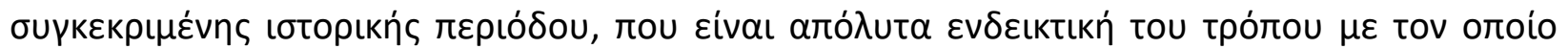

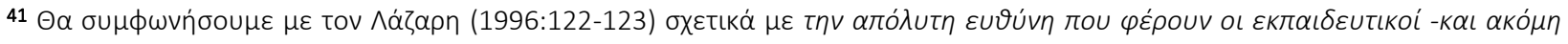

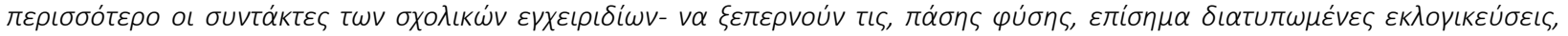

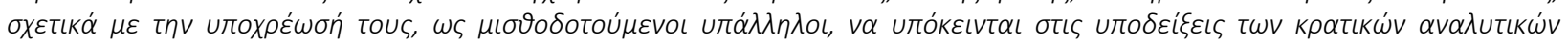

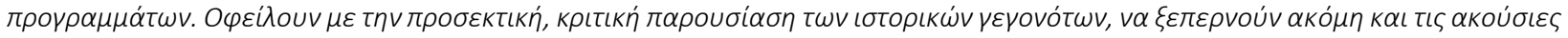

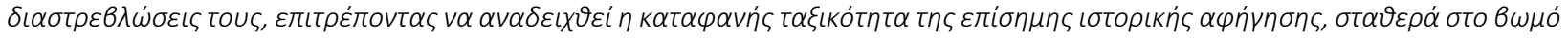

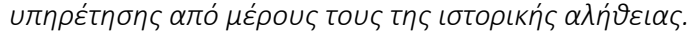


MULTILINGUAL ACADEMIC JOURNAL OF EDUCATION AND SOCIAL SCIENCES

Vol. 5 No. 1, 2017, E-ISSN: 2308-0876 @ 2017 KWP

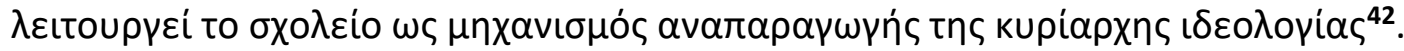

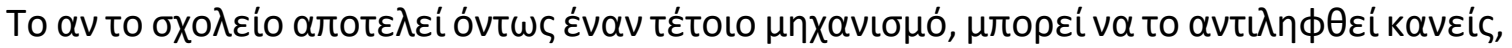

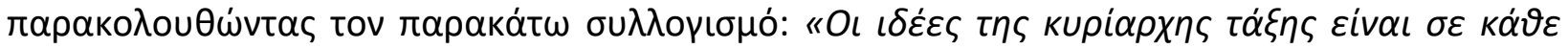

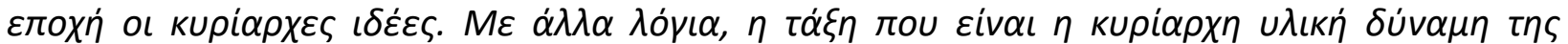

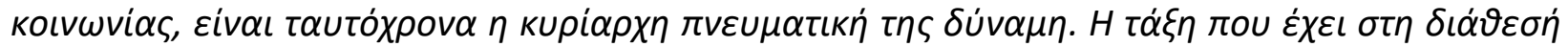

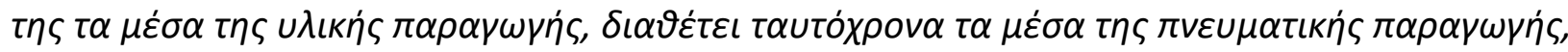

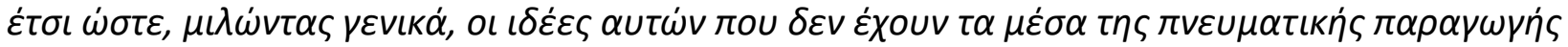

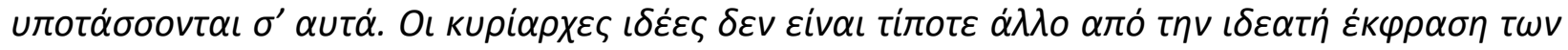

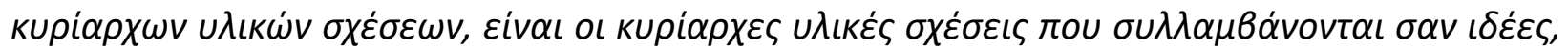

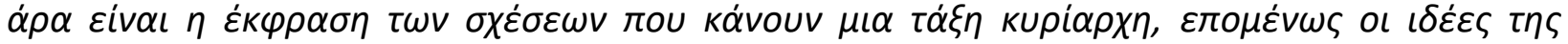

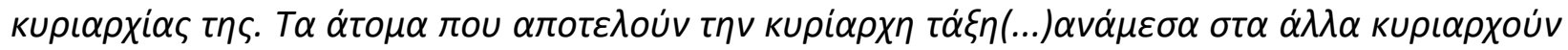

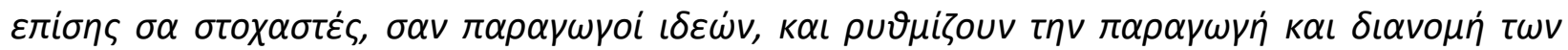

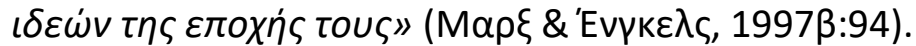

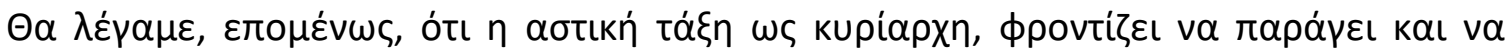

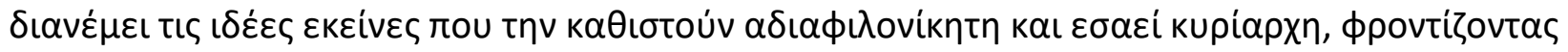

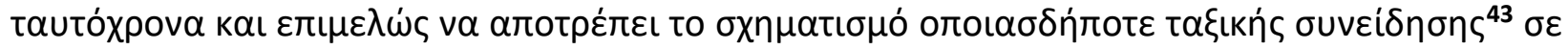

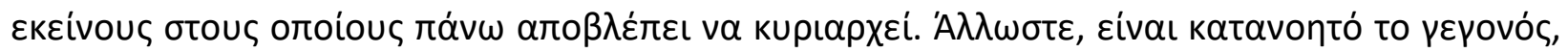

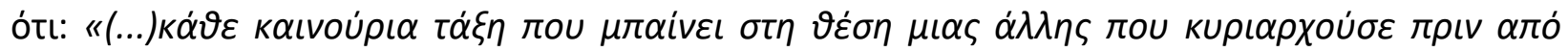

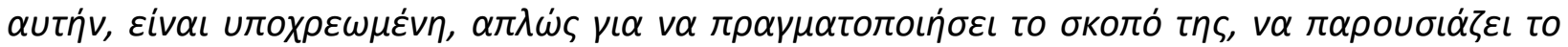

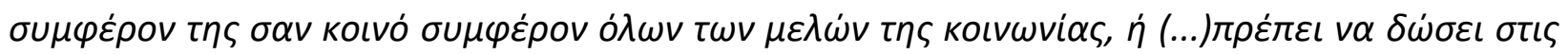

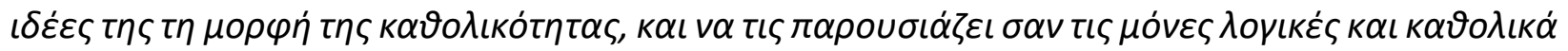

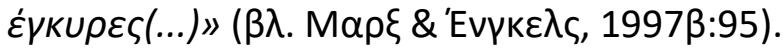

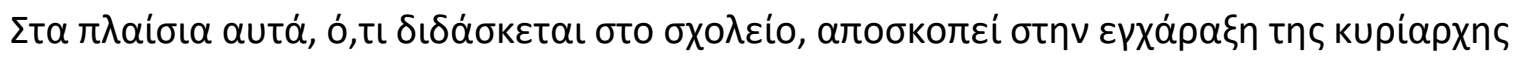

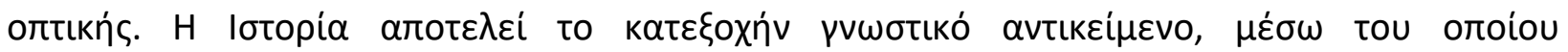

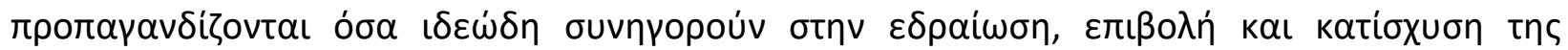

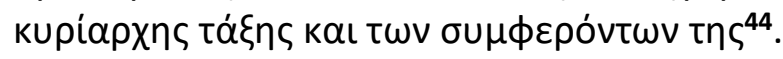

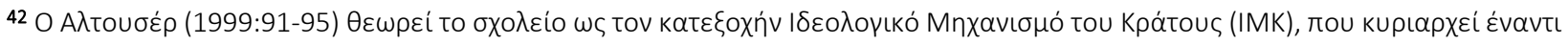

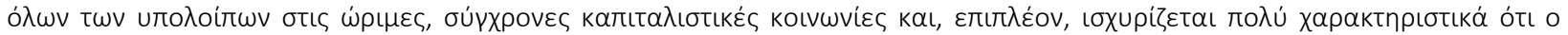

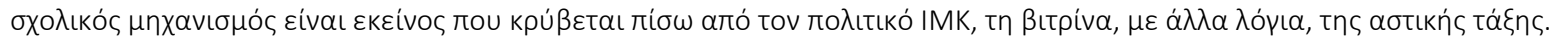

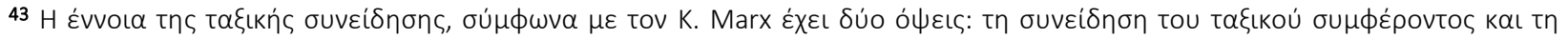

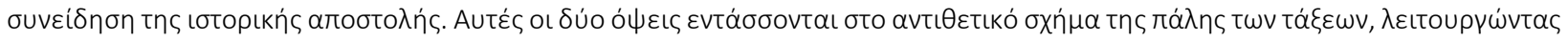

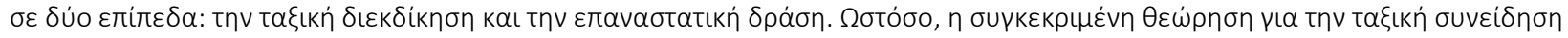

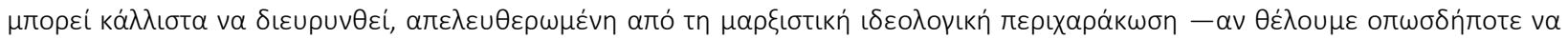

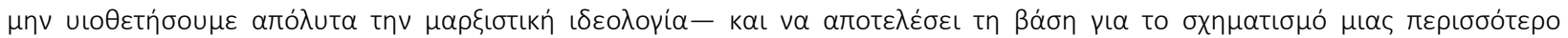

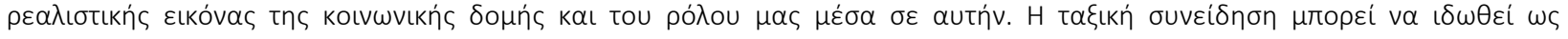

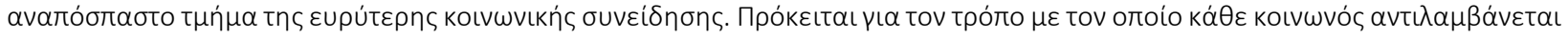

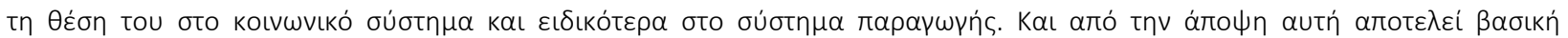

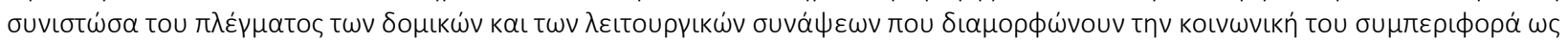

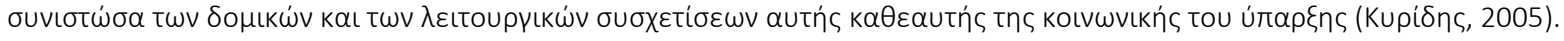

44 Evı

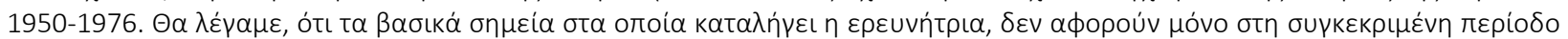

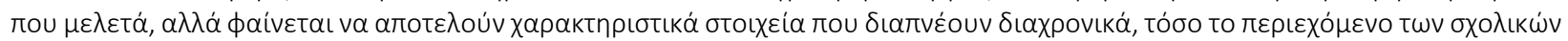

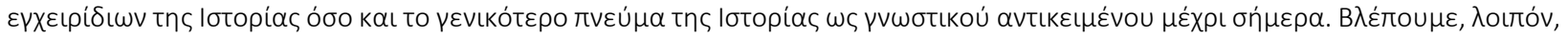

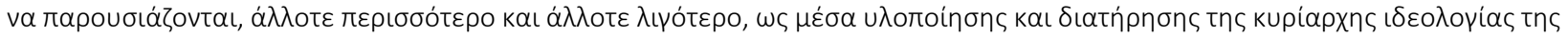

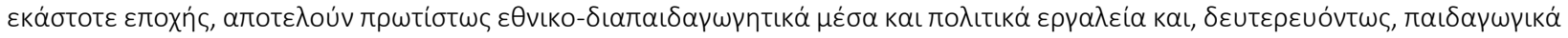

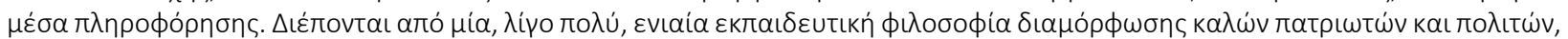

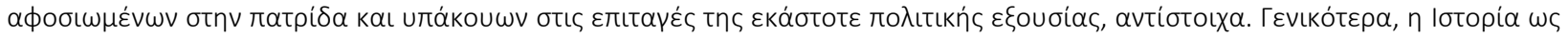

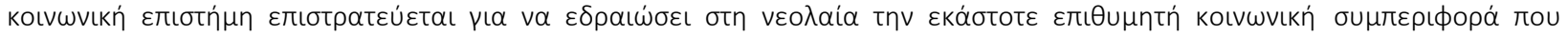

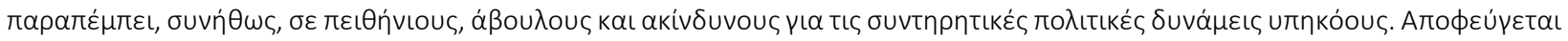


MULTILINGUAL ACADEMIC JOURNAL OF EDUCATION AND SOCIAL SCIENCES

Vol. 5 No. 1, 2017, E-ISSN: 2308-0876 @ 2017 KWP

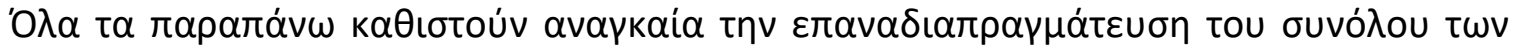

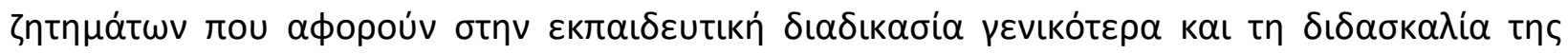

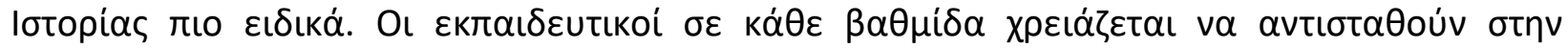

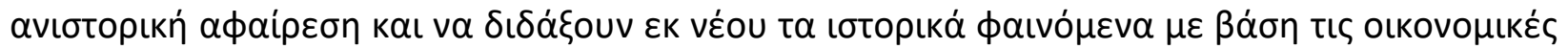

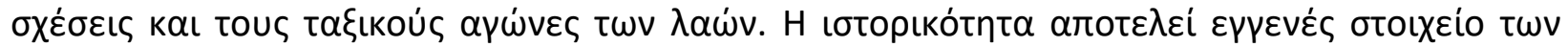

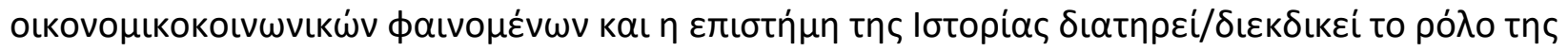

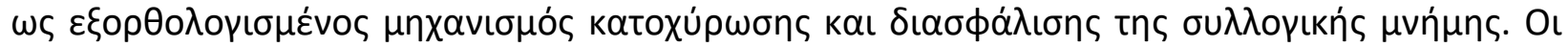

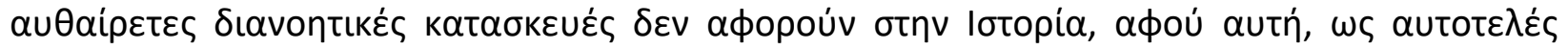

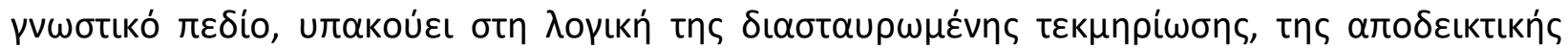

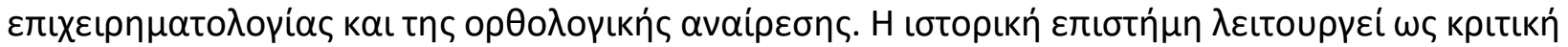

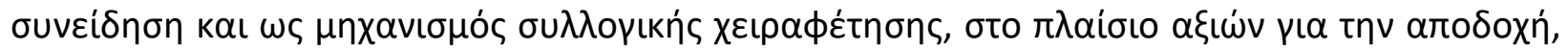

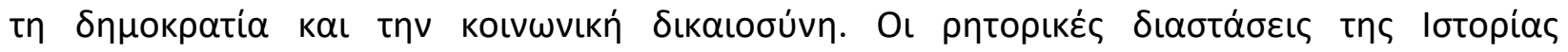

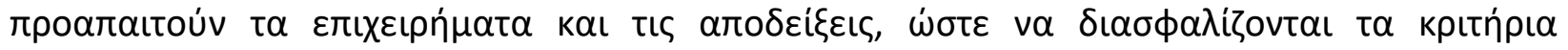

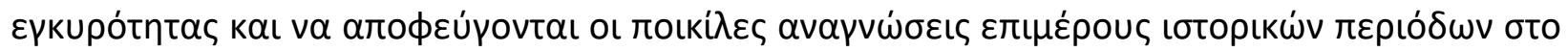

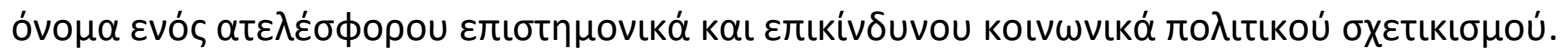

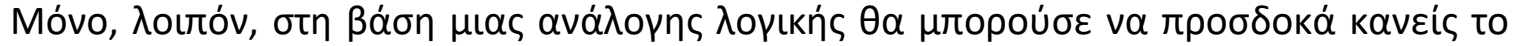

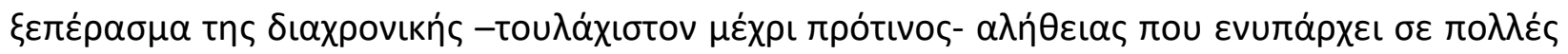

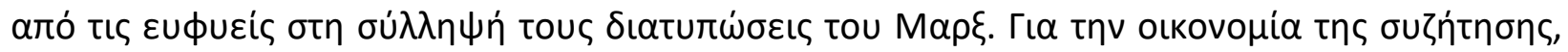

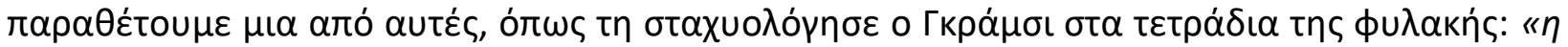

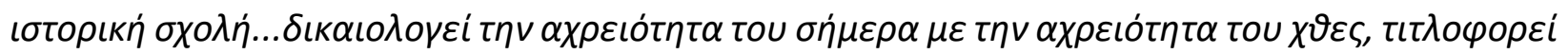

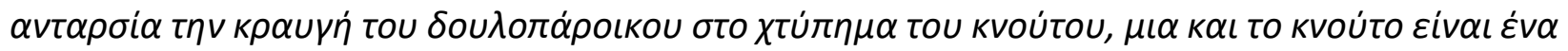

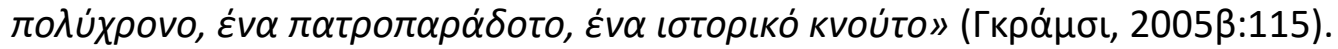

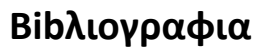

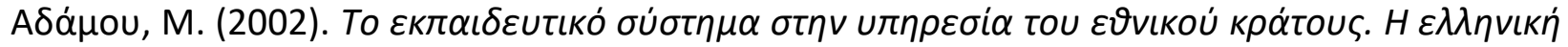

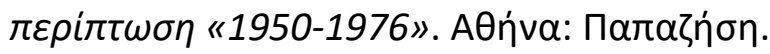

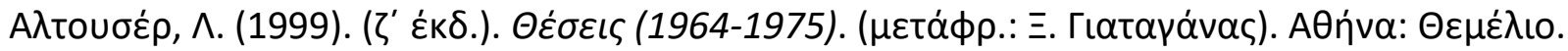

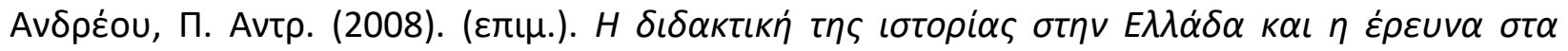

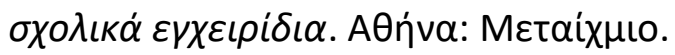

Andrew E., Sedgwick, P. (2005). Cultural Theory: the key concepts. New York: Routledge.

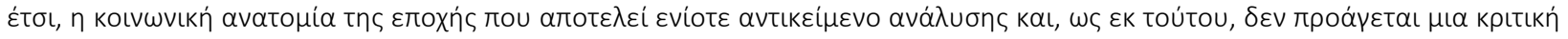

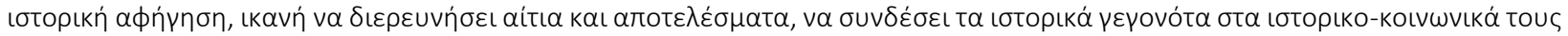

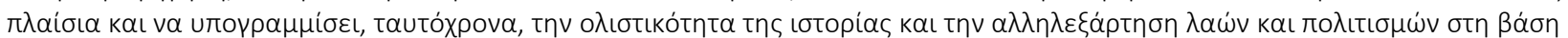

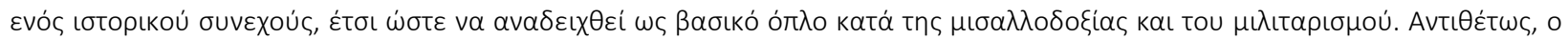

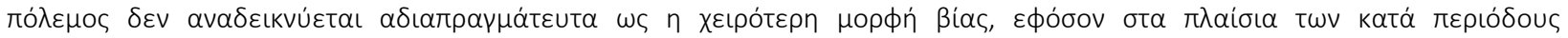

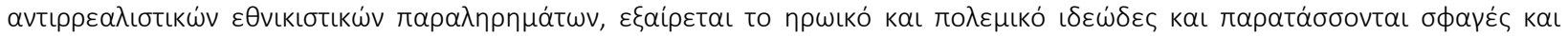

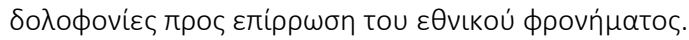

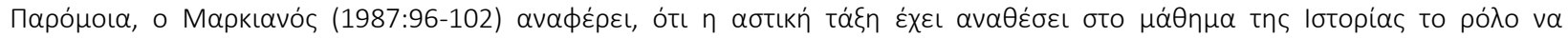

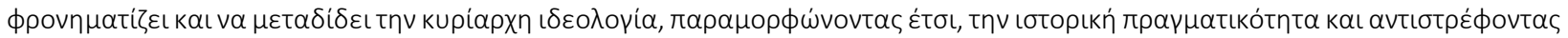

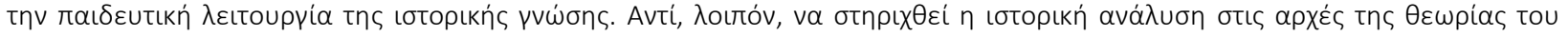

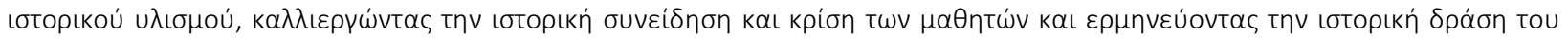

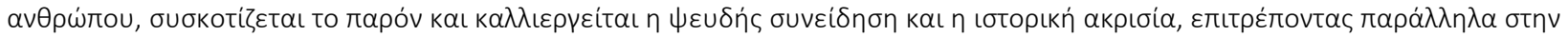

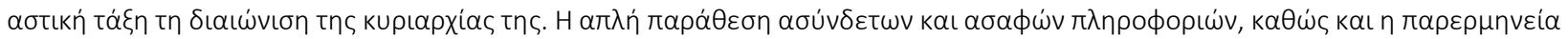

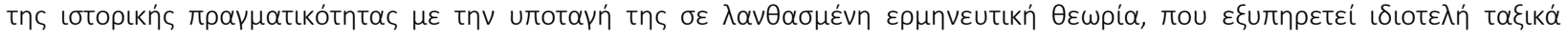

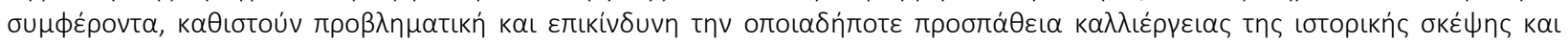

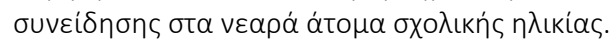


MULTILINGUAL ACADEMIC JOURNAL OF EDUCATION AND SOCIAL SCIENCES

Vol. 5 No. 1, 2017, E-ISSN: 2308-0876 @ 2017 KWP

Anyon, J. (1979). Ideology and United States History Textbooks, Harvard Educational Review, Vol. 49, No. 3, pp. 361-386.

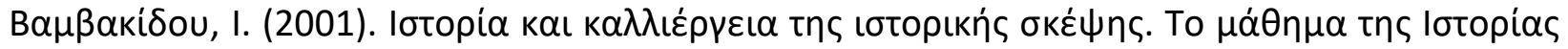

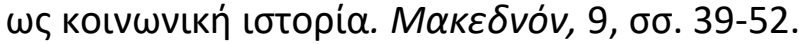

Burke, P. (1991). New perspectives on historical writing. Cambridge: Policy Press.

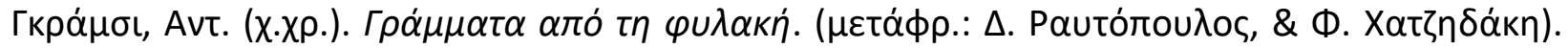

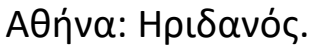

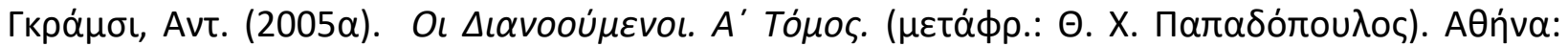

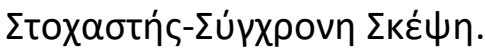

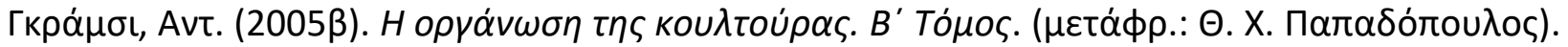

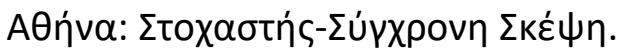

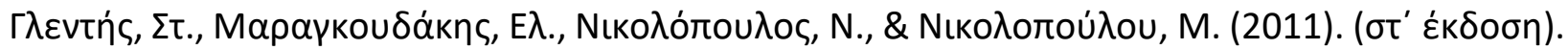

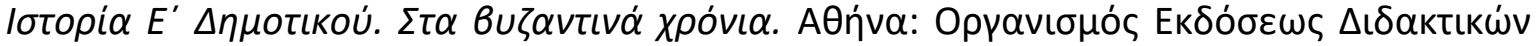

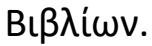

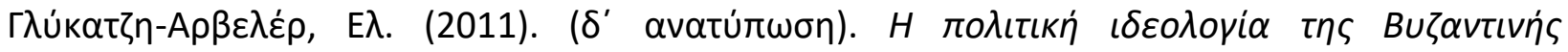

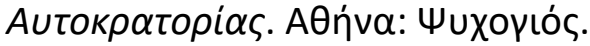

Derrida, J. (1993). Spectres de Marx. Paris: Galilee.

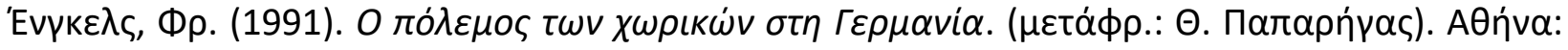

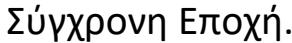

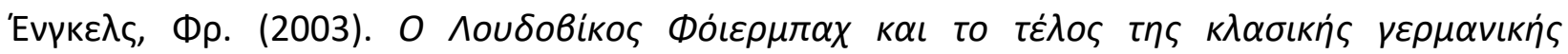

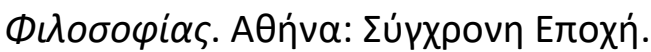

Edgar A., Sedgwick P. (2002). Cultural Theory: the key thinkers. London: Routledge.

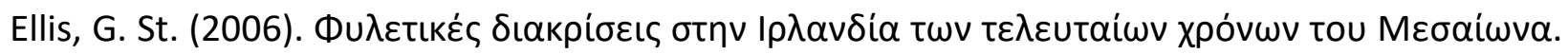

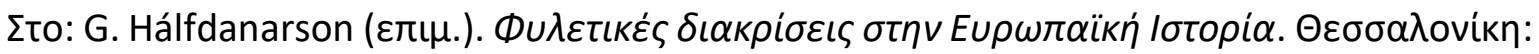

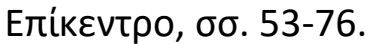

Foucault, M. (1969). L' archéologie du savoir. Paris : Gallimard.

Giroux, H. (2013). A Critical Interview with Henry Giroux, Global Education Magazine, No. 2, pp. 20-23, http://www.globaleducationmagazine.com/critical-interview-henry-giroux.

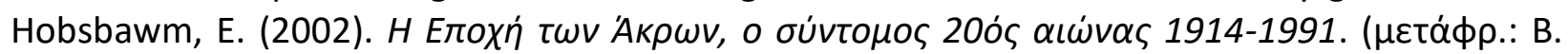

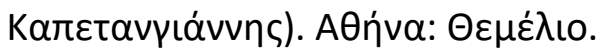

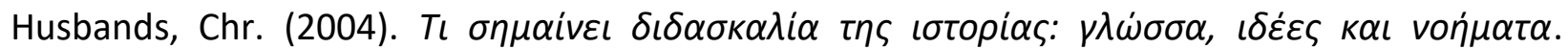
(

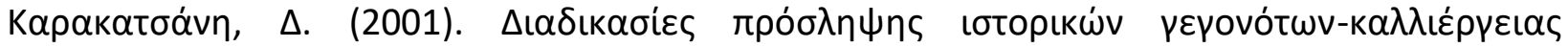

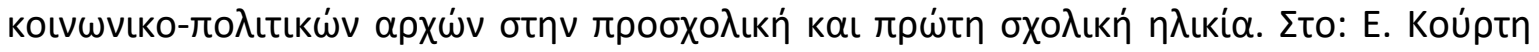

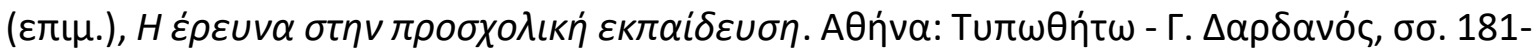
191.

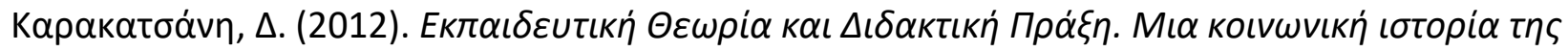

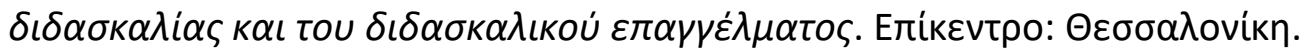

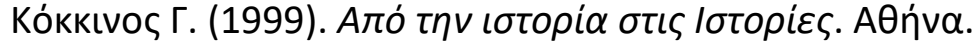

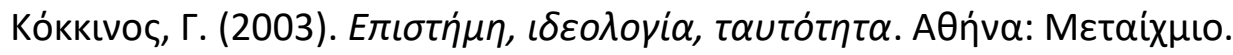

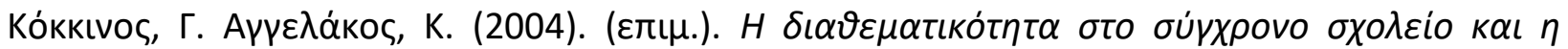

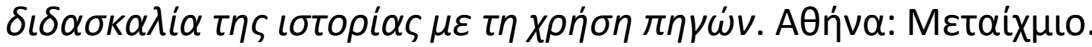

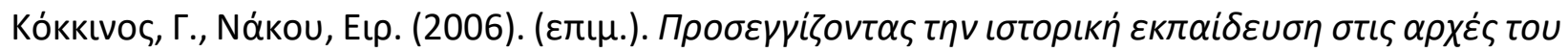

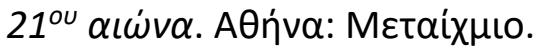


MULTILINGUAL ACADEMIC JOURNAL OF EDUCATION AND SOCIAL SCIENCES

Vol. 5 No. 1, 2017, E-ISSN: 2308-0876 @ 2017 KWP

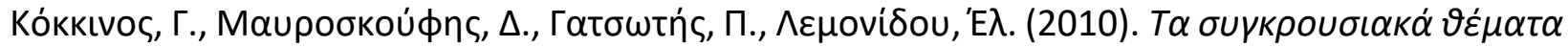

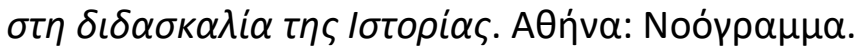

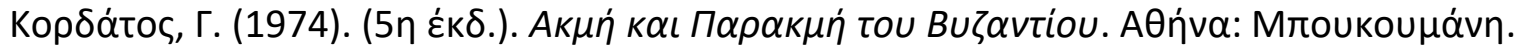

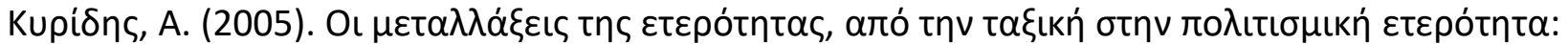

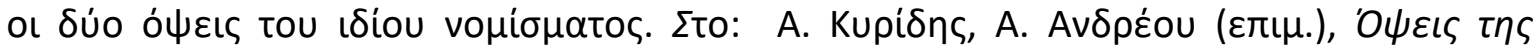

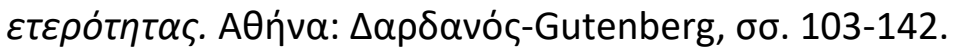

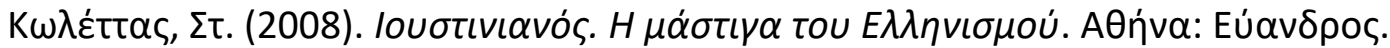

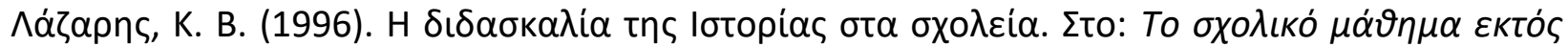

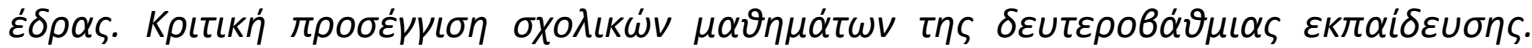

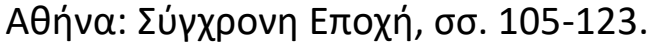

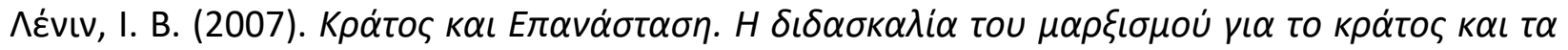

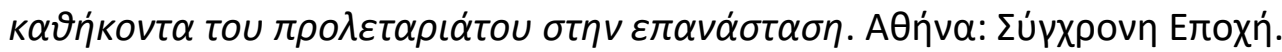

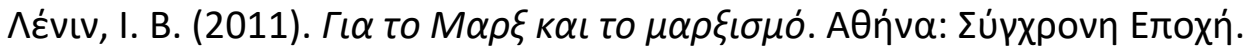

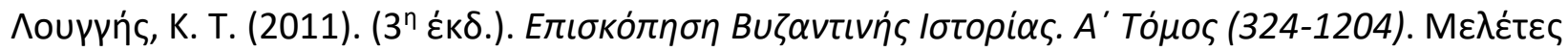

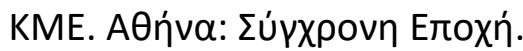

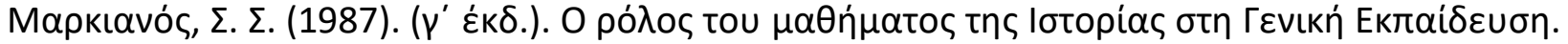

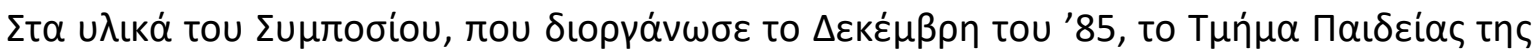

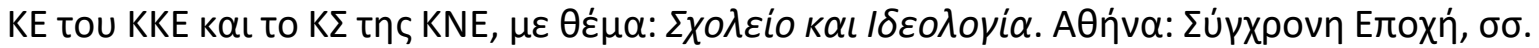
96-102.

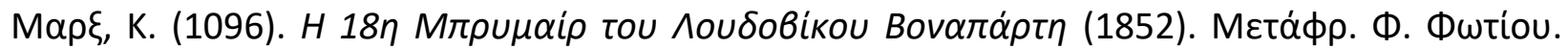
AӨńva: $\Theta \varepsilon \mu \varepsilon \dot{\lambda} ı$ เ

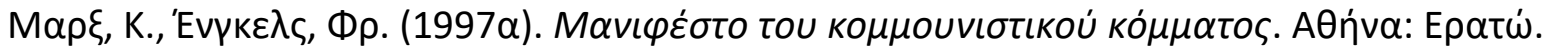

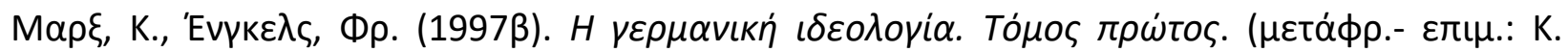

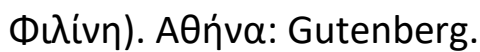

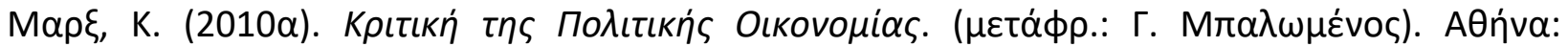

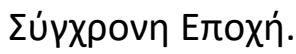

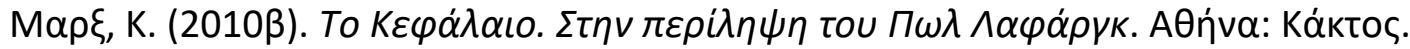

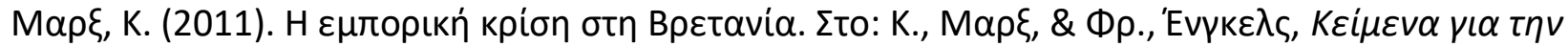

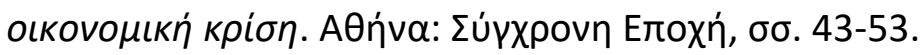

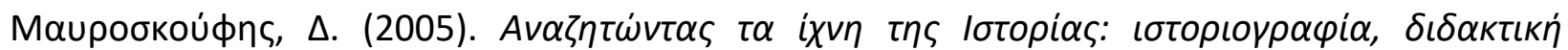

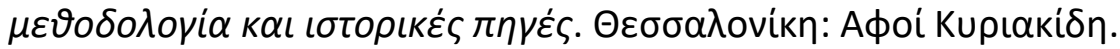

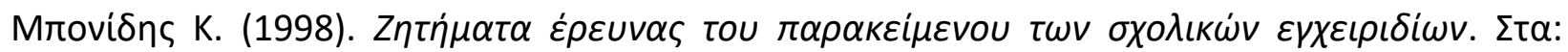

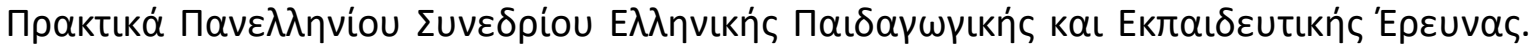
AӨńva: Aтрато́s, 239-246.

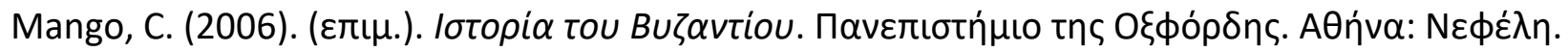

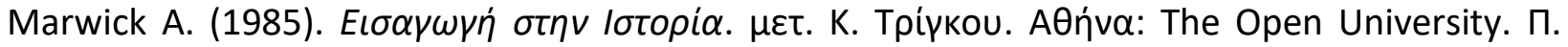
Koutбouнrós.

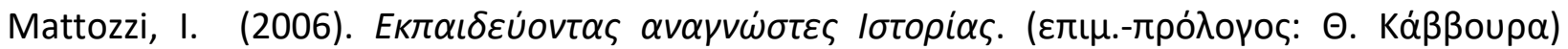

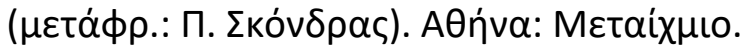

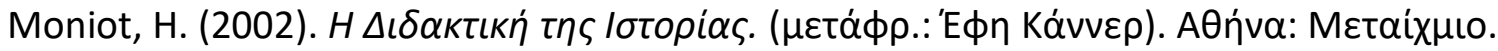

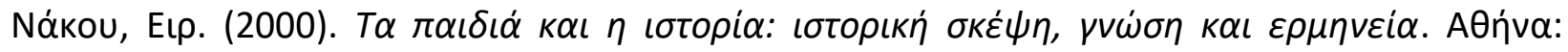

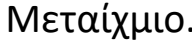

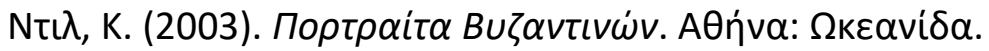

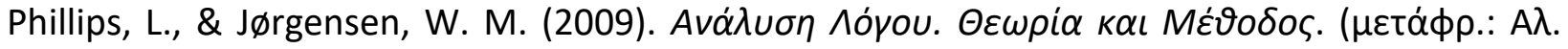




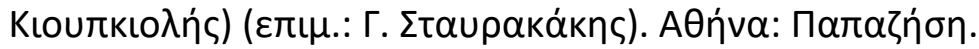

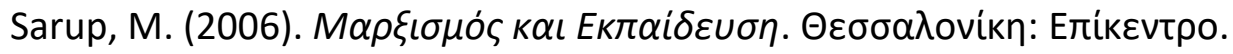

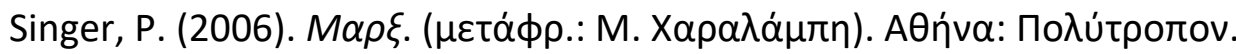

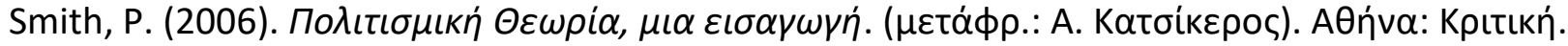

Storey, J. (1973). Cultural theory in Popular Culture. New York: Harvester Wheatsheaf.

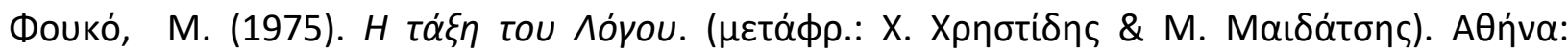

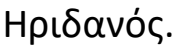

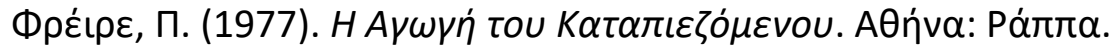

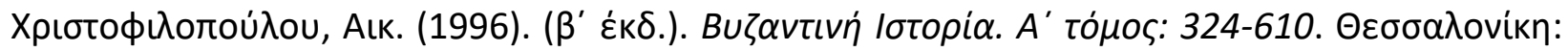
Báviac.

Williams, R. (1958). Culture and society. London: Chattoand Windus.

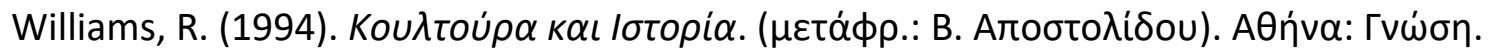

Willis, P. E. (1977). Learning to Labour: how working class kids get working class jobs. Aldershot: Gowe.

Willis, P. E. (1978). Profane Culture. London: Rutledge \& Kegan Paul. 